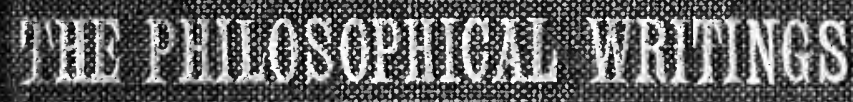

\author{
67 \\ RIOIRD BUNWIOGGE

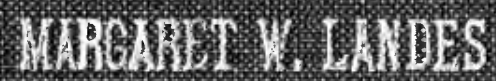



Shula luaton 



\section{THE PHILOSOPHICAL WRITINGS}

\section{or \\ RICHARD BURTHOGGE}

EDITED WITH INTRODUCTION AND NOTES

BY

MARGARET W. LANDES

HALLOWEIL PELLOW AT WELLESLY COLLEG, 1913-14

CHICAGO

THE OPEN COURT PUBLISHING COMPANY
LONDON

1921 
COPYRTGT EY

THE OPEN COURT PUBLISHING COMPANY I92I 


\section{PREFACE.}

THIS book is published in the hope of securing for Richard Burthogge the place which he deserves yet has never held in the history of British thought. Its editors wish to share with other students the rediscovery, which they owe to Georges Lyon, of a seventeenth-century English philosopher so free from the prepossessions of his Platonist contemporaries that he "grounds notions" in sense and so far advanced in the path which, a century later. Kant trod that he says: "The immediate objects of humane cogitation are all appearances, which are not properly in the things themselves."

All the writings collected in this volume are reprints from first editions in the possession of the Harvard University Library. All are printed entire save the Essay upon Reason, of which the greater part and (it is believed) the essential part is given including the chapter and section headings of the omitted chapters. The old orthography of English, Greek and Latin has, for the most part, been retained. Bracketed numbers are the page-numbers of the original editions. The kindness of the Harvard Library, in allowing the use of the texts, is gratefully acknowledged.

This volume is the third contribution to the study of seventeenth- and eighteenth-century English philosophical 
texts by graduate students of Wellesley College. ${ }^{1}$ The immediate incentive to its study of Burthogge is Prof. A. O. Lovejoy's reference to him in an essay on "Kant and the English Platonists." The editors take this opportunity to express their appreciation of Dr. Lovejoy's generous and expert counsel in the preparation of the book. Warm thanks are due also to Professor Rufus M. Jones of Haverford College, and to Professors Charlotte F. Roberts and Alice Robertson of Wellesley College, for Notes attributed to them.

The editor of this volume illuminates the text of Burthogge by biographical and philosophical Notes and, in her Introduction, calls attention to the anticipations both of Locke and of Kant which give the writings of Richard Burthogge, though hitherto all but unknown, their genuine historical significance. Miss Landes compares Burthogge's doctrine with that of his contemporaries and successors and, in an Outline, summarizes and combines the teachings, not always consistent with each other, of his different metaphysical works.

To her philosophical comments may be prefixed a brief remark about Burthogge's literary style. Readers of the Organum and the Essay will find those works marked at many points by a directness and a simplicity and by an occasional touch of humor which strongly distinguish them from most of the philosophical treatises by Burthogge's contemporaries. His predilection for plain language and for logical statement is indicated by his attitude of kindly scorn toward discourses "wherein Words are sensible but not the Propositions and yet are taken by those that make them for High Sence."

It is hardly to be hoped that the reader of this book will "make sense" of all that Burthogge says. The attentive

1 Earlier volumes are: an edition of Arthur Collier's Clavis Universalis, with Introduction and Notes by Ethel Bowman (Open Court Publishing Co., 1909); and a study of The Philosophy of John Norris, by Flora I. MacKinnon (Psychological Review Publications, 1910). 
reader cannot, however, fail to profit both by his keen and sympathetic comment on his immediate predecessors and contemporaries and by his first-hand introspection, sound argument and independent thinking.

\section{Mary Whiton Calkins.}

Wellesley College.

November, 1920. 



\section{CONTENTS.}

Introduction $\ldots \ldots \ldots \ldots \ldots \ldots \ldots \ldots \ldots \ldots \ldots \ldots \ldots \ldots, \quad$ ix

A. The Life of Richard Burthogge $\ldots \ldots \ldots \ldots \ldots \ldots \ldots$ xi

B. Burthogge's Place in the History of Philosophy ....... xiii

1. Burthogge's Relation to the Cambridge Platonists ... xiii

2. Burthogge's Relation to Locke and Kant ......... xv

The Philosophical Writings of Burthogge

Organum Vetus et Novum, or A Discourse of Reason and Truth, 1678. (Complete) ............................ 3

An Essay upon Reason and the Nature of Spirits, 1694. (With

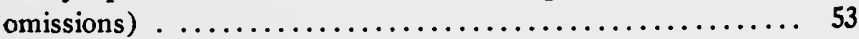

Of Human Reason. The First Part $\ldots \ldots \ldots \ldots \ldots \ldots \ldots .65$

Chap. I. Of Reason in General .................... 55

Chap. II. Of Apprehension ...................... 65

Chap. III. Of Notion, the Immediate Object of Apprehension 70

Chap. IV. Of the Distribution of Notions in the Restrained Sense of the Word $\ldots \ldots \ldots \ldots \ldots \ldots \ldots \ldots \ldots, 89$

Chap. V. Of Substance .......................... 96

Chap. IV [VI]. Of Mind in Matter ............... 118

Chap. VII. Animals are Either Invisible or Visible ....... 132

Chap. VIII. Another Essay About the Nature of Animals and Spirits . ............................... 134

Chap. IX. Of Substance in the Scholastical Consideration of It................................. 136

Of the Soul of the World and of Particular Souls, 1699 ..... 139

Outline of Burthogge's Philosophy .................. 179

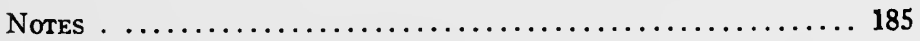

BIBLIOGRAPHY . ............................... 225

I. Complete List of the Works of Burthogge . ........ 227

II. Other Works to which Reference is Made .......... 230

INDEX $\ldots \ldots \ldots \ldots \ldots \ldots \ldots \ldots \ldots \ldots \ldots \ldots \ldots \ldots \ldots \ldots \ldots \ldots \ldots, 233$ 



\section{INTRODUCTION.}

\section{A. THE LIFE OF RICHARD BURTHOGGE.}

THERE are not many sources for the life of Richard 1 Burthogge. The meager accounts by his biographers are based for the most part on the short sketch of his life quoted anonymously by Anthony Wood in the Athenae Oxonienses.

Burthogge was born in Plymouth, England. ${ }^{1}$ The dates of his life are not definitely known, but are usually given as 1638-94. ${ }^{2}$ As Georges Lyon ${ }^{3}$ points out, however, the date of his death must have been later than 1694. It might be inferred from the fact that Christianity a Revealed Mystery was not published until 1702, that the date has been placed too early. This work, however, may have been posthumous. But the fact that $O f$ the Soul of the World, a letter to Locke, is dated 1698 , shows conclusively that the date of Burthogge's death must have been at least four years later than that given by his biographers.

Of Burthogge's parents we are told only that his father was a gunner." And of his early life nothing is recorded but the fact that he received his early education at the Exeter Grammar School. ${ }^{2}$ In 1654 he "became either a serv-

1 Anthony à Wood, Athenae Oxonienses, Vol. IV, p. 581. Georges Lyon, L'idéalisme en Angleterre au XVIII. siècle, p. 72.

2 Leslie Stephen, Dictionary of National Biography. Georges Lyon, loc. cit. Ueberweg, History of Philosophy from Thales to the Present Time, Vol. II, p. 365.

${ }^{3}$ Loc. cit.

- Anthony à Wood, loc. cit. Cf. Georges Lyon, loc. cit. 
itor or chorister of All-s. coll." He "took one degree in arts 4 years after, completed it by determination as a member of Linc. coll." $\mathrm{He}$ then studied medicine at the University of Leyden and in 1662 "was doctorated in physic." On his return to "his native country, [he] married, buried his wife, took to him a second wife who was a widow of the parish of Totness in Devonshire, on whose joynture he lives in Bowden near to that place, as he hath done above 20 years, practises physic, and by that and wiving he hath obtained a pretty foul estate. This person, who always kept pace with the fanatics, temporiz'd with the papists in the reign of King James II and therefore was made a justice of peace for Devonshire, which office he kept under Will. III as being a favourer of fanatics. He is look'd upon as a person of considerable learning, and of no less pride and ambition." The biographer is here quite evidently not free from personal feeling in sketching the facts of Burthogge's life. It is possible that he speaks with just scorn of Burthogge as one who diplomatically "kept pace with the fanatics," and at the same time "temporiz'd with the papists." Since, however, he furnishes no evidence, it is more reasonable to suppose that what he looked upon as diplomacy in Burthogge was only evidence of more advanced religious views. ${ }^{\circ}$ Religion in England in the seventeenth century was still dominated by tradition and dogma, and men of liberal religious views were rare.

In the years following his course at Leyden Burthogge was apparently finding time, aside from his professional duties, for philosophic reading and writing. Between the years 1671 and 1702 he published some eight or nine religious essays and three philosophical works. Of his philosophical writings the Organum Vetus \& Novum appeared in 1678, the Essay upon Reason, and the Nature of Spirits in 1694, and Of the Soul of the World in 1699.

${ }^{5}$ Cf., however, Organum, Sect. 41 , p. 35. 


\section{B. BURTHOGGE'S PLACE IN THE HISTORY OF PHILOS- OPHY.}

Burthogge is one of those individuals, appearing now and again in history, whose merit is unrecognized in his own day not only because his teaching is premature, but also because it is so pervaded by the dominating thought of the time that its element of originality is lost. As a philosopher Burthogge cannot be placed either with the idealists of his own time or with those of the following century. He holds a unique place between the two. All his writings bear in some measure the stamp of the Platonic idealism of the seventeenth century. His most significant teaching, however, is more closely allied to the idealistic philosophy of the eighteenth century. But for its Lockian strain of sensationalism his theory of knowledge is essentially that of Kant.

\section{Burthogge's Relation to the Cambridge Platonists.}

The influence of the Cambridge Platonists is obtrusively evident in Burthogge's writings. His method, except in the Organum and in the Essay, is the same uncritical method of the Platonists. His theological works are full of the eloquent exhortations, ${ }^{7}$ and long quotations from the Bible ${ }^{8}$ and the classics ${ }^{\theta}$ which make the writings of Cudworth, ${ }^{10}$ More $^{10}$ and Culverwel ${ }^{10}$ the most tedious of reading. And again,

- Ueberweg alone, of the writers of the history of philosophy, makes mention of Burthogge in a single short paragraph.

'See Christianity a Revealed Mystery and $A$ Brief Discourse concerning Perseverance in Grace.

- Of the Soul of the World, pp. 21-24; Christianity a Revealed Mystery, pp. 26ff; Causa Dei, p. 43. The page references, throughout, are to the original editions. The writer is indebted to the Harvard University library for the use of its Burthogge texts.

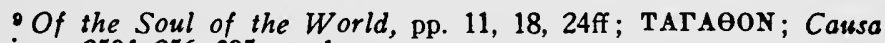
Dei, pp. 250f, 256, 395, et al.

${ }^{10}$ See Cudworth, True Intellectual System; More, Antidote against Atheism; Culverwel, Discourse of the Light of Nature. 
with the exception of the two works mentioned above, Burthogge's writings like those of the Platonists, are drenched with the theological views of the time. ${ }^{11}$ And even the Organum and the Essay do not escape the religious bias of the seventeenth century. ${ }^{12}$ But more specifically, Burthogge holds in common with the Cambridge Platonists at least two of their important tenets. His doctrine of the superiority of mind over matter is, with unimportant differences. the same as that taught by More and by Cudworth. And one of his doctrines of truth is in agreement with that of the Platonists, although he has a second teaching about truth which contradicts his own first doctrine as well as that of the Cambridge Platonists.

More and Cudworth, basing their teaching on Plato's Timaeus, held that not man alone, but nature as well, is dominated by a soul. They did not identify the soul of the world with God himself, but conceived it as an instrument in God's hands, made and used by him to manifest himself in the world. ${ }^{13}$ Burthogge, on the other hand, seems to identify the "Mosaical Spirit" with the Spirit of God $^{14}$ diffused throughout the world, although he holds at the same time, that God is "Pure Mind," independent of all matter. ${ }^{14}$ Burthogge's teaching also about the nature of the human soul is essentially that of the Platonists. More and Cudworth held that particular souls, i. e., souls of men and animals and even of plants, are "sprigs of the common Soul of the world," not "that very Soul it self," 15 though it is unreasonable, Cudworth adds, to suppose that every plant and blade of grass has "a Particular Plastick

${ }^{11}$ See Causa Dei; TARA日ON; Christianity a Revealed Mystery.

12 Organum, Sect. 41 ; Essay, Ch. VII.

${ }^{13}$ Cudworth, True Intellectual System, edition of 1678, p. 150: More, Antidote against Atheism, Bk. II, Ch. II, Sects. 4ff. $111 \mathrm{f}$.

${ }_{14}$ Essay, Ch. IV [VI], Sect. 1, pp. 124ff. Cf. Ch. V, Sect. 2, pp.

${ }^{15}$ More, Antidote against Atheism, Appendix. Ch. XI, Sect. 9; cf. Immortality of the Soul, Bk. III, Ch. XVI, and Cudworth, op cit., p. 171. 
Life." Similarly Burthogge calls the soul "a certain Determinate Vital Energy.... a certain Portion of the Spirit of the Universe, Vested in a Body...."

Again, in teaching that by intuition truth is attained, Burthogge is in agreement with the thought of his time To the Platonists truth always meant religious truth, which is known, they believed, by intuition. The more completely a man can get away from "meer speculation" and enter the realm of "spiritual sensation," the more certain is he of attaining a knowledge of truth. ${ }^{17}$ And Burthogge likewise teaches that apart from all sensuous experience we know the form of truth, which enables us to distinguish truth from error just as immediately as we distinguish sense-qualities. ${ }^{18}$ Burthogge, however, holds an empirical theory of truth which contradicts this view. The criterion of truth, according to this second theory is based not on intuition, but rather on the objective harmony of things among themselves. Truth is not necessarily that which we "clearly and distinctly" apprehend, ${ }^{18}$ nor that which is in accord with our faculties, ${ }^{20}$ but that which fits in with the whole objective scheme of things. ${ }^{21}$

\section{Burthogge's Relation to Locke and Kant.}

In spite of the abundant evidence in all Burthogge's writings of the influence of seventeenth-century thought, it is true that his theory of knowledge, his most important

${ }^{10}$ Essay, Ch. IV, Sect. 3, p. 150. Cf. Of the Soul of the World. p. 6: “.... particular Souls,.... are Portions of that Spirit [Mosaical Spirit] acting in the several particular Bodies in which they are."

${ }^{17}$ Smith, Discourse concerning .... Divine Knoweledge, Sect. 1. Culverwel, Discourse of the Light of Nature, especially Chaps. IX and XI.

${ }^{18}$ Organum, Sects. 63, 69.

${ }^{10} \mathrm{Ibid}$., Sects. 18, 68, 69.

${ }^{20}$ Ibid., Sects. 7, 72.

${ }^{21}$ Ibid., Sects. 75, 78. Cf. Sect. 17. 
philosophical teaching, remains singularly free from Platonist influence. It will be noted that in the Organum there are scattered passages ${ }^{22}$ in which Burthogge closely resembles his Platonist contemporaries in his estimate of sense, reason, and revelation. But these occasional passages, inconsistent as they are with his usual teaching, form no integral part of Burthogge's doctrine of knowledge, which stands, untouched by Platonist influence, as a remarkable anticipation of Kant.

Far from holding that sense is a hindrance to knowledge, Burthogge teaches, like Kant, that it is one of the only two sources of knowledge. The essentials of Kant's epistemology are found in the well-known words: "Thoughts without contents are empty, intuitions without concepts are blind.... The understanding cannot see, the senses cannot think. By their union alone can knowledge be produced." ${ }^{23}$ And this is exactly Burthogge's teaching: "The Understanding converses not with things ordinarily but by the Intervention of the sense." 24

Sensation, according to both Burthogge and Kant, is the passively received in knowledge, that which is given in experience $:^{25}$ "...the impressions of things without upon the Sensories, produce or occasion in them the Cogitations which we call Sentiments, as Colours, Sounds, Sapours \&c." ${ }^{26}$ And as objects can be perceived only through sensation, so, Burthogge teaches like Kant, they can be thought only through concepts or "notions." The mind knows nothing, he says, apart from its particular "manner of conceiving things." "The Understanding conceives not anything but under the Notion of an Entity, and this either a Substance or an Accident; under that of a whole or a part: or of a

22 Sects. 30, 32, 34, 35, 50.

${ }^{28}$ Critique of Pure Reason, A (1st ed.), p. 51 ; B, p. 75.

${ }^{24}$ Essay, Ch. III, Sect. 1, p. 60.

${ }^{25}$ Critique of Pure Reason, A 51 ; B 75.

2. Organwm, Sect. 24. Cf. Sect. 74. 
Cause, or of an Effect or the like. ${ }^{* 27}$ And again Burthogge is in agreement with Kant in his most important teaching that in order to have knowledge of the object the percept and the concept must unite. Neither alone is sufficient to give complete knowledge. ${ }^{28}$

The parallelism between Burthogge and Kant may be carried further. Burthogge holds not only that the object of knowledge involves both the sensational and the notional factor, but, like Kant, he teaches that it has no existence independent of thought. ${ }^{29}$ Both teach that the object of knowledge is phenomenal, not real. That the sensuous content of knowledge has no objective existence was not an absolutely new doctrine even in Burthogge's time. Locke, like Descartes, had already taught the ideality of the "secondary" sense-qualities. But that the mind itself, independent of sense-experience, actively contributes to the make-up of its own object is a doctrine which, according to the usual view, was promulgated for the first time by Kant. Yet in the light of the teaching of the Organum and the Essay it is clear that Kant's own "Copernican revolution" had an instigator at least a century older than Kant.

To hold, however, as Professor Lovejoy holds, ${ }^{30}$ that Kant's theory was the common property of the Cambridge Platonists seems hardly justifiable even in the light of the quotations given in support of this belief. What these quotations from Cudworth and More show is rather the tenacious belief in the superiority of mind over matter, and thus in the superiority of thought (in which matter is subservient to mind) over sensation (in which the mind is affected by matter). Nothing was more abhorrent to the Platonists

${ }^{27}$ Essay', Ch. III, Sect. 1, p. 57. Cf. Organum, Sects. 14-15.

${ }^{28}$ Organum, Sects. 9-10. Cf. Essay, Ch. III, Sect. 1, p. 59; Critique, A 50, 100, 109, 116; B 74, 145.

${ }^{29}$ Essay, Ch. III, Sect. 1; Organum, Sects. 8-13.

so Essays Philosophical and Psychological in Honor of Wm. Jaines, pp. 272-78. 
than the idea that matter could in any way assist mind. The passage quoted from Cudworth ${ }^{31}$ is, by his own confession, simply an outburst against the "atheistic argument" that since matter exists in its own right without need of any creative mind, our knowledge of things depends merely upon "passive receptivity." This teaching was an outrage to the Platonists merely because it belittled the mind, making it appear of so much less importance than matter, and not because it ignored the necessary conceptual element in knowledge as taught by Kant and Burthogge. "But sensible things themselves....," says Cudworth, ${ }^{32}$ "are not known and understood either by the passion or the fancy of sense, nor by anything merely foreign and adventitious, but by intelligible ideas exerted from the mind itself, that is, by something native and domestic to it." These words of the quotation, italicized by Professor Lovejoy ${ }^{33}$ to emphasize their agreement with the Kantian teaching, seem rather to show plainly that Cudworth is simply falling back on the familiar "innate ideas" theory in order to prove to the atheist that the mind is quite capable of getting on without any assistance from matter; that it would, in fact, fare much better could it be rid of sensuous perception altogether.

Burthogge, like Kant, falls short of idealism. He could not escape the influence of the traditional dualism of the seventeenth century any more than Kant could shake off the influence of Wolff's dualistic teaching. ${ }^{34}$ Neither Burthogge nor Kant ever denied the existence of reality external to mind. But since they find that the object of knowledge has no independent existence, they are forced to hold that reality, conceived as the thing independent of consciousness, is unknown. This teaching about the unknown thing is empha-

31 Ibid., pp. 272-74.

32 True Intellectual System, op. cit., p. 731.

${ }^{33}$ Essays.... in Honor of Wm. James, pp. $273 \mathrm{f}$. 236.

s4 See M. W. Calkins, The Persistent Problems of Philosophy, p. 
sized by Burthogge in both the Organum ${ }^{35}$ and the Essay upon Reason. ${ }^{36}$ And Kant not only includes it in "Paralogisms" and "Antinomies" it in all the other divisions of the Critique $;^{38}$ in the chapter on "Phenomena and Noumena" 39 of the "Analytic," and in the "Esthetic." ${ }_{40}$

Burthogge's teaching about the nature of the thing is essentially the same as that of Kant. The "thing" is, in the first place, unlike the "object," non-mental and wholly independent of thought." ${ }^{41}$ In the second place, the thing really exists. The object, Burthogge teaches with Kant, is only appearance or phenomenon, without reality. ${ }^{41}$ And finally the thing, for Burthogge as well as for Kant, is unknown. ${ }^{41}$ Thus does Burthogge, like Kant, unquestioningly and tenaciously hold to an external reality, a reality robbed, however, of all positive character save that of existence.

There is in Burthogge no explicit proof for the existence of the thing. That there exists independent reality was not questioned in the seventeenth century. And Burthogge. like his contemporaries, takes the "thing" for granted though he suggests the argument, later used by Kant, for the existence of it. Our sensations, he says, must have a cause; we know that we ourselves do not cause them ; they must therefore have an external cause. ${ }^{42}$ Kant several times in the Critique implies this causal relation between the phenomenon and the thing. ${ }^{43}$ "The understanding," he says, "... forms the thought of an object by itself, but as transcenden-

${ }^{35}$ Sect. 9.

${ }^{36}$ Ch. III, Sect. 2, pp. 71, 73.

${ }^{37}$ A $357,359,361,368,378,477 \mathrm{ff}$; B $505 \mathrm{ff}$.

${ }^{38}$ See M. W. Calkins, op. cit., p. 237, footnote.

39 A 250, 253, 258; B 300, 303.

40 A $26 \mathrm{ff}, 42,44 f, 49$; B $42 \mathrm{ff}, 59,61 \mathrm{f}, 67$.

11 Organum, Sects. 9-10.

12 Essay, Ch. III, Sect. 2, p. 73, cf. pp. 74 f.

13 A 252, 288; B 344. 
tal only, which is cause of phenomena." 44 This doctrine is formulated even more explicitly in the Prolegomena: "I grant ....that there are bodies without us, that is, things which, though quite unknown to us as to what they are in themselves, we yet know by the representations which their infuence on our sensibility procures us." 45 That the thing or reality is unknown seems, however, to Burthogge to require no proof. On the basis (1) of his view that external reality unquestionably exists, and (2) of his previous teaching that the object of knowledge has no independent existence. it follows inevitably that the external reality is unknown. If what is known is not external and if such external reality nevertheless exists, it follows that this reality must be unknown. ${ }^{48}$

The agreement of Burthogge's teaching with that of Kant is not complete. Marked as the likeness is between the two. Burthogge's epistemology seems to diverge from the Kantian at one important point. Along with his teaching that the mind independent of all external impression actively contributes part of its own object, Burthogge at the same time holds a sensationalistic doctrine. While agreeing with Kant in teaching that the notional factor is subjective in source, Burthogge seems to deny to the notion any a priori validity by holding, like Locke, that senseimpressions enter the mind directly, independent of a prior subjective conditions. "The senses," says Locke, "at first let in particular ideas, and furnish the yet empty cabinet."47 And again: "Let us suppose the mind to be, as we say, white paper, void of all characters, without any ideas; how comes it to be furnished?... . To this I answer in one word, from

44 A 288, B 344. note.

45 Sect. 13, Remark II. Cf. M. W. Calkins, op. cit., p. 240, foot-

46 For Kant's arguments in defense of the view that external reality must be unknown, see Critique, A 128f, 244, 378.

${ }^{17}$ Essay concerning Human Understanding, Bk. I, Ch. II, par. 15. 
experience." 48 And there are passages in Burthogge which give the same sensationalistic account of the origin of our knowledge: "...the impressions of things without upon the Sensories," he says. "produce or occasion in them the Cogitations which we call Sentiments, as Colours, Sounds, Sapours \&c. And Sentiments (again) impressing....the Minde and Understanding, beget or occasion in it those higher Cogitations which we call Notions, Apprehensions of Reason or Ideas...."49 This agreement of Burthogge's teaching with that of Locke, and the added fact that Burthogge's Essay upon Reason, dedicated" "To the Learned Mr. John Lock, Author of the Essay upon Humane Understanding," appeared four years after Locke's Essay, would suggest that Burthogge borrowed from Locke. A further consideration, however, proves the suspicion unwarranted. The Organum, in which Burthogge's complete doctrine of knowledge is given, was published twelve years before Locke's Essay. Moreover, it will be noted that of Burthogge's two works the later shows less evidence of agreement with Lockian teaching than the earlier. It is true that Burthogge insists in the Essay ${ }^{51}$ as in the Organum, ${ }^{52}$ that all knowledge comes through sense-experience. But the point of emphasis has been shifted in the later work. In the Organum Burthogge, like Locke, lays stress upon the fact that sense is the fundamental source of knowledge from which the notional is derived. In the Essay, on the other hand, Burthogge seems no longer chiefly concerned in showing that all knowledge begins with sense-experience but rather, like Kant. ${ }^{53}$ in emphasizing the fact that since all

48 Ibid., Bk. II, Ch. I, par. 2.

49 Organum, Sect. 24.

so Preface, p. [1].

${ }^{61}$ Ch. I, Sect. 1, pp. 3, 6f, 9ff ; Ch. III, Sect. 1, pp. 58ff ; Sect. 2. pp. $67 \mathrm{f}, 70 \mathrm{ff}$; Ch. IV, Sect. 1, p. 80 ; Ch. IV [VI], Sect. 2, p. 138; Sect. 3 , p. 152.

52 Sects. 9, 24, 26, 27, 32, 74, 92.

s3 Critique, A 104. Cf. the section on Phenomena and Noumena. 
knowledge comes through sense the object of knowledge must be phenomenal, not real. ${ }^{54}$

But granting that Burthogge seems to combine inconsistently a quasi-Kantian category doctrine with a Lockian sensationalism, the apparent inconsistency is not impossible of explanation. The explanation lies in two facts: in the first place, Burthogge does not include in his teaching an important part of the Kantian doctrine; and in the second place, his sensationalism is not of the thoroughgoing Lockian type. Burthogge never attributes, as Kant does, a priors validity to notions. While holding that notions are subjective and that they actively contribute to the make-up of the object, he never positively admits the Kantian teaching that these notions constitute the $a$ priori condition under which alone sense-experience is possible. And, on the other hand, Burthogge does not hold with Locke, that senseimpressions enter the "empty cabinet" unaccompanied. Burthogge's teaching seems to be rather that, though senseimpressions are the beginning of knowledge, they never appear in the mind by themselves. Upon the occasion of sense-experience there are inevitably aroused in the mind certain notions. These notions are not derived from sense, but, lying dormant in the mind, are made operative upon the occasion of sense-experience. In other words, Burthogge holds neither the Kantian view that notions are the necessary condition for sense-experience, nor the Lockian view that they are merely an outgrowth from sense-experience. He seems to hold rather, that they are the inevitable accompaniment of sense-experience, giving to it meaning.

But this reconciliation between Burthogge's sensationalism and his doctrine of subjective notions leaves still unexplained another apparent inconsistency in his teaching.

B4 Cf. Burthogge on the advantage of knowing that the object of knowledge is phenomenal (Essay, Ch. III, Sect. 2, pp. 68-69) with Kant (Critigue, 2d ed., Pref., p. xxi) and Locke (Essay, Bk. I, Ch. I, pars. 4-6). 
The form of apriorism against which Burthogge argues is the same widespread "innate ideas" theory of the seventeenth century, later attacked by Locke.ss In spite of this denial of original ideas independent of sensation ("Connatural and Ingrafted Notions; Principles designedly implanted in the Minde, to be a rule to it..."), ${ }^{\text {s6 }}$ Burthogge apparently admits, in the Organum, the validity of intuition in judgments of truth and falsity. This teaching seems to be directly opposed not only to his epistemological sensationalism, but also to his teaching that the criterion of truth is empirical. Burthogge indeed asserts both that the "form" or "notion" of truth must be known beforehand," i. e., independent of sense-experience, in order that it may be applied as the test of truth when the object is presented sensuously, and (in apparent contradiction) that truth is external harmony, something in the object ${ }^{58}$ which is perceived empirically only.

These two teachings about the criteria of truth certainly seem to be diametrically opposed, and yet it is possible once more to interpret Burthogge's meaning in such a way as to reconcile his intuitionism with his empiricism. If the account of Burthogge's epistemology as an intermediate form between the Kantian category doctrine and the Lockian sensationalism is correct, we need only apply this interpretation to his teaching about truth in order to explain the apparent inconsistency. In other words, Burthogge's empirical criterion of truth can be reconciled with his intuitionism in much the same way in which his sensationalism was reconciled with his doctrine of subjective notions. Burthogge apparently means that the "form" or "notion" of truth, like all other notions is an actual part of the object, but that it

5 Essay concerning Human Understanding, Bk. I.

so Organum, Sect. 73.

"I Ibid., Sects. 63, 64, 69, 74".

st Ibid., Sects. 68, 69, 72, 74, 75, 78ff, 83, 84. Cf. Sect. 17. 
XXiv PHILOSOPHICAL WRITINGS OF BURTHOGGE.

is a part contributed by the mind. According to this view, although the mind alone contributes the notion of truth, it does so only on the occasion of sense-experience. The mind never even becomes aware of its possession of the "notion" of truth, until the sensuous percept provides the opportunity for the application of the notion. 
ORGANUM VETUS ET NOVUM 

Organum Vetus ob Norum .
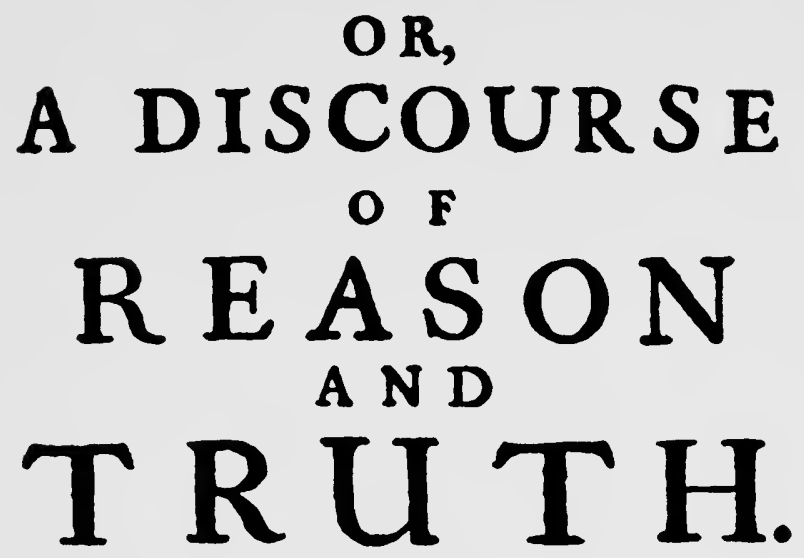

WHERE I N

The Natural Logick common to Mankinde is briefly and plainly defcribed.

By RICHAR D BUR THOGGE M.D. In a Letter to the moft Honoured Andrew Trevill Efq. Of Ethe in the County of Cornwal.

Marc. Ant. oes oweuter. 1. 7. 5. 12.

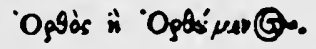

$$
L O N D O N \text { : }
$$

Printed for Sam. Crouch, at the Princes Arms a Corner-thop of Popes. bead ally in Cornbil. 1678 . 

URGANUM VETUS \& NOVUM OR

\section{A DISCOURSE OF REASON AND TRUTH.}

FOR THE MOST HONOURED ANDREW TREVILL ${ }^{1 *}$ ESQ; AT ETHE IN THE COUNTY OF CORNIWLL.

SIR,

That of making many Books is no End, was truly said by the wisest man that ever was: Not in this sense only, that multitudes of Books, begetting in the mindes of those that read them infinite Distractions, deprive them of the Benefits they might receive from fewer; but in another, that there is a Prolifickness in Books, that one produces another, and this a third, and so on [2] without End; and consequently that the labour men are at in making them, is not only Useless, but Endless.

You will have reason to believe this second Sense to be as just and true as the first, when you consider that I, who lately wrote an Apology for the Deity, am obliged by the Reflexions made upon it, now to write Another to defend it; and no question (but) the Latter may be as obnoxious to Unjust Exceptions as the Former: So that if Occasion given, be

* This index and those which follow refer to the Notes, pp. 185-224. 
also taken, there will never be an End of writing, but by what gives End to the Writer.

However, having received an Invitation to adde something to the former Essay, I am (at last) resolved, both in justice to myself and to my Book, to comply with $i$, and to enter into thoughts of the Causes that not irrationally may be presumed to have had an Influence on the Objectors, and into most of the Objections; and then to offer to [3] them (by way of Obviation) such Considerations as (it may be) will not prove unuseful to Rectifie Mistakes in other Matters, as well as in this.

And the Main Causes I intend to touch on (not to mention Envy, $\mathcal{E} c$.) are Three: Proud Ignorance, Ignorant $Z$ eal, and Impertinent Reasoning.

I. Proud Ignorance consists in a mans presumption of his own Omniscience, (for the Sciolist is ever most conceited) so that he presently and peremptorily condemneth that for Errour, which himself hath never learnt for Truth; as if there were no growth in Knowledge, or that any Humane Understanding were adequate to Verity: Whereas Capacities of the largest size are yet but narrow; and they that know most, do but the better know how little it is they know, and how much they are to seek. The most the Wisest know, is, that their own and others Ignorance is [4] the surest Object of Knowledge. True Knowledge is not conceited; it is humble, and aspireth after more. If any man think that he knoweth any thing, he knoweth nothing yet as he ought to know. 
2. IgNORANT ZEAL, (a cause of very general influence into many Mistakes, not onely in matters of Religion, but also in points of Philosophy) what is it but a Horse of high metal without eyes? Indeed, nothing is more commendable in Religion, or administers a better Argument of Sincerity in its Professors, than fervency of Zeal; but then it must be Zeal according to Knowledge, and managed with discretion, or else it is but Rage and Fury, not Zeal. Zeal regulated by the Holy Scriptures, that is, Zeal according to Knowledge, and governed with Wisdom, is Fire from the Altar: but then Irregular Zeal, Zeal without Knowledge, Zeal without $W$ isdom, is Wild-fire, which (as the corruption of the best is [5] worst) hath nothing more pernicious than it self to Church or State.

Zeal without Knowledge may be stiled Blinde Zeal, and is that when men are passionately concerned for or against an Opinion and Practice, from a strong, but groundless and unwarranted perswasion, that what they do, and what they are for, is highly to the honour and glory of God, and what they oppose, is against it: as if they knew abstractly of themselves, and by their own discoursings, what is for God's Glory, or what is otherwise, further than it hath pleased God himself in his Word to reveal it. That onely is for God's Glory, which is grounded on God's Word. The Word of God is able to make the Man of God perfect. The Corinthians had a Zeal for God, but not according to Knowledge: and so had the Jews, who persecuted 
and murther'd the Christians, but thought they did God good service. [6] What manner of men they were, who among them call'd themselves the Zealous, Josephus ${ }^{3}$ hath left on Record. Yes, the Disciples of Christ, in Zeal too, they would have Fire from Heaven, and cite an Example; but our meek and blessed Saviour tells them they knew not the Spirit they were of. They took it to be a Spirit of Zeal, but He knew it to be a Spirit of Passion. A persecuting furious Spirit is none of Christ's; it is Antichrist's. The Wrath of man worketh not the Righteousness of God.

Zeal without Wisdom may be call'd Imprudent Zeal, and is Zeal unseasonably and unfitly shewn in circumstances of time, place, and persons that will not bear it; as when men shall take their Pearls. their Reprehensions, Counsels, Instructions, or whatever other instances a Zeal is shewn in, and cast them before the Swine; and that though they have a Prospect themselves, or an Advertisement from o[7]thers, of the probable ill success, both that the Pearls shall be trodden under foot, and they themselves be rented; This is not to employ and use Zeal, but to lose $i t$. There is a time for every Purpose, and every thing is beautiful onely in that time. Pearls so cast, are cast away.

3. Impertinent Reasoning, (the third Cause I mention'd, and a Cause of all others of most general influence into Errours and Mistakes) I call not onely that which of the Logicians is named $\pi \alpha \varrho \alpha$ -

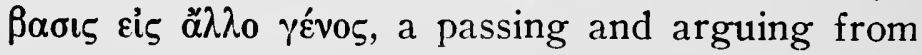


one thing to another, when yet there's no Agreement, no Connexion between them; but that also which is bottomed on single Mediums, and runs on in a long, but simple line and train of Consequences, from thing to thing; or else is founded but on second Notions, and inlaid with them: which way of Reasoning must be shewed to be Impertinent, and that by shewing a better, pertinent one. [8]

Thus, Sir, I am arriv'd to what I principally design'd; and I crave your pardon if, for my Readers satisfaction as well as for mine own, I now enlarge, and take the boldness to let him understand my apprehensions of Reason, both as to its nature, and the interest it hath in Religion, and how (I think) it must be circumstanced and condition'd, to assure us of Truth. By which Performance if I gain no more, I shall this; that as well the persons that approve my former Essay, ${ }^{2}$ as those that cavil it, will know the Rule and Method I proceeded by (in framing it;) which, to the former will afford a greater Confirmation, if it be Right; and to the latter, a fairer rise of assaulting (me) if it be not.

I. Before I can proceed to shew what Reason is, I am first to shew the many sences the Word is taken in; which, not done by most, is one occasion of the great Confusion in their talks about it. And $v$ Rea ${ }^{[9]}$ son (to omit some other sences not so necessary here) is in ordinary Language taken either largely, or strictly, or appropriately and most strictly.

2. Reason largely taken, is the same with Minde 
or Understanding, and so is commonly affirmed to exert it self in three Acts; the Apprehension of simple Terms, the Composition of those Terms by way of Affirmation and Negation, and Discourse, or illation of one thing from another. Reason strictly taken, is the Understanding as it issues out in its third Act, not in the Apprehension of simple Terms, nor in the Composition of them, but in Discourse and Illation; and so Reason is the Understanding as it argues, discourses, infers. But Reason is appropriately taken, or most strictly, as it is oppos'd to Faith and Revelation, of which hereafter.

3. Reason taken for the MINDE or Understanding, is that Faculty whereby a man is said to be Reason [10]able, Intelligent, Understanding; as Sight is that Faculty whereby an Animal is said to be Seeing: or 'tis that Faculty whereby a man is said to Elicite Acts of Reason, or to Understand; as Sight is that Faculty whereby an Animal is said to See. I so define it by the Act, for that the Act is better known than the Faculty. To Understand (as well as to see) is a first Notion, and he must be very simple that understands not what is meant by it; nor are there any Notions more intelligible, whereby to mark Faculties, than those or their Acts. Acts we see, being conscious of them when we exert them; but Faculties we see not, we know not but by their Acts.

4. The Acts of Reason in this large sence (as the same with Minde or Understanding) to speak of them as they offer and present themselves to 
mine (without confining of my self to Notions of the Schools, or common Logicians) are Two; [11] Apprehension and Judgement.

5. Apprenension is that Act of Understanding whereby it is said to See or Perceive things, and is the same in relation to the Minde, that Seeing is in relation to the Eye.

6. Apprehension is Conversant with things either as in themselves, or as they are noted; and they are noted either by simple ivords, or else by Propositions, which are words joyned by way of Affirmation or Negation; both which the Minde sees or apprehends but as it hath the Sense of them. Sence or Meaning is the Motive and immediate Object of Apprehension, as Colour is of Seeing. The Eye sees nothing but under Colour; the Minde apprehends nothing but under Sense.

7. I know well that Truth is usually affirmed the proper, adequate, immediate, formal Object of the Intellect; but (it) is not so. Not Truth, but Sence or Meaning is the proper, adequate, immediate $\mathrm{Ob}$ ject of the Minde, as to its first Act [12] [that of Apprehension;] Truth is onely the proper, adequate, immediate Object of it as to another, which is called Assent, and is a kind of Judgement. I understand and apprehend a Proposition which is false, that is, I have a Sence and Meaning of it, though when I Understand or Apprehend it, I refuse my Assent. So that it is not Verity that is the Motive and immediate Object of Understanding in its Acts of Apprehension, but Sence or Meaning. 
8. Sence or Meaning is that Conception or Notion that is formed in the Minde, on a proposal to it of an Object, a Word, or Proposition; as Colour is that Sentiment begotten, and caused in the Eye, upon the impression of its Object on it.

9. To understand this, we are to consider, That to us men, things are nothing but as they stand in our Analogie; that is, are nothing to us but as they are known by us; and [13] they are not known by us but as they are in the Sense, Imagination, or Minde; in a word, as they are in our Faculties; and they are in our Faculties not in their Realities as they be without them, no nor so much as by Picture and proper Representation, but onely by certain Appearances and Phaenomena, which their impressions on the Faculties do either cause or occasion in them.

Io. Every Faculty hath a hand, though not the sole hand, in making its immediate Object; as the Eye makes the Colours it is said to see, the Ear the Sounds, the Fancy the Idols, and so the Understanding ${ }^{4}$ the Conceptions or Notions under which it apprehends and sees things. So that all the immediate Objects of Humane Cogitation (to use the word in its largest sence) are Entia Cogitationis, All Appearances; which are not properly and (may I use a School-term) formally ${ }^{5}$ in the things themselves conceived under them, and consequently conceiv'd as if [14] they had them, but so onely in the cogitative Faculties. No such thing as Colour but in the Eye, nor as Sound but in the Ear, nor as Notion, Sense, or Meaning, but in the Minde. These. 
though they seem in the Objects, and without the cogitative Powers, yet are no more in them than the Image that seemeth in the Glass is there indeed.

I I. So that all immediately cogitable beings (that is, all immediate Objects of Humane Cogitation) are either Entities of Sense, as the immediate Objects of Sense, Colour, Sound, $\mathcal{E} c$. or of Imagination, as the Images therein, the Idols it frames; or of Reason and Understanding, Mental Entities, the Meanings or Notions under which the Understanding apprehends its Objects; which (Notions) though they seem to the Understanding to be without it, and to be in the things understood, yet (as I said before) are no more without it or in the things themselves, than Colours are [15] without the Eye, or Sounds without the Ear, or Sapours without the Tongue, although they seem so to Sense.

I2. Faculties and Powers, Good, Evil, Virtue, Vice, Verity, Falsity, Relations, Order, Similitude, Whole, Part, Cause, Effect, \&c. are Notions; as Whiteness, Blackness, Bitterness, Sweetness, \& $c$. are Sentiments: and the former own no other kind of Existence than the latter, namely, an Objective ${ }^{5}$ (one.) A Notion that will free the Minde of much Intanglement in framing Notions. We generally conceive Faculties, Good, Evil, and other Notions (under which the Minde apprehends things) to be Realities, and to have an Existence of their own without the Minde, and though there were no Minde to think of them, when indeed they are but Noemata, Conceptions, and all the formal being any of them 
I4 PHILOSOPHICAL WRITINGS OF BURTHOGGE.

have, is onely in it. And no wonder if he that takes Noemata to be Realities [16] findes himself confounded by that mistake, in forming his Conceptions about them. Notions therefore are very aptly, though somewhat barbarously, stiled by the Schoolmen, Conceptus Objectivi; Notions of the Minde, but yet seeming to be in the Object. He that looks for Notions in Things, looks behinde the Glass for the Image he sees in it.

13. Such Cogitable Beings as have no foundation, no ground in Realities, that is, in things without the Cogitative Faculties, but are mere effects of the Faculties, are call'd Chimerical (Entities;) and in the Imagination are Fictions, in the Understanding mere Notions; as in the former a Golden Tree, in the latter a Philosophical Romance, or Groundless Hypothesis. But such as have Foundation in Realities, are called Real, [Real Notions] not that in their own nature they are in Realities themselves, but that they have their Grounds in those that are; [17] they are real (as a School-man would express it) not formally, but fundamentally; they are inchoately and occasionally in the things, but not consummately and formally but in the Faculties; not in the things, but as the things relate to our Faculties; that is, not in the things as they are Things, but as they are Objects.

14. Those Words or Propositions any one hath a sence of, those things to which the Words or Propositions relate, he hath a Notion of. Sence is Notion; onely it is called Sence as it relates to the 
Words or Propositions, and Notion as it relates to the Things; but indeed Sence is Notion, and to have the sence of a Word or Proposition, is to frame a Notion of it, or of the things signified by it.

I5. 'Tis as impossible to apprehend a Word or Proposition one hath no notion, no sence of, as to see an Object that maketh no impression of Colour on the Eye; for [18] what Colour is to the Eye, that Sence, Meaning, or Notion is to the Minde.

16. Sence, Meaning, or Notion arises from a Congruity in the Object to the Faculty; so that to enquire $w h y$ one cannot understand or apprehend a Non-sensical Proposition or Word, is to enquire why he cannot see or hear Tastes, or taste and smell Sounds, or taste, hear, and smell Colours, or see an Object hath none.

17. That Congruity in the Object to the Faculty, whereby it either actually moves it, or is capable to move it to frame a Notion or Sence, ought to be distinguished from that Congruity which is in the $\mathrm{Ob}$ ject within it self, or with other Objects: The former (for distinction sake) I call a Congruity to the Faculty; the latter a Congruity in Things. The harmony of Objects to their Faculties, and that of them within themselves, or one to another, are distinct Harmonies. I [19] can make sence of a Proposition that is not true, so that 'tis Congruous to the Faculty, it moves that; when yet (it being false) the Parts of it are Incongruous one with another.

18. To understand and apprehend a Proposition or Discourse, it sufficeth not to have a Perception 
of the sence and meaning of the words; those words as in Conjunction, and ty'd together, ought to make such an impression on the Minde, as moveth it to make a Notion of them in that Relation. One may have a sence of the words in a Discourse, when yet he cannot make any of the Discourse it self, because he cannot frame a Conception, a Notion of them in the Composition that is given them in it. He cannot see how they are joyn'd.

19. There are a thousand Instances of Discourses of this kinde in Jacob Behmen, ${ }^{6}$ but I need not go so far as Germany to seek some; I might have many neerer home with ${ }^{[20]}$ in the compass of our own time and observation; but I decline them as Invidious: I will onely point to one in Dr. Fludd, ${ }^{\top}$ a person that could speak as good Sence (if he listed) as another, but I could never make any of many Passages I finde in him, and of one particularly, namely, that in his Mosaick Philosophy, Book 3. Sect. I. Chap. 4.

20. Those Discourses in which nor Words nor Propositions are sensible, or wherein the Words are sensible but not the Propositions, and yet are taken by those that make them for High Sence, may be called Enthusiasm. Of the former sort I apprehend the Whims of Basilides, of Valentinus, and the Gnosticks; ${ }^{8}$ and of the latter, those of the Familists. and of others of late.

21. Enthusiasm ${ }^{10}$ either may proceed from a Spirit, or from Complexion and a certain temper of Minde; the former I call Demoniacal, the latter Complexional: and not unlikely but in most Enthu- 
siasts [21] it comes from both: whereof an Upstart Sect ${ }^{11}$ among us, in its first appearing, afforded strong Evincements.

22. That there are Philosophical Enthusiasts, is as certain as that there are Theological; Enthusiasts in matters of Philosophy, as well as Enthusiasts in Matters of Divinity. Paracelsus, ${ }^{12}$ Helmont, ${ }^{13}$ and many other Chymists, are Examples of the first sort: as H. Nicolls ${ }^{\circ}$ the Father of the Familists, and others, are of the second: Jacob Behmen ${ }^{6}$ and Dr. Fludd may pass for Examples of both.

23. When Enthusiasts think they understand one another, (as they All pretend to do, and that seriously, and therefore must have some impression to justifie that Pretension, whereas yet no sober man can understand Any of them;) I conceive it not to be by Apprehension, but Sympathy; not Intellectually, by Apprehending, that is, by framing just, steady, distinct Notions of [22] what is said; but Sympathetically, by having excited in their minde on such Expressions, Motions, conformable to theirs that use them; for they all being of the same frame and temper of Minde or of Imagination, whatever touches One agreeably, also moves the Rest; as in Unison-Lutes, or other Instruments fitly tuned, but to strike One, is (at once) to move All.

24. Notions of the Minde are bottomed on Sentiments of Sense; so that as Realities are Grounds to Sentiments, so Sentiments are Grounds to Notions: the impressions of things without upon the 
Sensories, produce or occasion in them the Cogitations which we call Sentiments, as Colours, Sounds, Sapours, \&c. And Sentiments (again) impressing of the Fancy, and so the Minde and Understanding, beget or occasion in it those higher Cogitations which we call Notions: Apprehensions of Reason. or Ideas. Idols or Fantoms are in the Fancy, Ideas in the Minde. [23]

25. The neerer our Sensories are unto the Objects impressing them, (if not too neer) the clearer and distincter is the Sensation made by them; as we more cleerly and distinctly see an Object at a neerer than a remoter distance: so the nearer the Minde and Understanding is to Sentiments, the more cleer, distinct, and evident its Perceptions are; I mean, the more sensible Notions are, and the neerer to their Grounds, the more effective, more impressive and consequently clearer and more evident they be.

26. Hence Knowledge and Apprehension of things is better both acquired and conceived by first Notions, which are next to Sentiments, than by second which are more remote: The Knowledge which is had of things by first Notions, is more real, evident, cleer, distinct, than that which is by the second. First Notions are founded immediately on things; Second Notions are Notions concerning Notions: [24] These are not so impressive and effective as the first. By first and Second Notions, I both understand Terms or Words, and the Notions signified by them.

27. So much for the ОвјЕст of Apprehension, 
which is Sense and Notion; and for the Grounds of that Object, which is Sentiment: Now for the AFFECTIONS of Apprehension (if a good one) and they are two, namely, Cleerness and Distinctness.

28. Cleerness of Apprehension, which is in the Minde the same that Cleerness of Seeing is in the Eye, is opposed to Obscurity and Darkness, and presupposes Light.

29. Light is that which manifests, and consequently Intellectual Light is that means whereby the Understanding comes to See and Apprehend its Objects; or that which manifests them to it: and is either Light of Revelation, which is also called Light of Faith; or Light of Nature, which is also called Light of Reason ; ${ }^{14}$ where Reason is Appro ${ }^{[25]}$ priately taken, and most strictly.

30. The Light of Revelation is that Discovery or Manifestation God himself is pleased to make of things by his Spirit, and is chiefly in the Holy Scriptures. The Light of Nature ${ }^{14}$ is All other Light whatever but that of Revelation, whereby we See and Apprehend things, and is that we have by Sense and Discourse.

31. Some things there are that may be seen in both Lights, in that of Nature, and that of Revelation, though more cleerly in the latter than in the former; as that God is Good, and that he is the Maker and Conserver, and supreme Director of All things: Other things are onely to be seen in the Light of Revelation, being of a nature not to be discovered but in and by it; as the Mysteries of 
Christian Religion, the Doctrine of the Trinity, the Incarnation of God, $\mathcal{E} c$.

32. The Lights of Faith and Nature, of Revelation and Reason, [26] though they be not the same, yet are not contrary; I mean, that what is shewn or seen to be true in one Light, can never be shewn or seen to be false in the other: What is Apprehended by Sense rightly circumstanced and condition'd, to be This or to be That, or else by Reason rightly acting to be so, or so, it is never contradicted by Revelation. Things are nothing to a man but as they stand in his Analogie: for him to believe against his Faculties, is to believe a Contradiction. If in the Holy Sacrament of the Lord's Supper, the Elements first and last are Bread and Wine to Sense, and to Reason judging according to Sense, I cannot hold my self obliged by (any) Revelation to believe them Flesh and Blood, but in a Notion consistent with the judgment Sense and Reason make of them; that is, not flesh and blood substantially, but sacramentally; not flesh and blood really, but only by signification. Else Truth might [27] be Incongruity, Inconsistency. Transubstantiation is to me a Mystery; I am so far from making truth of it, that I cannot make any sense of it; I might as well believe that two and two make not four, or three and three six. as that it is not Bread, or Wine, which to my Eye, my Taste, my Touch, in a word, which being an Object of Sense, to all Examinations of my sense is so. What is against Sense, is against Knowledge. 33. An Object onely to be seen by the Light of 
Faith, may be said to be seen by Reason above Reason, by Reason assisted with the light of Revelation, above Reason not so assisted, but acting onely by the Aids of Nature; but still it is Reason sees in both: As I can see an Object with a Tube, that with my naked and unarmed Eye I cannot: or see in the Sun-light an Object that I cannot by Moonlight; but still it is the Eye that sees in both; the Organ is the same, although the [28] Lights be not It is the same Reason and Understanding, the same Faculty that sees in the Light of Revelation, as it is that sees by the Light of Nature; and the same that Argues and Discourses in the one, as by the other.

34. The great Designs of God in all the Doctrines, and even in the highest and most sublime Mysteries of our Religion, is to affect the hearts of men: and therefore as (I.) He represents and reveals them in first Notions; so (2.) He also doth it in sensible and comparative ones; and usually (3.) He representeth one thing by many Notions. (1.) To make it more Affective; and withal (2.) to signifie, that no one Notion he represents the thing in, is adequate and just to it. Thus he represents the great Mystery of our Union unto Christ, and our Communion with him, by that between the Vine and Branches, between the Husband and Wife, between the Head and Members: As [29] also the great work of Conversion that passes upon Men in the change he makes on them, from their Darkness into his most marvellous Light, He compares it to Gen- 
eration, to Adoption, to Creation: In fine, the New Covenant is not only stiled a Covenant, but also a Testament, and a Promise. All which resembling and comparative expressions may and ought to be employed and used for the apprehending of the things they are designed to signifie, and the making of them more affective; but neither of them so (to be insisted on) as if it were adequate, or just.

35. The Light of Faith and Revelation, must not be confounded with that of Reason and Nature; I mean, we ought not to consider points of mere Revelation in the light of mere natural Reason: Spiritual things cannot be discern'd but spiritually, and therefore must not be compared but with Spirituals. In Points of (mere) Revelation, we [30] ought entirely to confine our selves to the Notions, Comparisons, Similitudes and Representations God himself hath made of them, without pretending to be wise above what is written, and to say or understand just how in themselves the things are, abstractly from the Dresses Revelation puts them in.

36. He that pretends to understand the Mysteries of Christian Religion, or any Point of meer Revelation stript of those Notions, Resemblances, and Comparisons, when they be not revealed or discovered but in them; as he looketh not on these things in the Light of Faith and Revelation, but in that of Reason or Nature; so not looking on them in their own Genuine and Proper Light, no wonder if he either erre or trifle about them.

37. Justly liable to this Reproof I judge them 
that are not content to think and speak of God (the proper Object as well as Author of Revelation) in that manner that he [31] speaks of himself; who Reveals himself to us men in Analogous and Comparative Notions, not in such as adequate and ad. just him, but such as do proportion and suit with us; as if he had an Understanding, Will, and Affec:tions; and did purpose Ends, and elected Means to compass them; did consult and decree, and were touched with the Affections of Joy, Grief, Love, Hatred, Anger, Revenge, \& $c$.

38. They that tell us that he is not angry, that Revenge is an Imperfection not to be imputed to him, and pretend to tell us just what's meant by it. they might as well tell us that he doth not love nor hate; that he doth not propose Ends to himself, nor designe Means; that he doth not consult nor decree; that he hath no Providence, no Foresight, there being Imperfection in all those Notions; and yet without them, and the like, you can nor Think, nor Speak of God. Abstract the Deity from these and other Compa ${ }^{[32]}$ rative Notions, Notions of Him. which are not in Him, and yet wherein He pleases to Reveal Himself, and you will soon make Him such an one as Epicurus ${ }^{15}$ fanci'd, an Infinite Excellency, but unknown, not concerned, nor concerning of Himself with things below Him.

39. It seems to me, that he that would abstract God, or any matter of Religion, from the Notions or Comparisons which $\mathrm{He}$ or That is represented in, would do like one that world consider the World 
24 PHILOSOPHICAL WRITINGS OF BURTHOGGE.

onely in its Realities of Matter, Figure, Texture, and Motion, abstractly from those Phaenomena and Appearances occasion'd by them in our Senses and Mindes: And if the latter may be thought to have but an Empty, Dry, and Barren Notion of the World, the former would not have a much better of God (whom now we cannot know as $\mathrm{He}$ is) or of any Subject of Revelation, that should so consider $i t$.

40. Whoever well attends, will [33] finde that all the Notions under which we apprehend God, are Notions of Him, like those we have of the World, not as $\mathrm{He}$ is in Himself (for so we know him not;) ${ }^{16}$ but as He stands in our Analogy, and in that of the World; which Notions are very fitly stiled Attributes, not Accidents, as not speaking things Inherent Really in Him, but things ascribed by the Minde, or attributed to Him; as Colours, which but in the Eye, are yet ascribed to the Object; and Sounds, that indeed exist but in the Ear, are attributed to the Air: For we regarding God in that Relation that He bears to the world, and to our selves, and so considering Him, have excited in us such Notions by the impressions the things we look on, and God himself as interested in them, make upon us. The Attributes of God are but (as) so many Aspects. Much Obscurity and many Errours in forming Notions about God and his Attributes, are owing to an Unacquaintance with this Truth. [34]

4I. Having spoken of Clearness of Apprehension, and of the Lights that make it, I will onely adde a Consideration, which though obvious enough. 
is not reflected on as it should; namely, that the Lights are gradual; [even that of Revelation] and that all things are not equally clear (in them:) so that we ought to put a difference, as between Philosophical and Theological Points, and Points unrevealed and revealed; so in those revealed between Fundamental Points (which are but few and plain) and Superstructures upon them; between what is in Scripture in express Terms, and what is there but by Consequence; and in Consequences, between those that are immediate and next to Principles, and those that are remote and further off. As there are weighty Points of the Law, so there are Tythemint, Anise, and Cummin; he that makes no difference, takes not his measures by Jesus Christ's. As it is inept and foolish, so it is inhumane [35] and bloudy, not to distinguish Errours from Heresies. Heresie in Religion, is as Treason in the Law, a subversion of Fundamentals; and it must be plainly and directly so, and not by Consequences and farfetcht Deductions: For Heresie, it must be eradicated; but as for Errours, he that is exempt from them, let him throw the first stone at the guilty. But this is not intended as a Plea for Errour, God forbid! but for Humanity.

42. I proceed to the second Affection of Apprehension, which is Distinctness. And to apprehend a thing distinctly, is to form such a Notion and Conception of it, and to have such a sence as doth distinguish it from all things else.

43. Distinctness of Apprehension is acquir'd by 
Distinction, and by Definition. Distinction, as I take it, is of Words; Definition of Things. To make a Distinction is, when a Word hath many Signifcations, to determine, fix, or define [36] the Sence it is taken or us'd in, and by certain Marks and Tokens to distinguish it and circumscribe it from all the others (it hath.) Definitions of things are properly Descriptions. To describe, is to notifie, mark, and represent a thing in and by its Attributes, that is, according to the impressions that it makes upon our Faculties, and Conceptions it occasions in them. Essential Definitions are Non-sence. Things are not Explicable, but as they are to us in our Faculties.

44. The more particularly any thing is marked, the more distinct is the knowledge we have of that thing.

45. Most Errours in Divinity as well as in Philosophy, owe their being to confused Apprehensions, and confused Apprehensions their's to the Ambi$\checkmark$ guity of words, and the uncertainty of their Signification. He that uses words of many Significations without distinctly marking them, and without particularly no[37]ting what Sence he takes the word in when he uses it, may easily be apprehended to take it sometimes in one Sence, sometimes in another, that is, to take one Sence for another; and he that takes one Sence of a word for another, mistakes, and confounds things. To confound things. is to take one for another. Confusion of things comes from Ambiguity of words. A Word in one 
of its Sences may belong to a thing, when in all it cannot.

46. Caution. Take heed of being abused with the Agreement of Words, into a belief of answerable Agreement in Things.

47. Direction. To avoid confusion of Apprehension, the best way is to look beyond the words we hear or read, or have in our mindes, unto their Sences and Meanings : for Words may be uncertain and equivocal, whereas Sence and Notion is not so, but certain and fixt.

48. Having treated of Apprehension in the general, of its Object, and [38] of its two Affections, Clearness and Distinctness, it remaineth to speak of those Conditions which are requisite to the forming of a clear and distinct Apprehension; and they are four: a Due Illumination or Illustration of the Object; a Right Disposition of the Faculty; a Due Distance from the Object; and a Due Attention to it. The same Conditions in Apprehension as in Vision.

49. A Due Illumination of the Object; by which I mean here but Perspicuity of Expression: a Representation of things unto the Minde in plain, apt, and significant Words, and in a plain and instructive order and method. Plainness of Expression and Method is the Light of a Discourse; he that uses it is Didactical, [apt to teach,] but he that will clearly and methodically express his Thoughts to others, must first conceive them so himself: so that here I might say over again what I have already 
about Clearness and [39] Distinctness of Apprehension.

50. A Right Disposition of the Faculty; a Right Temper of Mind, [Rectitude of Minde] consists in a full and perfect Exemption of it from all the prejudices that either Education, Custom, Passion, or false Reasoning have imbibed it with. Prejudices are erroneous (or false) Anticipations, and are in the Minde as Tinctures in the Eye, which falsifie its Vision. Other Diseases of the Minde there are besides Prejudice, as Levity, Curiosity, Scepticism, $\mathcal{E} c$. in an Exemption, from which also Sanity of Minde consists; but the principal is Prejudice. And besides Sanity of Minde, there is (for the apprehending of some particular Objects) necessary also a Sanctity of Minde. The pure in heart [onely] see God.

5I. A Due Distance from the Object; not to look too neer, nor at too Remote a Distance.

52. Not too near. Too near looking is a cause of much entanglement [40] and errour, both in forming of Philosophical and Theological Notions; he that looks too near, doth either see nothing at all, or but confusedly: he looks too near to things, that not contented with common Notions of them, wherein all the world agrees, will have more exact ones; or that not contented with the knowledge of things according to appearances, as he may see them, is always attempting to know them in their Realities, in which he cannot; As in Quantity the common Notion of it, how evident is it! 'Tis evident 
to all men, and none but knows what is meant by it; and he that looks on Quantity but so, observes a due distance; but whosoever looks nearer, looks too near, and is confounded with the composition of the Continuum $^{17}$ [and well he may that takes a Phaenomenon, a Spectrum, an Appearance for a Reality.]

53. Not at too remote a distance. He considers Objects at too remote [41] a distance, that looks on them but in second Notions, or contents himself with general ones, which at best are but confused and uncertain; and being so, no wonder if they cause mistakes: the more particular and distinct, the surer the knowledge is: we are often deceived with appearances, and take one thing and person for another, when we only see them afar off.

54. Due attention is a fixed and steady beholding of the Object, in order to a framing clear and distinct conceptions about it; and 'tis opposed to Inadvertency, or a precipitate and hasty skipping from thing to thing, without a due considering of any: A Distemper of Minde, to which Youth and warm Complexions are subject, which though they may be more ingenious and witty, and more prompt and ready, are yet for that reason seldom so judicious, prudent and weighty, as those of cooler Tempers and of more Age. [42]

55. So much for Apprehension, the first Act of Understanding: I now pass on to the second, which is Judgement.

56. Judgement is that Act of the Understanding 
whereby it having compared and considered things (presented to it, and apprehended by it,) comes in the end and upshot, either to Assent, or Dissent. So that Judgement is a compounded Act, and (as it were) made up of two; one of which is Mediate and Inchoate, the other Ultimate \& Compleat; the first is Comparing and Considering; the second, Resolving and Decreeing: That the Premisses; this, the Conclusion. The former properly is Reasoning; the later, Resolving according to Reason.

57. Reasoning is (a) producing or shewing of (a) Reason. (A) Reason is the Ground of Intellectual Judgement; or the Cause why the Understanding either assents, or dissents. Assent is the Approving Judgement of the Understanding; [43] Dissent is the Disproving Judgement of the Understanding. To shew Reason for a thing, is to prove it: to shew Reason against a thing, is to disprove it. Plain Reason is that which convinceth: Forced Reason is that which only confutes. To confute is, so to entangle a person that he cannot answer: To convince is, so to shew him Reason, that he cannot deny it to be so. A man is often confuted, when yet he is not convinced.

58. Method of Reasoning is called Logick; and is either Artificial or Natural. Artificial is the Logick of Schools, of which the chiefest is Aristotle's: ${ }^{18}$ and is useful many waies, but among others, mainly (as a Whetstone) to acute and sharpen the Wit; and to render it more sagacious, circumspect and wary, both in making and admitting 
Deductions and Consequences. Natural Logick, that of plain and illiterate men, of which I designe to discourse, is the natural method [44] of Reasoning; in relation whereunto the Scots are said to have a Proverb, That an Ounce of Mother-wit is worth a Pound of Clergy.

59. Natural Logick is universal, a Logick of the whole kinde; so that what in Natural Logick is reason to one man, is so to all; for all having the same Faculties, and using them in the same Method, must needs come to the same issue, and by the same Principles arrive to the same Conclusion.

6o. As one naturally by often seeing and attending to his own acts, acquires a method how to look to see to the best advantage, as also Optical Rules by which he judges of Objects; which Method and which Rules are [to speak generally] the same among all men: So may he by frequent reasoning, and attending to his own and others reasonings, easily and insensibly acquire a Method [which as reasoning it self will for the general be the [45] same with all men] how to use his Reason to the best advantage, to reason out things. This common method of Reasoning, (which because common, and in some measure acquired without assistance of Art, I call natural) is natural Logick.

6r. All Reasoning is either Speculative or Practical. Speculative Reasoning is shewing a thing is true or false: Practical Reasoning is shewing a thing is to be done, or not to be done. (A) Speculative Reason is the ground of Speculative Judg- 
ment. (A) Practical Reason, the ground of Practical Judgment. Speculative Judgment is judgment that a thing is true or false: Judgment that it is true, is Speculative Assent; that 'tis false, Speculative Dissent. Practical Judgment is Judgment or Decree that a thing is to be done, or not to be done. Judgment that a thing is to be done, is Judgment for it, or practical Assent: Judgment that a thing [46] is not to be done, is Judgment against it, or practical Dissent.

62. Speculative Reasoning is either Proving or Disproving. To prove, is to shew a thing to be true; to disprove, is to shew a thing to be false. So that in natural Logick, [as to speculative Reasoning,] there are but two Topicks, or principal places of Arguments, and those are Verity and Falsity: The one affords us a medium of Proving, the other a medium of Disproving: I prove what I say, by shewing the Truth; I disprove what another says, by shewing the Falsity of it.

63. Truth and Falsity are to the Minde, as white and black to the Eye; as these are kinds of Colours, and so the objects of the Eye; so the former are kinds of Sense, and consequently objects of the Minde: And as the Fye rightly circumstanced and condition'd sees white to be white, and black to be black; so the Understanding sees Truth rightly sheron to be Truth, and Falsity to be Falsity. [47]

64. Wherefore to prove a Truth to be one, is but in a right method to shew it to the Minde, the Understanding apprehending a thing to be true 
when rightly shewed, as the Eye doth see the shew to be white that is duely held before it. A Notion may be true, yet not acknowledged to be so, because not rightly apprehended, or seen; and it is not rightly seen or apprehended, because not rightly shewed: Then Truth is rightly shewed, or shewed to be Truth, when 'tis shewed Systematically, or Harmonically. The like is to be said of Falsity. But to enlighten this Point, I am to shew at large what Truth, and consequently, what Falsity is.

65. TRUTH, in the apprehensions of some of the School-men and of others, is that conformity which is in things to their original Ideas in the Divine Intellect. All second Beings are but Copies of the Minde of the first, in which they have their Exemplars: and wherein doth [48] the verity, the truth of Copies consist, but in a conformity to their Origi nals?

66. But this notion of Truth (however true it may be) is not pertinent to us; 'tis Metaphysical Truth that it relates unto; a Truth of things as standing in the Analogy of God; but the Truth we treat of, and whose notion we are enquiring after, is Logical, a Truth of things as standing in our Analogy, and which is the ground of Assent. Certain it is, this notion that the Schools afford us, is not (nor can it be to us) a Medium of Reasoning; since we cannot say what is conformable or what is not unto the divine Exemplars. He must see the Original, and compare the Copy with it, that or: Knowledge will affirm this to be true. 
34 PHILOSOPHICAL WRITINGS OF BURTHOGGE.

67. Of late the old Catalepsis has seen the light again, that comprehension discoursed of by Cicero in his Lucullus. ${ }^{19}$ The meaning of which is, that there is no other Criterium, [49] no other judicial note of Truth, no other Rule, Mark, or Measure whereby to know a thing to be true, than clear and distinct Perception. And thus also the Cartesians. ${ }^{14}$

68. But on the contrary, clear and distinct Perception is not the Cause and Ground of Assent, but onely a Condition of causing; Truth is the onely Adequate and effectual Motive or Reason of Assent; but to be so, it must be clearly and distinctly perceived. Truth (as whiteness) is something in the Object that invites Assent: clear and distinct Perception is not in the Object, but of it; and consequently is not Truth, but conversant about Truth. Sight is not Colour, but of Colour; so neither is Perception Truth, but of Truth. Besides, that cannot be a certain mark of Truth, which may be affirmed as well of Errour as of Truth. I may as clearly and distinctly perceive a thing to be false, as to be true. A thing may be evidently [50] false, as well as evidently true.

69. If any say (as doubtless some will) that by clear and distinct Perception, they mean nothing but a clear and evident apprehension of the truth of things; I answer, That then either they know what Truth is by its mark and definition, and by the impression that it makes on the Minde, as well as what Whiteness (is) by the impression made thereby on the Eye; or they do not. If they do not, 
how can they say they clearly and distinctly perceive a thing to be true, who know not Truth? They might as well say, they clearly and distinctly see a thing to be white, when they know not whiteness. Or if they know what Truth is, then that Impression, that Form, that Notion of Truth they have, ought rather to be insisted on, and not the (bare) Perception. They should say, The thing is true, we see clearly the Form and Notion of Truth in it. For indeed, nothing [51] makes a thing true, but the Form and Notion of Truth therein: For did I apprehend a thing to be true never so clearly and distinctly, yet if I did but apprehend it so (as I may, and many do) and that the Notion and Form of Truth were no wise in it, it were not true by vertue of the Apprehension I had of it, but onely seemed so. As I clearly and distinctly see an Image in the Glass, when indeed it is not there; or an Oar in the Water bowed and crooked, when indeed it is not so. It is an Errour (and a most dangerous one too) to assert, that seeming or intellectual sense (for clear and distinct Perception signifies no more) is the measure of Truth: There are so many ways wherein a thing may be seen clearly and distinctly, that is, may seem true, and yet not be so. No convincing Hereticks, or opinionate Philosophers, if Seeming be the mark of Truth.

70. To this Opinion, I am now [52] to adde another much of kin to it; That of the truly-Noble and Learned the late Lord Herbert, ${ }^{20}$ namely, That Truth consisteth in the Analogy, Agreement, Har- 
mony of things to our Faculties, inviting a most free and full Assent: Or, in his own Terms; Veritas est Harmonia inter objecta \& Facultates, habens sensum gratissimè \& lubentissimè sine ulla haesitatione Respondentem.

7 I. All the difference between the Former and the Latter Opinion is, that in the former Apprehension clear and distinct, in the latter Assent Free and Full, is made the Mark and Measure of Truth. Of this (Latter) Opinion, as that eminent Person (last mentioned) among the Moderns; so among the Antients were a many noble Philosophers; in

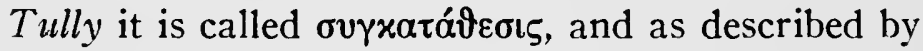
him, it hath the same Foundation that his Lordship builds on, namely the oixelótns of Truth. That Truth is so Domestical and [53] Congruous to the Faculty, so Analogous and fit to it, that the Inclination of the Minde thereto, in Nature and Necessity, resembles that of a Stone, or whatever or other heavy Body you'll imagine, to the Center.

72. But (I) a bare Congruity between the Object and the Understanding is not the ground of Truth, but of Sense or Intelligibility; and though there be a Congruity in all Truth, because there is a sense in it, and happily more Congruity because a more agreeable Sense; Yet since that Congruity is unobservable, unremarkable but by Assent, and Assent (of it self) is no sufficient Evincement of Truth; I lay it by as Illogical and useless. (2) Nor doth the Understanding blindly incline to Truth; and as it were by Sympathy, or a natural Motion 
of Aggregation; its Assent is (an act of) Judgement: The Minde proceeds therein judicially upon Allegations and Proof; judging a [54] thing to be true, that is, assenting to it, onely because it sees therein the Form, Notion, and Mark of Truth, as it judges a thing to be white wherein the Eye assures it there is the form of Whiteness. And (3) one may readily and chearfully assent to Falsities and Errours, and mistake them for Truths; and therefore free and full Assent is no sufficient evincement of Truth. Not to urge that chearfulness of Assent, that readiness and promptness we many times observe in it, is oftner an effect of a Passior: bribing of the Understanding, than of a pure clear impartial Reason.

73. Wherefore, others of the Antients, as well as of the Moderns, abundantly convinced of the insufficiency both of Perception clear and distinct, and of Assent free and full to ascertain them of Truth, and yet unwilling to have Nature (so liberal in other matters) exposed to the reproach of Deficiency in One so important as intellectual [55] Judgement; They have conceited humane understanding furnish'd by her with certain [ Anticipations, that is, with Connatural and Ingrafted Notions; Principles designedly implanted in the Minde, to be a rule to it to direct it. ${ }^{21}$ Thus in the speculative Understanding they have set up a habit, which they call Intelligence; in the Practical another which is called Synteresis; in both, a Con stellation of Principles, shining with their own Light 
38 PHILOSOPHICAL WRITINGS OF BURTHOGGE.

and imparting it to others that want it; not much unlike to what is affirmed of Dionysius ${ }^{22}$ in his Celestial Hierarchy concerning Spirits, that those of superiour Orders enlighten all beneath them in the inferiour.

74. But were there really such a System of Notions and first Principles ingrafted in the Minde by Nature, in whose Light all others were to shine and to be seen, it would follow that Contemplation of our own mindes, acquainting us with the Chain. Concatenation, and So[56]rites of the Principles therein, and Propositions deducible therefrom, would more import to the rendring us Philosophers (not to say Divines also) than observation of the World and Experience; and so the greatest School-men (those Metaphysical Alchymists) that insisted much on this Method, and spun out all their notions of their own Bowels, should have been the wisest and most fruitful of men. Whereas we know the men, and the manner of their Communication; all their Discourses are indeed subtle and acute; but also empty and barren, and no more agreeing with Realities (and in our Analogy) than Light with Darkness.

Again, the Soul in its state of Union and Conjunction with the Body, is so dependent on it in all its Operations, that it exercises none without the Aids of it. Ratiocination it self it is an Animal act; not an abstract Action of the Soul, but a (Concrete) act of the Animal; it [57] is the Man reasons. ${ }^{23}$ And in the ordinary method of Nature, we receive 
into our Mindes no Impressions, no Images, but what are handed to them by our Senses. I am apt to think that person who should never have seen, nor heard, nor tasted, nor smelt, nor felt any thing, would have his minde as little furnish'd with Idea's or Notions, as his Memory with Images, and would understand as little as he had sensed. Besides, those very Principles themselves we call First ones, or Anticipations shining with their own lustre and light, Propositions which we cannot but assent to as soon as we hear them, or minde them; It will appear, if we reflect warily on what doth pass in our Mindes, that even these are not assented to, but on the Evidence they bring; I mean not assented to naturally, but (as other Propositions are) judicially. For instance, that the whole is greater than the part, we assented not unto it on the first hearing. but first [58] considering what was meant by Whole, what by Part, what by Greater, what by Lesser; and then having sensibly, either by Eye-sight, or by Imagination, compared one unto the other, we evidently saw it to be so; that the Notion of Greater, even to Sense, ever agreed to the whole; and that of Less, to the Parts. The like that Two and Two make Four. This is the way we first admitted to belief the Propositions which are called Principles; and it is no other than that wherein we admit all others. Onely the Propositions (which are) call'd Anticipations, or first Principles, are Propositions of so easie, sensible, and plain an evidence, and so obvious, that we early admitted them, so early, that 
we cannot well remember when we first did so; and therefore they are stiled Anticipations, or proleptick Notions: for being of so early an admission and existence in our Mindes, they preceded all our (after) knowledges, whose acquirement we well remember. [59]

Further, Beings are not to be multiplied without Necessity, and there is none of faigning such Anticipations and Habits of Principles to direct the Minde in inquisitions after Truth, since all acknowledge there are no such principles in the Eye, the Ear, the Nose, the Tongue to direct them, and why then in the Minde? Besides Reflection on our ordinary reasonings, evinces that in them we seldom attend to such Principles, but to the Object discoursed of; nor need we to do otherwise, if it can be evidenced that there is a certain Notion, Form, Ground of Truth that runs through all things true; which Form or Notion of Truth, assoon as the Understanding rightly circumstanced and conditioned, apprehends in an Object, it cannot but acknowledge it to be true, as it would another to be white or black, wherein it is assured by the Eye rightly circumstanced and conditioned, that there is the Form of Whiteness or Black ${ }^{[60]}$ ness. As for Anticipations, they are too particular, and not of a nature so large and comprehensive as to be the Rules and Measures of Truth, which is infinite. Let those Anticipations be reckoned, and then Experiment be made upon comparison with the im- 
mense Latitude of Questions, and of Truth relating to them.

75. Thus I have shewn the Indications, Marks, and Notions of Truth that (in my judgement) are not proper, adequate, or useful; it now remaineth that I shew one (that) is. And Truth, as it is the Ground, Motive, and Reason of Assent, is objective Harmony, or the Harmony, Congruity, Even-lying, Answerableness, Consistence, Proportion, and Coherence of things each with other, in the Frame and Scheme of them in our Mindes. Truth is universal and exact Agreement or Harmony.

76. On the other hand, Falsity (as the ground, motive, and reason [61] of Dissent) is Objective Disharmony, or the disharmony, incongruity, inequality, unanswerableness, inconsistence, disproportion, and incoherence of things, in the Frame and Scheme of them in our Mindes. Any Disagreement or Disharmony is Falsity.

77. Probability or Likelihood of Truth, is an appearance of Congruity. A thing is probable, when it hath some consistence and agreement; it Quadrates and lies even with what we do know; but in regard there are particulars relating to the same Systemes and Frames of Thoughts which yet we do not know, therefore we know not if it will lie even and square with them. Improbability is apparent Incongruity.

78. That Truth is Harmony and Proportion, and consequently that Probability is apparent Harmony, apparent Proportion; and Falsity, Disharmony, Dis- 
proportion cannot be but very evident to him that [62] shall consult with Nature and common sense.

79. In Nature it is plain: For Harmony, it is the Reason of the World; the World was made by it, cannot be known but by it. The rule of Proportion is the King-Key, unlocking all the Mysteries of Nature. The Great Creator framed all things in the Universe in Number, Weight, and Measure: Extremes in it are united by participating Middles; and in the whole System there is so admirable Uniformity as ravishes every one that beholds it: every thing in its place is aptly knit with what is next it; and all together into one most regular Frame of most exact Proportions. Every thing we look on affords Examples; and Galen ${ }^{24}$ in his Books of the use of Parts, has a Thousand, to whom (if in so plain a matter it be necessary) I remit the Learned Reader.

80 . And 'tis a common sense, that what is congruous is true, and what [63] is true is congruous; so common, that none ever fancied any notion of Truth but in Congruity: some School-men, in Congruity to the Divine Intellect; Others in Congruity to our Faculties; and all men (though they speak not out, and it may be minde not that they do so) in Consistence and Congruity of things with one another; all generally concluding that Narration (for instance) to be probable, which seems consistent; and Probability being appearance of Truth, if what seems consistent be probable, what is so is true. But to give a Mechanical instance; one that would repair a broken China-dish, or make up a 
Watch or other Engine taken abroad, what Measures doth he naturally take to do so? what Rule proceeds he by? None verily, but by that of Congruity; he makes no question but that when he hath found a place for every part wherein it lies consistently and aptly with others, so that in the whole [64] there is exact Coherence and Congruity, no Flaw, no Unanswerableness, it is truely set together, and every part in its place. Truth is Harmony.

81. And seeing Truth is Harmony, and the Universe it self, as it consists in our Analogy, is but one System; it follows that properly there is but one Science (which some will call Pansophy) one Globe of Knoivledge, as there is of Things: As also that the partition of Sciences, or rather the crumbling of them into so many, hath been a great impediment of Science; the dependency of Things, and their Relations one to another, thereby becoming unobserved and unconsidered. And in fine, that the more large, general, and comprehensive our Knowledge is, the more assured and evident it is. It is in Science as it is in Arch-work, the Parts uphold one another, and mutually contribute strength and beauty. The confinement of the Understanding [63] to particular Knowledges, as also the limiting of it in any unto certain Methods and Terms of Art, is like too straight a swathing of the Childe, and spoils its growth.

82. So much for the two Topicks of natural speculative Reasoning, namely, Truth and Falsity. It now lies on me more expressly to describe How 
44 PHILOSOPHICAL WRITINGS OF BURTHOGGE.

Reasoning is performed in reference to them; and so what the Nature of it is. And natural speculative Reasoning is Systematical, and Harmonical; it is a shewing, an evincing the Truth or Falsity of a thing, by conferring and comparing thing with thing; it is a shewing a Notion to be true or not true, by representing of it in a Frame, a Scheme of real Notions, with all its Relations in it; and so by Comparing, Evidencing how it squares, agrees, and harmonizes, or otherwise.

83. That Natural Reasoning is Harmonical, Systematical, that it is conferring, comparing, is evident [64] in the Natural Reasonings of Plain and Illiterate, but Understanding men; who not having other Logick but that of kinde, to verifie their Tales, desire but to have them heard out from end to end; and who no otherwise confute their Adversaries, than by telling over again in their own way the whole Relation, that so both may be compared. Besides, the comparative method of Reasoning, used by the Minde in intelligible Objects, is no other than that we naturally use in those that are sensible: For, be it a visible Object we enquire ${ }^{25}$ into, and examine the truth of, we turn it every way, and into all postures, so to make a certain judgement of it ; and Circumspection, (which is Cicero's word for it) or the Mindes comparing and conferring of things is no other. And if Truth indeed be Harmony, Proportion, Congruity, an Object cannot be evinced true, but by being evinced Harmonical, Congruous, Proportionable; and [65] it cannot be evinced Har- 
monical, Congruous, Proportionable, but by being conferred and compared, and upon collation and comparison shewn to be so.

84. To prove Harmonically, is in a Scheme and Frame of Notions bottomed on things, to shew the thing to be proved, to quadrate, lie even, and to be entirely congruous and answerable. To disprove a thing Harmonically, is in a Frame and Scheme of Notions bottomed on things, to shew it not to quadrate, but to be incongruous, unanswerable, and unadequate.

85. The best way of Confuting Errour, is to do it by shewing the Truth: There is so great a delicacy in Proportions, that a Scheme of Thoughts may seem congruous and agreeing by it self, which compared with another, is observed no longer so; as two pieces of fine Cloath looked on at a distance, and not compared together, may be judged equally fine, and one no better than [66] the other; whereas when put together and felt, and so compared, the difference is plain and discernible.

86. The Effect of Reasoning, (and as it were the Conclusion) is Assent, or Dissent, according to evidence. Evidence is the Assurance we have a thing is true or false, and so is either of Truth or of Falsity, and answerably bottomes either Assent or Dissent.

87. Assent is the judgement of the Minde upon evidence of Truth, that the thing is true. Dissent is the judgement of the Minde upon evidence of Falsity, that the thing is false. 
46 PHILOSOPHICAL WRITINGS OF BURTHOGGE.

88. Evidence of Truth is either certain or probable. Certain Evidence is full Assurance. Probable Evidence is good Assurance, but not full. Certain Evidence is evidence of certain Truth. Probable Evidence is evidence of probability. Probable Evidence is now a-days termed a Motive of Credibility. [67]

89. In Proportion, as the Evidence is, so is the Assent. If the Evidence be certain, that is, indubitable and unquestionable, [and that is to be understood to be so, of which there is no cause to doubt, or make any Question] then the Assent is firm and certain, and without doubting; (but) if the Evidence be but probable, the Assent then is infirm. and with doubting more or less, as the Evidence is lesser or greater. To Doubt, is to fear lest the thing to which Assent is given should not be true.

90. Evidence of Certainty, is to the Minde (as to its Assent) all as much as Evidence of Infallibility: For the Minde as firmly adheres to what it hath all reason for, and no reason against; all reason to believe it to be so or so, and no reason to believe it to be otherwise, as to what it apprehends impossible to be otherwise; seeing it were unreasonable and contradictious for Reason any wise to doubt, when it [68] hath no reason at all to do so. I am as sure that once there were such persons as William the Conquerour and Henry the Eight, and that there are or lately were such Cities as Rome and Constantinople, as I am that Two and 
Two make Four, or that the Whole is greater than the Parts.

91. Firm Assent in matters in themselves mutable and of a contingent nature. may be called Confidence; but in matters of a necessary, firm, and immutable nature, it is Science. Infirm Assent, or Assent with Dubitation, is called Opinion. Suspition is a beginning Assent, or an inclination to believe a thing, and is short of Opinion. Suspition on grounds is called just suspition. Suspition on no grounds is mere suspition. Probability is appearance of Truth: And ground of Suspition is Appearance of Probability. Suspition is also called Presumption.

92. Assent on Evidence by the [69] testimony of our own Senses rightly circumstanced and conditioned, is as firm as firm can be, and is called Knowledge. Assent to a thing upon anothers knowledge and not our own, is called Belief. To Believe, is to take a thing upon anothers word; and if that word be divine, the belief is called Faith; or if but humane. it is called simply Belief or Credit. Belief is grounded on the wisdom and veracity of the person believed: for he that believes another, believes him to have wisdom enough not to be imposed upon or deceived himself; and Veracity or Truth (which among men is called Honesty) enough not to impose upon or to deceive him. The Word of God therefore is the most proper object of belief, God being so wise he cannot be deceived, and so true he cannot deceive. Notoreity of a thing [of a fact] is the certainty of it on 
Common Knozvledge: It is not Presumption, nor Probability, but Certainty. [70]

93. Assent to Falsity under the notion of Truth, if it be firm, is called Errour: If infirm, and with dubitation, it is erroneous Opinion.

94. Ratiocination Speculative, is either Euretick or Hermeneutick, Inventive or Interpretative; and this latter again is either interpretative of the World, the Book of Nature; or of the Scriptures, the Book of God. But of these perhaps, another time, as also of the method of Reasoning which I called Practical, and is either that of Prudence (I. Humane, or 2. Christian) or of Conscience.

Now on the whole Matter, who seeth not the share and interest (that) Reason hath in matters of Religion? Men are reasonable Creatures, and therefore their Religion must be reasonable: Every Tree must bring forth Fruit in its kinde. Faith it self it is a rational Act [If I have any reason to believe Men, I have all reason to believe God] and [71] Ratiocination is as much imploy'd in points of Revelation, as in points of mere Reason. Truth is the immediate reason of Assent in matters of Revelation as well as in others; and there is an Analogie of Faith as well as of Nature; the Mediums are different; but Ratiocination is the same in both: We are as well obliged to compare Spiritual things with Spiritual in the one, as Natural things with Natural in the other. Thus are the Bereans applauded as persons of nobler and more generous 
Mindes than those of Thessalonica, because they took not all on trust as these did, but examined the things were told them, and compared them with the Scriptures.

It is easie also to infer, that if any person shall give himself the trouble of disproving what in my Apologie I presented to the World; to do it to Conviction, he must produce a frame and Scheme of Thoughts more Congruous and Harmonical [72] than mine, and must account for those Phaenomena which I therein essay'd to solve, in a method more perspicuous and natural, and with more agreeableness and uniformity of Notions than I have; or else he will not Confute, but confirm it.

I say this, to shew the fairer play to those that undertake to answer me, if after I have said it any shall resolve to do so; and I say no more, to shew the Opinion I yet avow to be mine of all the Objections whispered up and down, that in themselves they have as little force and evidence, and as little conviction, as those that make them have yet had either Courage to own them to the world, or Candour to own them to me.

Thus, Sir, I have performed what I principally designed. I have shew'd the nature of Reason: I have shewed the true method of Reasoning; as also the nature of Truth, and (up and down my Discourse dispersedly) the causes of [73] Errour: and I have shew'd the extent of Reason. In which performance, whatsoever other Incongruity or Errour I may have been guilty of, sure I am I have com- 
50 PHILOSOPHICAL WRITINGS OF BURTHOGGE.

mitted none in dedicating it: For to whom could I address a discourse of Reason and of Truth more properly, than to a Person who is so great a Lover and owner of both? and withal who is so perfectly honoured as you are by all that have the happiness to know you: But by none more than

Sir,

Your most humble

Servant and Son,

Richard Burthogge.

Bowdon, Aug. I4. I677. 
AN ESSAY UPON REASON. 



\section{A N}
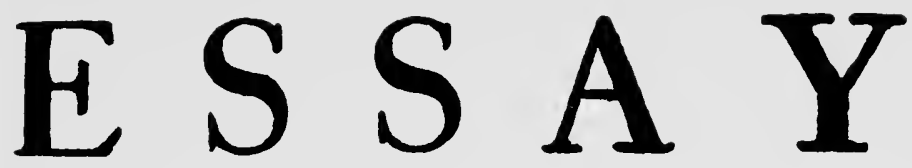

UPON

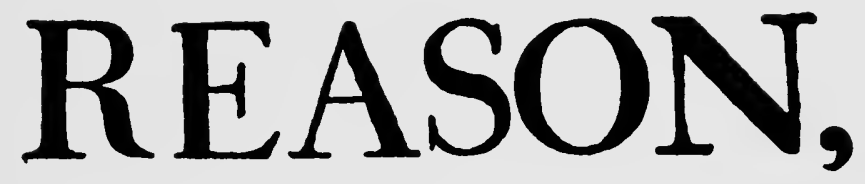

A N D THE

Nature of Spirits.

By Richard Burthogge, M. D.

$$
L O N D O N \text { : }
$$

Printed for John unton at the Raven in the Poultrey. 1694. 



\section{OF HUMAN REASON.}

THE FIRST PART. CHAP. I. OF REASON IN GENERAL.

\section{SECT. I.}

In what sense Reason is taken and discoursed of here. A double account of it; the first, more Notional; the second, more Real. Of the Agreements of Reason, Sense, and Imagination. (I.) That all three are Cogitative and Conceptive Powers. Cogitation what. Monsieur des Cartes, and Honoratus Faber, their Opinion, that Sensation is not Cogitation, considered. (2.) That Sense, Imagination, and Reason are Mental and Spiritual, and not meerly Mechanick and Material Powers. The Differences of those Powers; that all Sensation is Imagination, and what is commonly called Imagination, is but Internal Sensation. Intellection or Reasoning, is Know'ing without Imagination. Instances, setting out these several Notions. The power of Knowing without Imagining, why called Reason. [2]

Reason taken for Human Mind, or Understanding (which is the sense I take it in now) is defined 
by most, the faculty whereby a Man is said to be Reasonable, or Understanding; in like manner as Sight is defined, the faculty whereby a Living Creature is Denominated Seeing, or Visive, or Reason is that faculty whereby a Man does Exercise the acts of Reason, or doth Understand; as Sight, the faculty whereby a Man or any other Animal doth see, or discern Objects.

Nor are they altogether without Reason, who do so define and explicate it; for Acts of Perception properly so called, are not Known, or Knowable, but in and by themselves; we Know not, nor are capable of Knowing, what the Act of Seeing is, but by seeing; nor what that of Hearing is, but by Hearing; or what the Act of Understanding is, but by Understanding. And again, Perceptive faculties are not Known, or Knowable, but by their Acts: We Know not what the faculty or power of Seeing is but relatively, with relation to the Act of Seeing: Nor what the faculty or Power of Hearing is, but by the Act of Hearing; nor what the faculty or power of Understanding or Reasoning is, but by Acts of Understanding or Rea ${ }^{[3]}$ soning: In a word, no Faculties, no Powers are Known, or Knowable, but by their respective Acts or Exercises, and therefore they cannot be defined or set out but by them. All this is certain.

However, since this is but a notional fruitless way of Explicating Reason, and too short, too narrow to satisfie a Curious and Inquisitive Mind ; therefore to settle an Idea of it, that may be more to pur- 
pose, more real, and more edifying; I will show, in the first place, the Agreements it hath with other Conceptive Cogitative faculties, what it holds in common with them; and afterwards, set out the Differences that do discriminate and divide these several faculties, each from other, and this particularly from the Rest.

The Conceptive Cogitative Faculties that are in Man, (for so I call the Faculties by which he makes acquaintance with external Objects) are his external Sense, Imagination (as it is called) and Reason or Understanding: Three Faculties which do all Agree and Concur in this, that they are Conceptive and Cogitative, and consequently Mental and Spiritual, and not meerly Mechanick and Material Powers.

First ; All three are Conceptive, Cogitative Powers; Sensation and Imagination, as well as Reasoning or Intellection, are [4] Cogitations. Cogitation is conscious Affection; Conscious Affection, is Affection with Consciousness of that Affection; and by another name is called Knowledge. Knowledge, as it has a double relation, so it may be considered two ways, to wit, either in reference to the Object, which is Known, and so, properly, it is Apprehension or Conscious Perception; or, as it respects the Image and Idea, by means of which we do perceive or know that Object, and so it may be called Conception. Conception properly speaking, is of the Image, or Idea; Apprehension, Knowledge, or conscious Perception is of the Object, by means of that 
Idea, or Image: It is as proper to say, that the Sense and Imagination do conceive, as that the Reason or Understanding doth; the former does as much conceive Images and Sentiments, as the latter does Ideas and Notions.

Conception and Cogitation, really are but one Act, and consequently, all Conceptive are Cogitative Powers, and Cogitative Powers Conceptive. Only, to clear the Notion of Consciousness, by which Cogitation or Knowledge is distinguished, tho' never divided, from Conception, we must further consider the Way and Manner how Consciousness Arises. And it seems to me to arise, ordinarily, from the distinction [5] and difference that is in Conceptions; for, should any person have his Eye perpetually tied to one Object, without ever closing of, or turning it to another, he would no more be sensible that he saw that Object, or know any more what it was to see, than if he had been blind from his Birth. For since Consciousness of Seeing is nothing but a perceiving by the Eye, that one is Affected, or otherwise Affected than he was, with the appearance of Light, or Colour. If a person had never seen but one thing, and never but seen it, he could have no perceivance (that) he is so Affected, that is, he could not be sensible or conscious (that) he did see. Thus, tho' in our Members the parts that do compose them are contiguous one to another, and do always touch, yet we do not feel them touch, that is. they touch, but we are not sensible they do, because no difference being in the Affection, there is no 
Sense, no Consciousness of it: But Dislocation is soon perceived; as also it is when any part is pressed unusually. I conclude, that as difference of Conception arises from different Affections of the Faculties by Objects, so Consciousness, or Sense of Conception, arises from the difference of Conceptions. Did we know but one thing, or had but one Act of Conception, we should not know [6] that we did know that one, that is, that Conception would not properly be Cogitation, but would be, as touching without feeling. However, since there is so great a diversity of Objects in the World, all-around us, and consequently, so many various Impressions made upon the Mind, by those Objects, so that its Conceptive Power cannot but be diversly Affected, and moved. and the Mind also have a perceivance of that diversity; hence it comes to pass, that Conception is always Cogitation. In short, Conception is Modification of Mind, and Cogitation is Conception with Consciousness of it. Consciousness of Conception is a sense of the Alteration made in the Mind by that Conception (of which it is conscious;) si nihil (says Cotta apud Cicer. l. I. de Nat. Deor.) ${ }^{26}$ inter Deum \& Deum differt, mulla est apud Deos cognitio nulla perceptio.

I know very well that Monsieur Des Cartes. ${ }^{27}$ the ingenious Honorato Fabri, ${ }^{28}$ and many others do differ from me, for denying (as they do) that Sensation is Knowledge, and consequently, excluding both Conception and Consciousness from the Idea of it, they must also deny, that Sense is a Cogitative 
or Conceptive Power. But then, it is hard to say, what that Idea is, that they have of Sensation. Besides, 'tis [7] most certain that in Men, Sensation is Conscious Perception, for whatever Impression is made upon our Eye by any Object, we do not for all that, discern, or see the Object, if we do not attend unto, as well as receive, the Impression; that is, we do not discern or see, but when we Know we do. Then only we have a Sensation of Objects, when we are Conscious that they do Impress us; that is, when our Organs being Impressed, there arise and spring up in us, by means of those Impressions, certain Images or Conceptions, that (many of them) by a Natural delusion do seem as really to Exist without us, in the Objects themselves, as if they were indeed so many real Affections of them, or Inherent Accidents in them. And those Images being but Modifications of Mind, arise not in us upon any Impressions but when the Mind Attends to them, for else they cannot Affect it.

But happily it will be told me, that this Consciousness of Impressions, which is in men, when they do see, or hear, or otherwise perceive Objects, by the Affections of their External Organs, Arises in them only from the Concomitance of the Understanding; because in men, whatever Affects the Sense, is also perceived by the Understanding; but that there neither is, nor [8] can be, any such thing in other Animals, which are as void of Consciousness of any Impression made upon their Organs, as they are of that Reason and Understanding that 
makes it in Men. But as this may be said, so it may be as easily Replyed to; for 'tis as impossible, that Men should have any clear, or indeed any Idea, at all of Sensation, in other Species of Animals, but by that, which they have of their own; as it is certain, that Sensation in Men cannot be understood to be without Conception, nor Conception without Attention of Mind. Attention of Mind, is the Application of it unto Objects, and therefore in Men, is called Minding: Without Attention no Conception, and without Conception no Consciousness; Consciousness being (as I have said) nothing but a Sense of Alteration made in the Mind, by some new Affection of it, that is, by a new Thought or Conception. Besides, there are many other things that do make for this Opinion, that all Animal Sensation is Cogitation; particularly, that great Sagacity that is in some Animals, which cannot be accounted for with any clearness, but by allowing to them a great degree of Knowledge and Consciousness.

And hence it follows, that Sense and Imagination, as well as the Understand[9]ing and Reason. are Mental and Spiritual, not meerly Mechanick and Material Powers. By Mechanick and meerly Material Powers I understand such as do result from Matter only, and the Modes of Matter; from Local Motion and Rest, and from Size, Figure and Texture. By Mental Spiritual Powers, I understand such as cannot be conceived to arise from Matter only, and the Modes of Matter, without the Influence of Mind; and in the number of these I 
reckon Sense, and Imagination, as well as the Understanding or Reason. It is true, the term [Mind] is Appropriated, by way of excellency, to the Understanding or Reason, this being a faculty that hath the participation of Mind in a higher degree than the others have: But yet, there is Mind, and as much of Mind in all the Conceptive Cogitative Acts of Sense or Imagination, as there is of Conception and Cogitation in them. Thus I have shewed how Sense, Imagination, and Reason do agree, now I am to shew how they differ.

Sense, (by which I mean the power of Seeing, of Hearing, of Tasting, of Smelling, and of Feeling,) is that by which we make acquaintance with External Objects, and have Knowledge of them by means of Images and Apparitions, or [10] (which is a better expression, as being more General and Comprehensive,) by Sentiments excited in the External Organs, through Impressions made upon them from Objects. Imagination is internal Sense, or an (After) Representation of the Images or Sentiments (that have been) excited before in the Sense: This is the Basis and Foundation of it ; Composition, Division, and Enlargement of Images, is but Accessory, but Superstructure, and an Improvement of Sense. Reason or Understanding, is a faculty by which we know External Objects, as well as our own Acts, without framing Images of them;; only by Ideas or Notions. In short, Sensation, properly, is Imagination, for every Sense Imagines; and that, which commonly is called Imagination, is 
but Remembrance, or Recollection of Sensation. Imagination, is Repetition of Sensation made from within, Sensation, is Imagination occasioned by immediate Impressions from without us. Reason or Understanding, is refined, Sublimated Sensation, that is, a conscious preception of things by Notions or Ideas, and not by Images, or sensible Representations. And thus, all the cogitative powers that are in Man, may be reduced to Two, to Sense and Reason; the former comprehending the Imagination, which is but [11] the power of Remembering Sensations, and of Amplifying them; and the Letter comprehending Intellectual Remembrance, which is only a recollection of Ideas or Notions.

But to make a Reflection of more light, it may be minded, that when we look on a Book, (to Instance in a thing that is next to hand,) and read any Sentence in it, as this, God is a Spirit, we have at that time in our Eyes the Figures of the Letters that compose the Words, and so do know by them, what the words are; and this is Sense. But if putting aside the Book we will endeavour to Recollect those words, we must do it one of two ways; either by Retrieving in our thoughts the very Figures and Images of the Letters and Words before presented to our Eyes; or (which we oftnest do) by recalling the Words and Sentence, and saying to our selves, or unto others, God is a Spirit, without thinking in the least, of any Figures of the Letters that do make the Words, or of the Images of the Words that compose the Sentence. In the former we do Imag- 
64 PHILOSOPHICAL WRITINGS OF BURTHOGGE.

ine the Sentence, as raising again the Images of the Words that make it, and this is Sensible Remembrance; but in the latter, though, when we Recollect the Sentence, we must withal (some way [12] or other) mind again the words that compose it, yet we do it without Imagining them, and this is Intellectual Remembrance, or the act of the Reason. Add, that at the same time that we do see the Schemes and Figures of the Letters, and have the portraictures and draughts of the words presented to our Eyes, which is Sense, we have, or may have, in our minds the sense and meaning of those words. of which sense or meaning however, we have neither Picture or Figure; and this is Understanding: In the former we have Images, in the latter only Ideas; we See the words, but understand the meaning. This power of the Mind, (of perceiving without Imagining,) is called Reason, because in those Acts in which it does converse with things by means of words (and those are most of the Acts exerted by it) the sense and meaning of the words is (as it were) Inferred and Reasoned from them. What I have said, suffices to make the Notion or Idea of Reason or Understanding conceivable, by men who use Attention, and do think, but nothing will be enough to explicate and set it out to such as cannot endure that trouble, but will swallow all things without chewing-[13] 
SECT. II.

Of Reason as taken for Contrivance, Contrivance, what, Sagacity what. Reason taken but for Contrivance, not Characteristical to Man. Of the Imaginative Contrivance in Irrational Animals. An Instance of it in a certain Hen. Apprehension, Composition, Illation. Acts of the Imagination, as well as of the Reason or Understanding. Composition of Phantasms, how Illustrated by Mr. Hobbs. That Reason taken for the Understanding (in the Notion of Understanding setled before) agrees to no other Animal but Man. Of Prince Maurices Parrot. The Acts of Reason as taken for the Understanding. reduced to two, to wit, Apprehension and Judgment.

$\begin{array}{llllllllllll}* & * & * & * & * & * & * & * & * & * & * & * \\ * & * & * & * & * & * & * & * & * & * & * & *\end{array}$

CHAP. II.

Of Apprehension.

SECT. I.

Apprehension, the first Act of Reason. Of Words, the ordinary Means of Apprehension. The Ends and Uses of Words. I. To distinguish things as they are in the Mind, in which, words do stand for things. Why Mind is called Understanding. 2. To express our Thoughts and Conceptions one to another. The Importance of 
Words unto Knowledge, in this second Use of them. Of the Sense of Words. Of Canting. All Use of New Words, not Canting. The Sense of Words twofold; Verbal, and Reall. This distinction of the Senses of Words Illustrated, and the Usefulness thereof explained. Why the Meaning of Words is called Sense.

Apprehension, or that Act of the Reason or Un. derstanding, in respect of which it is said to see or perceive things, is the same in reference to this faculty, that seeing is unto the Eye: for the mind to apprehend, perceive, or know any Object, is the same (to speak by way of allusion and similitude) as for the Eye to see, or discern one. [24]

What I have said in the former Chapter, does cast some Light on this Subject; but yet to set it out more fully, I will consider, First, the Ordinary Means the Understanding uses in its Acts of Apprehension, and those are Words. Secondly, The immediate Object of Apprehension, and that is Notion, or Intellectual Sentiment; Sentiment of the Mind. Thirdly, The two chief Affections of Apprehension, and those are clearness and distinctness; of which three considerations; the Second properly is a Subject of Metaphysicks; the Third of Logick; and the First is common to both.

* $\quad * \quad * \quad * \quad * \quad * \quad * \quad * \quad * \quad * \quad * \quad * \quad * \quad * \quad *$

A Distinction then there is (and that a remarkable one too) between the verbal, and real, meaning 
of words; which to set out more fully, I will show' First, The Occasion, and Rise of it, and then Secondly, The Use and Benefit of it.

First then, this distinction Arises from the Imperfection and Inadequacy of Human Knowledge; we Knowing little of things but under words, and words being (immediately) the signs but, of our Conceptions, which are always short and narrow, and, too often, indistinct and confused. Now if the sentiments we have according to the Vulgar and Ordinary way of conceiving, which is but general and confused, do cohere and hang together, when one of them is affirmed or spoken of another, so that the Notions are compossible in common acceptation, we call it sense, though really the things themselves (for which those words are understood to stand) be Incompossible, and repugnant each to other, and therefore indeed it is Nonsense. This is to be better understood in Examples. Such Propositions as these, that Colours (even as to their Images) are in the Objects in which they do appear; that Odours are in the things smelled; that Sapors are in the things that are tasted; these and the like Assertions are not com[36] monly understood, or said, to be Nonsense, because, Knowing in the general and confusedly, what is meant by colour, what by Odor, and what by Sapor, as likewise what is meant by the thing seen, by the thing that is tasted, and by the thing which is smelled; nothing appears in those confused general Notions (which we have,) to hinder us from thinking that Colours, Sapors, and 
Odours do as really Inhere in those external objects, as they seem to do. And yet to a Person that hath distinct, real, and just conceptions of the several subjects and predicates in those propositions, it is evident, that 'tis as gross and palpable Nonsense to affirm that Colours, Sapors, Odours, and other Accidents, (which are but Phaenomena and Intentional beings) do really exist in the Subjects where they seem to be, as to say, that there are Notions and Cogitations in a Wall, in a Figg, or in a Rose, than which there cannot be a greater Bull or absurdity.

The Usefulness of this distinction, is greater than most will think; since from the want of making, or of observing it, it comes to pass, that so many do run into great mistakes and errours, in their discourses; Do skirmish one with another, to no purpose, and without end; and of [37] ten $d o$ differ from themselves, as much as each from other. For few there are that do fix and settle even the verbal Sense of words, (which often have a doubleness of meaning, and then are called Ambiguous;) and fewer that do think of the real, without which yet, they can never come to any certainty; so that, (as Mr. Hobbs has ingeniously said; words that are $\mathrm{W}$ ise Mens Counters, become Fools Mony. ${ }^{2 \theta}$

The meaning of words, as well the verbal, as the real, is called Sense, because the Perception of it ought to be as Clear, and distinct, and as steady and fixt, as that of Sense is: For words, to be understood as they ought, must have their meanings be as clearly and distinctly perceived, by the mind, as 
objects of Sense when they are Seen, or Heard, or Tasted, or Smelled, are by the Senses. [38]

\section{SECT. II.}

All Falsity is not Nonsense; but all impossible Falsity is. Repugnance in the mind to yield assent to propositions that are Nonsence. Whence it arises. Of Enthusiasm, as it is a kind of Nonsence. What Enthusiasm is. The distributions of it. Examples of the sereral Kinds of Enthusiasm, out of Dr. Fludd, and in the Magick Aphorisms of the Rosy-crusians. That Enthusiasts where they seem to understand one another, do so by Sympathy only. and not by way of Apprehension and Judgment. How this may be, set out in a story very Remarkable.

$\begin{array}{ccccccccccc}* & * & * & * & * & * & * & * & * & * & * \\ * & * & * & * & * & * & * & * & * & * & *\end{array}$

\section{SECT. III. [47]}

Of Questions, their Nature, and their distribution. That a Question is neither true, nor false; neither Affrmative nor Negative. An Objection removed. That procceding by way of Question, or as it were of Inquiry, in Common Discourse, is very useful, as well as Civil. Judgment required in putting Pertinent Questions.

$\begin{array}{cccccccccccc}* & * & * & * & * & * & * & * & * & * & * & * \\ * & * & * & * & * & * & * & * & * & * & * & *\end{array}$


7 PHILOSOPHICAL WRITINGS OF BURTHOGGL.

CHAP. III.

Of Notion, the immediate Object of Apprehension. SECT. I.

That Notion may be considered two ways. Ist. In general; and 2ly. more specially. Of Notion in the general sense of the Word. No Original Native Notions. Why it seems as if there were. The Notion of Apprehension cleared. Of Notion in the special and limited Sense of the Word, what it is. That the understanding apprehends things but inadequately, and under Notions in the limited sense. This evidenced by several considerations. An Objection against it removed.

I have spoken of words the ordinary, but instituted, means of Apprehension; I am now to speak of Notion, the immediate Object (some would call it the natural means) of Apprehension.

The word Notion, may be considered two ways. either as it does signifie more generally and largely, or as it is taken in a more restrained, special and particular sense. [52]

A Notion in the general and larger aceptation of the word, is any conception formed by the Mind in reference to Objects; and so taken, is the same with a thought, or that, in respect of the Mind, that a Sentiment largely taken, is, in respect of the sense. I say a Sentiment largely taken; for instance; when Sentiment is taken in respect of the Visive Power, 
not strictly and properly for light, or colour only; but largely, for any perception that the Eye has, by way of sight, of things, or of their relations and habitudes. And since there is so great an Analogy between the Eye and the Understanding, and between the Sentiments of the one, and of the other, it will be an easy inference, that no reason can be given why there should be Original Innate Notions in the Understanding (as some imagine there must) that it may be able to apprehend, which will not equally argue, that there should be the like original Figures and Images in the Eye, which should enable it to see; and yet none will Allow of these.

But to show how It comes to pass, that there are (as there are) appearances as if the mind had some original innate Notions, ${ }^{21}$ which for that reason are called Prolepses and Anticipations, and withal to bring some light to the business of Apprehension. [53] which (as to the way of it) is obscure enough, and but seldom touched to any purpose: I will offer an Observation very common, but (as it may be applied) very luciferous in reference to this Subject.

Everybody observes, that if a Blow is aimed at the Head of any person, he will hold up his Arm to receive it, and keep it from his head, without thinking either that, or why, he does so; and this is said to be done Naturally, and by instinct; because, in truth, it is done without premeditation, and so, at that time, without any actual conceived design.

And yet again it is certain, that an Infant will not do so, or any Child before it has been taught and 
instructed to do it; which makes it plain, that the loing so in those who are come to reason, is no effect of natural instinct, but of use; only the Child was taught to do it so early that by the time he comes to the Age of Discretion, having forgotten, or rather, having made no observation, when it was first taught, or first did it, and upon what Motives, and doing it now without deliberation it hath the aspect of a thing effected by Nature, and not of a custom or habit.

In the same manner in the business of Reason, we may, and often do proceed up ${ }^{[54]}$ on Principles instilled into us very early, and are Acted by them, without Knowing how, or why, it being no Effect of present consideration. Experience confirms this, since we may be certain, if we do but attend to our own Actions, that, many times, we are carried to the Affection, or Disaffection of things, and the Approbation or Disapprobation of them, we Know not why, and yet all the passions and Motions of our Mind, have Reasons for them; for all Effects must have Causes; but these, sometimes, are so early graffed in us, and, at other times, so unazwares, that we remember not they were so; and then the Effects, only being observed, and the causes lying deep, hidden and secret, we do call it Nature, or Instinct, though in truth, it be Reason, and habit, as much as any thing else is.

Again, much the same way we do compute or reckon; for when we use any greater numbers, either in Addition, or in Substraction, or in any 
other Arithmetical operation, we do it without any actual consideration of what the lesser particular numbers are that make the greater, for that we have done before, (perhaps long, ) and consequently are possessed of the Ideas (may I so express it) without the Images of them. But at first, we had [55] a particular Knowledge. As, when we Multiply and say, Six and Six is Twelve, and Twelve and Twelve is Four and Twenty, we do it without considering actually at that time, that six is so many unites. though at first (but possibly so long ago that we do not remember it) we did so, and must (do so) to Know the particular value of that number; and the like is of others.

And thus also with an easie Application may it be conceived, how words come to stand in the inind for things, and that when we have the word, we think we have the simple Idea of the thing; it is just as the Figure [6] doth stand for the number [Six]. And that when once we have had a distinct Idea or Notion of the Number, afterward, (without actual thinking thereof,) we use the Figure instead of it, and that as well, or better than if we did distinctly consider the Number it self. Now, words do carry the same Relation unto things, that Figures do unto Numbers, and both Words and Figures seem to derive the power which they have of standing in the Mind as Representatives, from the connexion they have, Figures with Numbers, and Words with Things; after the same manner as we hold up our Arm, or a Stick, to save our Head, with ${ }^{[56]}$ out 
74 PHILOSOPHICAL WRITINGS OF BURTHOGGE.

thinking of saving it. For though the Action prevents all actual thought of the End of it, yet 'tis done for an End, in vertue of its first Direction and Use. This Discourse attended to, and well digested, will open a great light into the way in which the Understanding comes to have Apprehension of things by the means of Words; and to form its Ideas and Notions, taking Notions largely for any Thoughts or Conceptions.

But besides the former Sense of the Word [Notion,] there is Another which is more Restrained and Limited; in which a Notion is Modus Concipiendi, a certain particular manner of conceiving; a manner of conceiving things that corresponds not to them but only as they are Objects, not as they are Things; there being in every Conception some thing that is purely Objective, purely Notional; in so much that few, if any, of the Ideas which we have of things are properly Pictures; our Conceptions of things no more resembling them in strict Propriety, than our Words do our Conceptions, for which yet they do stand, and with which they have a Kind of Correspondence and Answering; just as Figures that do stand for Numbers; yet are no wise like them. [57]

To make this clearer, it must be considered that the Eye has no perception of things but under the Appearance of Light, and Colours, and yet Light and Colours do not really exist in the things themselves, that are perceived and seen by means of them, but are only in the Eye. Likewise the Ear 
has no perceivance of things, as of a Bell, of a Lute, or of a Viol, but under sounds, and yet sound is only a sentiment in the Ear that hears, and is not, or any thing like it, in the Bell, or Viol, or Lutie that is heard. For as the Eye has no Perceivance of things but under Colours that are not in them, (and the same time with due alteration, must be said of the other Senses.) So the Understanding Apprehends not things, or any Habitudes or Aspects of them, but under Certain Notions that neither have that being in Objects, or that being of Objects, that they seem to have; but are, in all respects, the very same to the mind or Understanding, that Colours are to the Eye, and Sound to the Ear. To be more particular, the Understanding conceives not any thing but under the Notion of an Entity ${ }^{30}$ and this either a Substance or an Accident; Under that of a zehole, ore of a part; or of a Cause, or of an Effect, or the like; and yet all these and the like. are only Entities of Reason con ${ }^{[58]}$ ceived within the mind, that have no more of any real true Existence without it, than Colours have without the Eye, or Sounds without the Ear. Every person that hath the least Understanding of the way in which we do apprehend things, will yield this to be true as to Whole and Part, to Cause and Effect, and to all the Notions which are commonly termed by Logicians the Second; and it is as certainly true in reference to Substance and Accident, to Quantity, Quality, and those other General Notions under which the Understanding apprehends its Objects, though com- 
monly they are called First ones, and in comparison of the others are so.

I have laboured the more to make the Notion that $I$ have in this business plain and easie, because much of what is to be said hereafter will depend upon it; and now taking it for granted that my meaning is Intelligible, what remains, is to evince true; and this I shall do, from the very Nature of Cogitation in general, (as it comprehends Sensation as well as Intellection, ) since that the Understanding doth Pinn its Notions upon Objects, arises not from its being Such a particular Kind of Cogitative Faculty, but from its being Cogitative at large; let us then reflect [59] again on the Nature of Cogitation at large.

It is certain that things to us Men are nothing but as they do stand in our Analogy that is, in plain terms, they are nothing to us but as they are known by us; and as certain, that they stand not in our Analogy, nor are Known by us, but as they are in our Faculties, in our Senses, Imagination, or Mind; and they are not in our Faculties, either in their own realities, or by way of a true Resemblance and Represcntation, but only in respect of certain $A p$ pearances or Sentiments, which, by the various inpressions that they make upon us, they do either Occasion only, or Cause, or (which is most probable) concur unto in Causing with our Faculties. Every Cogitative Faculty, though it is not the Sole Cause of its own inmediate [apparant] Object, yet has a share in making it: Thus the Eye or Visive 
Faculty hath a share in making the Colours which it is said to see; the Ear or Auditive Power, a share in producing sounds, which yet it is said to hear; the Imagination has a part in making the Images stored in it; and there is the same Reason for the Understanding, that it should have a like share in framing the Primitive Notions under which it takes in and receives Objects: In [60] summ, the immediate Objects of cogitation, as it is exercised by men, are entia cogitationis. all Phaenomena; Appearances that do no more exist without our faculties in the things themselves, than the Images that are seen in water, or behind a glass, do really exist in those places where they seem to be.

But as this is a truth that Many will admit with more facility in reference to the Obiects of Sense, and Imagination, as Colours, Sapors, Sounds, $\mathcal{E} c$. Than to those of the Mind or Understanding, such as Substance, Accident, Quality, Action, \& $c$. So I find my self obliged to give a farther demonstration that it holds in these, as well as in those; which I hope to do by the following Considerations.

First, the understanding converses not with things ordinarily but by the Intervention of the sense, and since sentiments of sense are but Appearances, not Pictures, or proper Representations, it is hard to conceive how such conceptions are framed only by their occasion, and only wrought out of them, should be portraits of the things themselves, and made just and exact to them. 
Secondly, The understanding is a power [61] of that nature that many think it doth not immediately Attinge (as they call it) or reach particular singular beings, which yet are the only beings that compose the Universe, as members or parts of it ; and really, it uses to proceed by way of Abstraction, and therefore doth more Connaturally converse with Universals, that are not of Mundane existence, than with singulars that are. Now, since things as they are in the mind, do undergo an Abstraction and sublimation, certain it is, they must put on another dress there, and so appear in quite another shape than that they have in the World. In short, All Agree that our conceptions of things are but inadequate, as indeed they must needs be, since things have much Refraction (may I so express it) both before they come and after that they come, to the mind; and if they are inadequate, they cannot be commensurate, that is, they cannot be so just and exact, to things, as to show them as they be, and in their own existences.

Thirdly, It may be Argued from the very nature of an Idea or notion; since this after a sort is a sentiment of the mind, as a sentiment (properly so called) is, after a sort, an Idea or Notion of the sense; the [62] immediate objects of the sense are sensible sentiments, and those of the understanding are Intellectual ones; which they must needs be, because the understanding it self is a kind of sense, only a more sublimed and raised. Mens ipsa (says 
Cicero, l. 4. Academ. Quaest.) quae scnsuum fons est, etiam ipsa Sensus est, \& $c^{31}$

In fine, this is so certain a truth, that whosoever reflects, tho' never so little, cannot chuse but observe that as he takes in nothing by his sense but under sentiments, which are the notions of sense, so he receives in nothing in his understanding, but under certain notions, which are the sentiments of the mind; since he knows nothing Intellectually but either in general only, under the notion of a thing, or more specially under that of a substance, or else of an Accident; and what are all these but Objective Notions? $?^{5}$ as will appear in particular upon the examination and Tryal of them.

Let us then inquire first into the thing, (for we shall shew it of Substance and Accident hereafter) and what is thing but modus concipiendi? a notion or sentiment that the mind has, of whatsoever any wise is, because it is? Thing indeed is the most general notion, but then it is but a notion, hecause it is general; and has the most of [63] a notion, because it is the most general. To be more particular; If the Question be asked, what thing is? or what is meant by that word? Some have no other Answer but this, that a thing is that which hath essence. But then it may be farther demanded, what is meant by essence, which is said to be had? What it is to have essence? And what is meant by that, which hath it? Or if it be said, that a thing is that, which is, (as it is by others;) the same difficulties again occur: for it may be demanded, what that is, which is? And 
what is meant, when it is said to $b e$ ? And whether Existence be Essence? especially since Existence seems not the first conception of a thing; but is a second, or after-conception; as not being that, which makes a thing to be what it is, [a thing;] but what only makes it a thing in being.

By this, it plainly appears, that the meaning of the word [thing.] is but an inadequate conception. arising in the mind upon its conversing with $O b$ jects, and so cioth speak a certain particular sentiment, which the mind has of them; a sentiment better understood, than defined by words; but a sentiment too, that doth not enter us into the knowledge of the Reality it self (may I so express it,) of that which is: achich we only apprehend inadequately, ${ }^{[64]}$ under the Disguise and Masquerade of notions. As, that it is that, which is: or that which has essence: or the like: but not by any adequate exact conception. And as for Substance and Accidcnt, which yet are the first steps we make toward a distinct Perceivance and knowledge of things: what are they. but likewise Modi concipiendi? Entities of Reason, or notions, that (it is true) are not without grounds, but yet that have, themselves, no Formal being but only in the Mind, that frames them; there being no such thing in the World as a Substance, or an Accident, any more than such a thing as a Subject, or an Adjunct; and yet we apprehend not any thing but as one of these, to wit, as a Substance, or as an Accident: so that we ap- 
prehend not any at all, just as they are, in their own realities, but only under the Top-knots and Dresses of Notions, which our minds do put on them.

But here it will be told me, that plain unlearned men, who yet do exercise the Acts of Reasoning well enough, and perhaps in the best manner, as doing it without $A r t$, and in a way the most agreeable to Nature, do conceive and speak of things without conceiving or minding of Notions, such as I have mention'd; for they conceive and speak of man, of good and [65] evil, of vertue and vice, and the like, without conceiving or minding of Substances, or Accidents. But this is easily got over. For tho' unlearned plain men do not explicitly and in terms denominate goodness, z'crtuc, vice, \&c. Accidents, yet since they do conceive them (as All do) all things that are in a man, or in some other thing, tho' they do not call them Accidents, yet do they conceive them as Accidents: And when they do conceive, or say of a man, for instance, that he is vertuous or zicious, or the like, they do conceive him to have i'ertue or vice in him; that is, tho' they do not think of the name substance, yet they do really conceive that person to be one: since a substance is nothing but a subject, or a thing that has other things in it as Accidents; whereas in truth, neither Accident, nor Substance hath any being but only in the mind, and by the only vertue of cogitation or thought. $|66|$ 
82 PHILOSOPHICAL WRITINGS OF BURTHOGGE.

SECT. II.

Inferences from the former Discourse; first, that human knowledge for the most part is but intentional, not real. The usefulness of this Inference; an Objection against it removed. (And yet) Secondly, That the immediate Objects of the cogitative Powers are somewise external to those powers; and this, both as to appearances, (which is sensibly demonstrated) and as to their grounds. Two other Inferences added; the first in reference to the grounds of the Doctrine of the old Academy; the second concerning the obligation we are under ordinarily to conceive and speak of things as they are in our Analogy, and do appear to our faculties.

I infer from the former Discourse; First, that human knowledge (at least for the most part) is but Intentional, not Real; and that we have no Perception of any thing, (in any degree to speak of,) just as it is in its own Reality and being. For all our notions and conceptions of things, are of them under sentiments; the understanding it self (as I argued before) [67] being but a higher and more sublimated sense; and sentiments (as such) are in their own formalities but apparently only, not existently, without the faculties that do conceive them. To be particular, we have no perception or knowledge of any thing but as it is a Substance, or an Accident, or a Quality, $\mathcal{G} c$. And these are only 
notions: for example, as to H'ater; we have no knowledge of it by all, or any of our senses, what really it is in it self, just as it is, and absolutely speaking; for we are utterly ignorant (otherwise than by Conjecture) of the Magnitude and size of the little parts that compose it; Ignorant of their figure and shape; and Ignorant also of the kind, and degree of motion they have; all this we are Ignorant of, and yet this is all that is Real in Water. But as Ignorant as we are of what it really is, in it self, and absolutely considered, we have much Comparative Relative Knowledge of it; for we know it by sense to be fluid; to have some degree of tenacity or vis cosity ; to be moist ; in a word, to have so many Qualities (for so we conceive and speak) that all put together, do give the mind a sufficient rise to distinguish it, as a different substance, from Earth, or Fire; So that a person that has at any time had [68] the perception ${ }^{32}$ of them all, will not mistake them afterward, one for the other.

But here it must be remembred, that (as I have shewed before) tho' we do not see the reality of things immediately, and just as it is in the things themselves, yet by means of sentiments and notions: we do somewise, perceive it; as the Eye that sees not anything immediately but Light or Colours, yet by means of Light and Colours, discerns Gold, Silver, Stones, Wood, as also the Magnitudes, the Figures, the motions, the distances of things; with a thousand other Realities, so the understanding discerns infinite Realities, infinite habitudes of 
things: not indeed immediately, but either under the sentiments of sense, or by means of its own, which I call notions; as of Substance, Quality, Cause, Effect, Whole, Part, $\mathcal{E} c$.

I have been somewhat longer in the Explication of this Inference, because to know the nature of our Knowledge, must needs be of great advantage unto us; and much relieve us in our Inquiry after the nature of Things: since it frees us from the confusion, that our mind must necessarily be in, should it take the Apparitions of things (for such sentiments and notions are) to be external and real Existences. Would not a thinking man be much per ${ }^{[69]}$ plexed, to make a satisfying conception, what that Image is, that he sees in a glass, or in water, if he was perswaded of its being a Reality (of Existence,) and not a meer Apparition? The like must he be, who takes Objectives Notions for real Existences, and who confounds Attributes that are only Objective, and that do belong to things but as they are Objects with those that do belong unto them as they are Things, and that are Real,

However, it will not follow, as some have weakly objected. that then nothing is Real; for tho' the Images themselves of Whiteness, Blackness, Redness, Greenness, that do scem inherent in visible Objects, are not really so, yet really there are Dispositions and textures of particles in those Objects, that. by the various Modifications which they give the Light, do occasion in the Eye, to which the Light is reflected, all that diversity of sentiments (which 
we call colours) that does appear in those Objects. The same, mutatis mutandis must be said of sounds, sapors, odors, and of Tangible qualities, and in proportion will hold also in mental notions. For tho' the very Notions of Entity, Substance, Accident, Whole, Part, Cause, Effect, and the like, do not really exist without the mind; yet as they do seem. Real, and some [70] more Real than others, so really' they have in things without us certain grounds or Foundations, that, upon our converse with these things, do naturally Occasion, or Excite, such notions and sentiments in us. But I will speak to this matter more particularly, because it is of importance.

First then, the immediate Objects of Cogitation. both the Sensitive, and the Intellectual, are, in appearance, external to their several faculties: that is, such Objects do so seem to be without their several faculties to which they correspond, that, in apperrance, they are either the very ultimate Objects themselves of those faculties, or, at least, do Exist in them, and upon this account are called Obiccts: for Whiteness seems to the Eye to be in snow, or in a white wall; and sound to the Ear, to be in the Air: a Man doth seem to the understanding, to be really a Substance, or a thing that is invested with Acciclents.

If it be Inquired how it comes to pass, that sentiments and notions, which really are not in the things that are without us, do yet appear as if they were. and consequently that they seem to be Obiects? it must be Anszecred, that this arises from the very 
nature of cogitation it self, and of [71] the cogitative faculties; and that both Reason and Experience do evidence, it must be so.

First, Reason sheweth that it must be so; for as we are conscious that we have a perceivance of $\mathrm{Ob}$ jects under certain Images, and Notions, so we are not conscious of any Action by which our faculties should make those Images or Notions; and therefore being sensible that we are Affected with such Images, and Notions, so long as, and no longer than we do Attend to things without us, (which things are therefore called Objects;) and not being sensible that we are so by any Action from within our selves, it cannot but appear unto us that we are Affected only from the things without us, and so, what really is only in our selves, must seem to come from those things, and consequently to be really in them.

Experience also shews; (to wit, that what is really but in the cogitative faculty, does yet seem without it;) for if the Eye by any accident becomes infected with Colours, as, (to instance in a more received, than often experienced, Matter,) with yellow, by the yellow Jaundice, or with Green, (as I have sometimes observed, before the coming of Convulsions;) ${ }^{33}$ that is, [72] (for this is the Reality) if the Visive Spirits, or whatever other parts of the Eye, that are immediately concerned in the Act of Vision, be Preter-naturally put into the same motions with those, which by the Impressions of Yellow or Green Objects they are naturally put into, in 
either of these Cases, the Object beheld by that Eye, will appear as yellow, or green, tho' to every bodies else, it is but White, or Red, or of some other colour And whence comes this, but hence? that the Images conceived in the Eye, (for in the Instances alledged. the Images of yellow and green are no where else,) are naturally pinned upon the Object. As is farther evident in Dazling; which is, when an Impression made upon the Eye by one Object, becomes translated to another; thus, coming out of a bright Sunshine, on a Summers day, into a darkish room, one sees a splendor in every corner, and upon every $\mathrm{Ob}$ ject. The like Appearance there is, upon the beholding of Objects thro' tinctur'd Glasses: So that it must be concluded, that the immediate Objects of cogitation, I mean the very Images and sentiments that are perceived, do, to all appearance, seem as external to the cogitative powers, as even the ultimate Objects themselves, that are [73] perceived under them; which was the first thing to be shewed.

The second point to be shewed is, that the immediate Objects of cogitation are external in their grounds, as well as in appearance, and in truth, are therefore external in appearance, because they are so really in their grounds. And this is as certain, as that every Effect must have a Cause. For things without us, are the Causes that do excite such Inages and Notions in us: In the order of Nature, we do see a thing so long as, and no longer than, we keep our Eye upon it; and therefore that we do see it, must come from some impression from the Thing: 
and since to see a thing, is nothing but to have some Image from it, and so of it, in the Eye, and the Image is as the Impression, and the Impression as the Thing that makes it, it follows that the grounds of the Image is in the Thing without us. And since the Image (by which I mean Light or Colour) is the immediate object of $V$ ision, and, that what is instanced in one Act of cogitation, will equally hold in all, it follows, that the immediate Objects of all other cogitations, as well as of vision, are ordinarily and naturally as external in their grounds, as in appearance; that is, are fundamentally external, as well as apparently. [74]

I thought once to have ended this Chapter here. but now before I do so, I will add an Inference or two from the former Doctrine; the first is, that we learn from it the Foundation of that Opinion the Academicks of old were in, That no judgment could be made of Truth; that things do seem to us, but cannot be perceived by us; and that no certainty. but great probability only, is to be Attained unto by men. For as this Opinion had all the Phaenomena of cogitation to give it countenance, so those Philosophers saw it ; for they evidently perceived, that they saw not the Realities, but only the Appearances of things; Plato the chief of them, one of the most penetrating, as well as the most elegant, of all that ever were, affirmed that the present, was a word, of Veri similitude only, and not of Truth and Reality: That the beings in this World were only Shadows but that the Substances themselves were in the 
Ideal. ${ }^{34}$ How far herein he went with the Truth, may easily be perceived by what I have discoursed before, concerning the Nature of Cogitation; as also, where he strikes out.

The Second Inference is, That since Sentiments, and Notions bottomed upon the Realities, do seem, the former to the Sense, the latter to the Understanding, to be Realities; and since we are obliged to con ${ }^{[75]}$ ceive, and speak, of things, ordinarily and popularly (for all are not Philosophers) in that way and manner that they seem to be; it follows, that we are obliged to conceive, and speak of Sentiments and Notions in Common Conversation, and to the people, as if really they were the things themselves that are perceived; or at least were in them: And so may say, the Snow is white, the Emerald is green, and the like. [76]

\section{CHAP. IV.}

Of the distribution of Notions in the Restrained sense of the Word.

SECT. I.

Notions are either the Notions of things, or Notions about things. Of the Notions of things. And first of Entity or Thing. The Pinax Entium, or general Table of things. Things are either Real, or Cogitable. And these either meer Cogitables, or real Cogitables. A Reality, zohat A Cogitable what. Of Real Cogitables. Real Cogitables, either Proper, or Reductiz'e. Proper 
Real Cogitables of two sorts; of the Sense, or of the Mind. These of the Sense, of two kinds; Connatural, or Preternatural. Apparent colours, are real Connatural Cogitables. Real Cogitables of the Mind, like those of the Sense, of two Kinds; Connatural, or Preternatural. Real Cogitables Reductive, subdivided into those of sense (External, Internal) and those of the Understanding.

Notions taken in the limited Sense of the word, for Objective Ideas, by [77] and under which the Understanding apprehends, and conceives, of, things, and which, for this reason, may be called Fundamental (as being essential to the business of Knowledge,) are either Notions of things; such as Entity, Reality, \&c. Or Notions about Things, such as whole, part, cause, effect, $\mathcal{E} c$. of which the former are conceived as absolute, the latter more as relative Notions.

The Notions, (or Modi concipiendi, that I call Notions) of things, may be reduced to four, to Entity or thing, Reality, Substance and Accident.

Entity or thing is taken in several senses; either first, in the largest, in which it is the same with something, or Aliquid. Or 2dly. more strictly, as it comprehends but substances, Accidents and Modes. Or 3dly. Most strictly, as it stands for Substances only. I take it not at this time in the largest Sense. 
Thing in the largest Sense, is that which any wise is, or that is Knowable, directly: for Nothing. no wise is, nor is Knowable, but indirectly, and by means of thing, of which it is a Negation; Nothing is Not a thing. [78]

And thing. or Entity, taken in the largest sense for

\section{Aliquid}

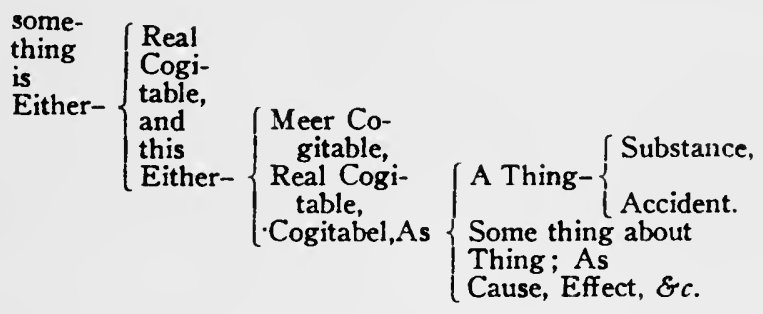

For that which any wise is, is either without the thinking of any one upon it; or it is no longer than while one is a thinking, and because he is a thinking, on it.

That which is without the thinking of any one up on it. and whether it be minded or no, is a real Thing, or a Reality; a thing that so is in the world, as that it is a part, or Appurtenance of it, and such a thing is matter, and every Affection, and every System of matter; and such a thing also is Mind.

That which no longer is than while one is a thinking, and because he is a thinking, on it ; [so that tho it have that which is [79] called in the Schools an objective being, ${ }^{5}$ a being in the Cogitative Faculties, yet hath none without them in the World:] 
this I name a Cogitable; a Cogitable thing, or Entity. And thus, all the Sentiments of Sense, those of the Mind, and even meer Objective Notions, are Things, not things of Mundane and External Existence, but of Cogitation and Notion; Intentional, not Real things. For such are Colours, Sounds. Sapors, Time, Place, Substance, Accident, Cause, Effect, \&c. they are Intentional things, things that, as such, have only an esse Objectivum, an esse Cognitum, as the Schoolmen phrase it.

* $\quad * \quad * \quad * \quad * \quad * \quad * \quad * \quad * \quad * \quad * \quad * \quad * \quad * \quad *$

SECT. II. [86]

Of meer Cogitables, or Fictions. What a Fiction is. That all Fictions are Creatures either of the Mind, or of the Internal Sense; None made by the External Senses. The Reason of it. Two Philosophical Doctrines observed, one concerning meer Cogitables, the other about Real Cogitables Reductive. Why the Representations of things in Prophetical Dreams, are always made as if they were present.

$\begin{array}{llllllllllll}* & * & * & * & * & * & * & * & * & * & * & * \\ * & * & * & * & * & * & * & * & * & * & * & *\end{array}$

\section{SECT. III. ${ }^{35}$}

Of Thing strictly taken, and of the Difference betwixt the Notions of things, and those that are only about things. Of the Idea of Substance, and that of Accident. Spinosas Notion of Sub. 
stance, and that of an Accident considered. Maxims of Thing in general.

Thing taken strictly, as it comprehends but Substances, Modes and Accidents, is whatever seems External to any Faculty, and consequently, seems to have Being in the World, as a Part, or an Appurtenance, of it, whether it be really so or no. And in this sense of the Word, as Real Things themselves, (which are eminently called Things.) So likewise the Sentiments we have of these things, as Colours. Sounds Sapors, $\mathcal{E} c$. are Things; and thus also, $\mathrm{No}$ tions are [92] Things, both the more general and common Notions, those of Substance and Accident, and the more special, the Notions of the severa! Species of Quality, and those of Relations, $\mathcal{E} c$.

But when I say, that not only things themselves, but the Sentiments and Notions we have of them, are Things, it must be understood with distinction; for the Things themselves, (so I call the grounds of Sentiments and Notions) are Realities of True Existence; but Sentiments and Notions being only Real Cogitables, are only seeming Realities; Realities of Apparition only, not of Existence: Thus the Notion of Substance is a Reality of Appearance only, but the things that we apply it to, are Realities of Existence.

By the Notion of thing as taken strictly, we have a Rise afforded us to apprehend the difference between the Notions the Understanding hath of things. and those it hath only about things; for the Notions 
that I call the Notions of things, appear to the Understanding as Things External unto it; for (not to mention Substances) even some Relations, and Intelligible Qualities do seem to the Understanding, as really Inherent in the things they are Attributed to, as the sentiments of [93] Colours, Odors, and Sounds do unto the Senses. But for Notions that are only framed by the Mind about Things, such as Cause, Effect, Measure, Measured, \& c. they seem not to it to have being in the things themselves, but to arise from its own Reflexions, upon comparing and considering of Things. Thus, at the same time that the mind conceives of Almighty God, that he is the Cause of all, as it does conceive, that the word [God] is the name of a Real Being, so it conceives also, than the term [Cause] is not, but that it only signifies a certain Kind of Relation between God and Things, as these do spring from him, and so is only the name of a certain Objective, and not of a Real, Being.

Of the things that do Appear unto our Faculties to have a Reality of being, some are perceived by them immediately, in their own proper Formal $\mathrm{Na}$ tures, and those are either Modes, or Compleat Accidents; Others are not perceived by them immediately, in their own proper Formal Natures; but only by means of, and under, those that are perceived so; and these are called Substances: Compleat Accidents and Modes are Appurtenances, Substances are the things to which they do Appertain. [94] 
It is true, Spinosa is in another perswasion; who tells us, that he understands by Substance. that which is in it self, and is conceived by it self, that is, as he expresses it, a thing in whose conception that of another is not involved. Adding, that by Attribute he understands the same that he means by Substance, to wit, a thing conceived in and by it self, in whose conception that of another is not involved. Thus says he, Extension, in as much as it is capable of being conceived in and by it self, is an Attribute; but Motion that cannot be conceived but as something in another thing, is None. Only he says too, to prevent Objections; that a Notional distinction may be made between a Substance and an Attribute, in this manner, that a thing may be called an Attribute in respect of the Understanding, which doth Attribute such a certain Nature to a Substance; and then a Substance is the thing that the Understanding doth Attribute that Nature unto.

But as what this Philosopher says on this occasion is not very clear, so it is certain, that the Notion of Substance, ${ }^{\text {se }}$ as also that of an Attribute, is Relative; nor are the Instances he puts so well adjusted, but that some exceptions may be brought against them. I can no more conceive [95] any Real Extension, than I can any Motion, but as a thing that belongs to another; Extension to the thing extended, as Motion to the thing moved. And tho' I do not believe my Understanding, the measure of other mens; yet I cannot but think, it will be found on tryal, as hard a task for any other, as it is for me. 
to think otherwise; For what is meer Extension. but an Extension that belongs to nothing? And what is Extension that belongs to nothing, but an Extension of nothing? and certainly, an Extension of nothing, is nothing really, whatever it may be in Imagination; but more of this in another place.

\section{Maxims concerning Thing in general}

I. Nothing can be, and not be at once.

2. Things that but Appear, do equally Affect the Mind as those that really are.

3. Things are not to be Multiplied Unnecessarily; as they are, when the Fictions of Men, are made to pass for the Creatures of God. [96]

\section{CHAP. V. \\ Of Substance.}

SECT. I.

The Idea or Notion of Substance. Self Subsistence, how in the Idea of it. The Idea of Substance only Relative. Neither Extension nor Existence the Idea of it. Substances are either Principles, or Principiates. The Grounds of this Division. Substance that is a Principle, is either Mind or Matter. Considerations premised for the better Understanding of this Discourse. The Ideas of Mind and Matter. The Grounds of the distribution of Substance into Mind and Matter. Abstracted Mind is as con- 
ceivable as Matter, under the Notion of Substance. Spinosa's Notion of Mind rejected.

The Primary Notion or Idea which we have of Substance, ${ }^{36}$ is (as I have hinted in the former Chapter) that of a thing which is a Subject, or an Ultimate Object; that is, we have not any Real immediate Conception of it, but only a Notional. Or (to speak more plainly, [97] according to the Principles laid before) Substance as such, is not a thing conceived just as it is in its own Reality, but a thing conceived under a certain notion; that is, a substance is a thing that is a Subject. For when the Understanding does think of the things we call Accidents (which are the only things that do immediately, and at first present themselves unto us,) for example, when it thinks of Odours, Colours, sapors, figures, \& $c$. it doth at the same time conceive, that besides these there must be other things that have them, in which those odors, colours, sapors, figures, $\mathcal{E} c$. are. And those things that are conceived to have others, we call substances; as those that are conceived to be had of others, or to be in them, we call Accidents: but what those things, which we do Denominate Substances, Are, in themselves, stript of all their Accidents, is no wise known; All we know of any substance is, that it is the subject of such and such Accidents; or that it is Qualified so or so; and hath these, and the other Qualities.

This Notion of a substance [that it is the same with a subject,] I call Primary, because though 
that [of subsisting by it self,] is deemed so by others, yet, in our ordinary way of Reasoning, and Investigating of things, this [of self subsisting] is a consequent one, to that of being [98] a subject. For conversing with things; as the first that do present themselves to our consideration, are the Accidents of them; so the first reflection the understanding makes, upon these Accidents, is, that other things are under them, which do uphold and support them, and consequently, that are subjects, or substances. But then indeed, when it comes again to consider, whether these subjects are also in subjects, finding in its self a certain Reluctance to conceive (that) they are, because, if they were, there would be no end, things would be in one another infinitely; therefore it concludes, that that, which is a subject of Accidents, is it self in no subject; that is, it is self-subsistent. Thus the notion of being selfsubsistent, arises from that of being a subject: Nor is the notion of [being self-subsistent] a more Real one, than that of [being a subject.] For what is Self-subsistence but an Atribute that belongs to something else? but what that something else is, to which it belongs, I am willing to learn; and will ever honour as my great Master, that Person who will effectually teach me. We have no Ideas of any substances, but such as are Notional and Relative; that is, such as do arise from them as they stand in our Analogy, and are cloathed with Accidents. [99] A truth that might be made to appear by a full Induction of all the particulars; But I will instance but 
in some; but those the most obvious, and most commonly discoursed of. For what Idea have we of Earth, but that it is something material, that it is fixt and tastless? What of Salt? but that of some thing sapid, and easily soluble in water? And what Idea have we of reater? but that it is something material, moist, and fluid in such a degree, and the like? So that the Idea of a substance is that of a thing which is a subject; and this is a Relative Idea. ${ }^{38}$

But many, who cannot satisfie themselves with the former, do conceit that they have found a Better, a Real, a Positive Idea of Substance. Of these, some do hold, Extension is that Idea, so that substance is Extension; and accordingly as Extension is either Penetrable, or Impenetrable, so they frame the Notions of Spirit, and Body; or the species of substance, as it is immaterial, or material. ${ }^{44}$ Others hold, that Existence or Being is the Idea of substance in general, and that substances of this or that particular species, are only determinate Talities of Being; for since in being is the Idea of an Accident, being (say they) must be that of a substance, and as to be is to exist, so being is nothing but existence. [100]

I shall have another occasion hereafter to consider the first of those Opinions when I come to Answer a certain Objection, touching the Idea of God; but will say of it now, that those who profess it, cannot make out (as they ought to do) a clear and satisfactory Idea of Extension in general, that shall agree in common, both to that which is Im- 
penetrable, and to that which is Penetrable. Besides, it is not conceiveable, that a Spirit should be only a Penetrable Extension, since (as will appear more fully hereafter) Extension has but little to do with mind or thought, which is Essential to a Spirit: and without which a Spirit cannot be a Spirit: and Penetrability, and Impenetrability has all as little.

Nor is the second Opinion more conceiveable. For not to Insist, that Existence properly taken is only of Causates, (existere properly being [esse extra causas,] and nothing properly is [extra causas] that was not first (in causis;) I will take it at large, for any being in act; yet even so, it is not of the Idea, or first Conception, of substance: for [being] taken not as a Noun, but as a Participle (as here it is taken,) is in the very sense of the term, a word of Relation; being is not a thing, but of a thing; not a thing, but a mode of it, [101] and consequently presupposing it; and that which presupposes thing or substance, cannot possibly be in the Idea, or first conception of it. In short, Accidents have being, tho' not the same being as substances; but to proceed.

Now, if this is the proper notion of substance in general, that it is a thing that is a subject of Accidents, it will follow, that we cannot frame any Notions of substances in particular, or make any agreeable Distributions of them, but according to the several Accidents, of which they are subjects. And this I desire may be noted, because it will he 
of very great use in clearing what I shall say hereafter, in the prosecution of this Discourse.

Of Substances some are Principles, some Principiates. By Principles, I mean substances that are causes of other things, but are themselves uncaused. By Principiates, (give me leave to make an English word of one not very good Latin) I mean substances that are caused, or composed of Principles. Principles make, Principiates are made to be.

That there are substantial Causes, and substantial Effects, in the World, is evident to sense; For even to sense, some substances begin to be, and some do cease being. Now that which begins to be, is [102] made to be after having not been, must of necessity have Something, (and this something must. of necessity be another thing,) that makes it to be; that is, it must have a Cause. So that Causes and Effects there are; else nothing could begin to be, or cease being. And if there are Causes, either those Causes, all of them have Causes also, and consequently, as they (as Causes) make other things to be; so, (as things that have Causes) themselves are made to be by others; or else, at least some of them have no causes, but are self-subsistent and uncaused. If all Causes have Causes, then an infinite Progression must be owned in the account of Causes, than which nothing can be more repugnant to the mind of Man; to Science; and to the Order and Unity of the Universe. And indeed then, there must be a number actually infinite, since all Causes are actual. But if any Causes are uncaused, (as 
certainly some must be, for the reasons Alledged) those uncaused Causes are Principles, or first Causes. More shortly, either something in the Universe of being is uncaused, and so is a Principle, for what is uncaused is a Principle; or else, every thing is Caused; but every thing cannot be Caused; for if every thing is Caused, Nothing must be the cause of Something. For if [103] every thing is caused, every thing was once nothing, for what is Caused was nothing before it was Caused; and if every thing was once Nothing, either Nothing must be the Cause of some, or, (which in effect is the same) nothing may become something without any cause, than which No thought can be more unreasonable.

Again, as nothing is more certain than that there is some Principle, so the Stoicks (the Wisest of all the Philosophers, as well as the most Devout) affirmed, that there are two, Mind and Matter. Thus Seneca in his Epistles (Ep. 65. $)^{37}$ Universa ex Materia \& ex Deo constant. All things (says he) are composed, or, do Consist of God and Matter. And indeed, we cannot be more assured by all our faculties, that there is Action, and Passion in the World, and that the World could neither be, or persevere in being, without them, than we are to speak Philosophically, that there are two Principles, one, the Principle of all the Action; the other, the Principle of all the Passion is in it; the former the Active Principle, or first subject of Activity, the latter the Passiz'e Principle. or first subject of Passivity: 
of which, I call the first, Mind, the second, Matter. This Assertion Zeno in Laertius fully agrees unto, when he tells us, that the Principles of [104]

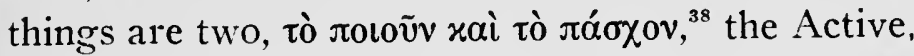
and the Passive; Nor doth the great Originist Moses say much less, when in his Genesis, he writeth of the Spirit of God that moved, and of the Abyss and Waters upon which he moved; and methinks, in all Animal Generations, in which there must be a Male and a Female, as who should say, an Active and a Passive Principle, there is some (and this no very Dark or Obscure) Adumbration of it.

Before I do proceed to a more particular Consideration of these Principles, I would have it observed, that we ought to Distinguish what is manifest, certain, and of undoubted truth concerning them, from that which is but doubtful and uncertain. Now it is certain, that there is such a thing as we do call Matter; such a thing as Mind, such a thing as Motion; and that Matter is alter'd, figured, textur'd, and infinite ways wrought upon \& moulded by means of motion. Again, it is certain that all things have not Mind in equal proportions, but that some exert the acts of it in a higher way and degree, and some in more ways for kind than others do ; and also certain, that the exercises of Acts of Mind in all the ways and all the degrees of them in Corporeal Animals, (for we are not so well acquainted with others,) do much depend ${ }^{[105]}$ upon the Nature and Qualifications of their Organs; that is, upon Texture and Disposition of matter. These things we 
IO4 PHILOSOPHICAL WRITINGS OF BURTHOGGE.

are as certain of, as that our selves be, and have a true use of our faculties. But if we advance farther, and to endeavour to Enter and Penetrate into the very nature of Matter, into that of Mind, and into the Nature of Motion; here being forsaken and destitute of sense to hunt for us, we are much at a loss, and as unable to proceed in our search an inquiry after them, as to their just Realities, as we are in that of things, which are wholly out of our view. It is hard to conceive just what matter is in its own Positive Reality ; also what Mind is, and even what Motion is, (as taken for a subordinate Principle.) Nor can it be Demonstrated, that (as some will have it) there is only one substance in the Universe, and that Matter and Mind are only several Modifications of that one substance; nor be Demonstrated, that Matter (for this I think they mean by substance) is in its own Nature, a vital Energetical thing; and that the diverse Gradations of Life, that are observed in the several species of Animals, arise only from the several Modifications of Matter, and of that life of nature (as those Philosophers call it) which is Essential thereto, and is [106] the root of those Perceptive, Appetitive, and Motive Powers that do dress up being in all the Shapes and Forms in which it appears upon the Stage of the World. I will not build upon such Hypothesis; which being unevident, must needs be doubtful and uncertain, if not false. A Philosophy that shall be solid. and sound, must have its Ground-work and Foundations firmly laid; which none can have, but that 
which is bottomed, rais'd and built upon eridence; I mean, upon the certain Testimony of our faculties. And therefore since our faculties do rather go upon Notions, than on Realities, and do plainly Distinguish between Mind and Matter, and (as I will show in the Progress of this Discourse) do Contradistinguish them, I hold my self obliged to treat of these distinctly, but still in the Real Notional way.

Mind then is Cogitative, thinking, or perceiving substance; or, Mind is the first subject of Cogitation. Matter is Extensive, spacious, substance; or, the first subject of dimensive spacious Quantity. In other, but Equivalent terms; Mind is Active sub stance, Matter Passive substance. I affirm, that these latter Definitions are equivalent to the former, because, in effect, it is the same to say, that Mind is Active, as to say, it is Cogitativ' ; and the same to [107] say that Matter is Passive, as to say, it is Spatious Extensive substance. Nor is Mind Cogitation. or matter extension, as Des Cartes makes them; but the former is Cogitative, the latter Extensive substance. ${ }^{32}$ We find a Reluctance in our minds to conceive that Cogitation is a substance, as also to conceive Extension as one; and yet we cannot conceive Mind and Matter but as substances.

The main Reason why I do distinguish Substance into Mind and Matter, as into first Original kinds, is, because (as I hinted before) Cogitation and Extension, that do Constitute their several Ideas, are of no Relation one to another, for what hath a Thought to do with a Cube, or a Triangle? 
IO6 PHILOSOPHICAL WRITINGS OF BURTHOGGE.

or with Length, or Breadth, or Depth? Certainly Cogitation and Extension are quite different Accidents, without any thing in their Ideas, that is Common to both; and therefore the first subject of the one, cannot be conceived the first subject of the other; their subjects must be substances of quite as different kinds as themselves are, at least to us; since all the diversity we can conceive in substances, is and must be, taken from the accidents they have, these being the Characters by, and under which alone, we do perceive and know, and by consequence, can only distinguish them. [108]

I insist herein the more, for that many think that Mind is only an Accident, and that taken for a substance, it is unintelligible, and a meer Chimera: so that, tho' Matter is acknowledged (by them) to be a substance, it will not be yielded, that Abstract, separate mind can be one. ${ }^{40}$ But those that think it so, if they consider'd, that men have no conception of substance, nor can have any of it, but as it is a subject of Accidents, they would soon change their Opinion. For the Accident of Cogitation, or of Activity, that Mind is the subject of, is as distinctly and clearly conceivable, as that of Extension, or of Passivity, which matter is the subject of. Nor is the thing it self that is the subject of Extension, or of Passivity; any more Conceivable but by, and under this; that is, the substance of mind and matter are equally conceivable, and equally unconceivable. They know no more what that is in it self, that is extended, 
than what that is, that is Cogitative; and may be as sure, that they do think, as they are, that they are spacious, ay, they cannot know that they are spacious, but by thinking. But of spatiosity or extension, (the Accident that constitutes matter,) I shall have occasion to discourse hereafter, when I come to speak of quantity, I proceed now to discourse of mind. [109]

The Idea I have given of Mind, that it is the Intmediate subject, or (as others perhaps would chuse to say) the Immediate Principle, of Cogitation, Energy, or Activity, is much more easie to be conceived than that of Spinosa, when he defines the human mind to be the Idea of a body, or thing, actually existing: $:^{41}$ for Mind, even the human, is not so properly said to be an Idea, as to be the Principle, our Cause efficient, of Ideas; since all Ideas (even in common sense) are conceived: and Mind is that, which conceives them. Thus it is in our Refracted, Inadequate, Real-Notional way of conceiving; and for an Adequate and just one, as it is above our faculties, so I do not find that Spinosa, or Mal. Branche after all their Ambitious Researches in that higher way have edified the World thereby to any great Degree. This way of seeing all things in God, ${ }^{42}$ and in their own proper Realities, is a way much out of the way. Otherwise, when they keep the lower way of sense, many of their thoughts are surprizing, and excellent. [110] 
IO8 PHILOSOPHICAL WRITINGS OF BURTHOGGE.

SECT. II.

$A$ two fold Consideration of Mind; one, as it is $A b$ stracted from Matter; the other as it is Concerned with Matter. What is meant by Concernment of Mind with Matter- Of Mind. That is the Idea of God. God as pure Mind, is in himself, and directly incomprehensible. Houtever, he is knowable as it were by Refraction, and Reflection; in an Hypothesis, and by way of similitude. That a Parabolical, Comparative way of knowing God, ought to content us. Of the Divine Attributes; the true conception of them. The wanity of those who talk of seeing all things in God. Spinosa's Opinion that God is all substance Rejected, for several Reasons. That this Opinion seems to imply, that God is no singular self-existent, self-subsistent Being. The Ground of this Opinion touched. Another sentiment concerning God, that he is infinite Extension indued with Goodness, Wisdom, and Power, considered. The Ground of this underminded, and the nature of the Divine Omni. presence represented. [111]

Mind may be considered, either in it self, as it is Abstract and simple, free from all Concretion and Composition with matter; or else as it is concreted or concerned therewith.

By the Concretion of mind with matter, I mean nothing but the acting of Mind in this or that par- 
ticular manner, by means of matter. As it is in our selves, who do not see, or hear, or feel, but by means of Organs, that is, of matter.

Mind as it is in it self, Abstract and Simple, free from all concretion or concernment with Matter, I call Pure Mind; Mind Concreted with Matter, I term, Mind in Matter.

Pure Mind, is the Notion or Idea of God; as is implied by our Saviour, when he says, Joln 4. 24. God is Spirit; he does not say, God is a Spirit, but God is Spirit; $\pi v \varepsilon \tilde{u} \mu \alpha$ o ๆะóร, All Spirit, nothing but Spirit. In like manner Seneca, in the Preface to his natural Questions, first demanding what God is? Answers, he is Mens universi, the mind of the Universe; and being obliged, for the cleering of his notion, to show the difference between the nature of God, and that of Man, adds, Mind is only the Principal part of our nature, but the whole of Gods, which is no[112] thing but Mind God is pure Mind. all Reason. In his own terms thus, Quid ergo interest inter naturam Dei \& nostram? Nostri melior pars Animus est, in illo mulla pars extra animum. Again, in his Epistles (Ep. 65.) He has this expression, Nos nunc primam \& Generalem causam quaerimus, haec simplex esse debet; nam \& materia simplex est; now, says he, we seek the first Universal cause, which ought to be simple (or uncompounded) for even matter it self is simple. Only, I doubt, he (as many other Philosophers did) tork God but for an immanent an ingredient Cause 
of all; which perhaps is only true of the Mosaical Spirit of God. ${ }^{43}$

But God as he is Pure mind, is an Inaccessible Light, that dazzels all the eyes that behold it; and therefore, we can hope to acquire but very little particular knowledge of him, or acquaintance with him, under this notion. But then again, as the Sun that cannot be beheld directly, in its own proper light, may yet be seen by Reflection; so may the Deity, in an Hypothesis, and by way of Parable; by speaking of him after the manner of men. The holy Scriptures themselves go this way. They Represent God as an Infinite Almighty Person, (suppose a man,) that hath Understanding, Will, and Affections; that [113] consults and decrees; and that is touched (as men are) with the motions of Love, Hatred, Desire, Aversion; and in consequence of this Notion, do further Represent him, sometimes as a Father, sometimes as a Lord, or as a great King, that Governs the Universe, according to the Rules and Laws that he himself hath set, and by rewards and punishments. Now, all this is Parabolical, and but Comparative Knowledge: However, we ought to satisfie and Content our selves therewith; for though it is not to know the Deity in the Reality, as he is in himself, yet it suffices for the Principal End for which we should endeavour to know him; which is to Adore and Obey him. Besides, it is well nigh the only particular Knowledge of him that we Mortals are capable of, in this Terrestial State; and, in fine, is almost as much, in 
effect, as that which we have of any thing else, even in the Corporeal World.

It is true we understand that Matter and Motion are Real things, and that all others that are Corporeal, do result from these; but this (at least) is only a General Confused Knozoledge, and no more than that we have of the Abstracted Pure Mind. For, as to the particular Natures of things, their Internal Fabrick and Texture, ${ }^{[114]}$ and that degree of Motion, that is in the particles which compose them, (of this) we have only a weak imperfect Conjecture, without certainty. All the particular Knowledge that we have of things by which we distinguish them one from another, both in reference to their Kinds, and to the Individuals of those Kinds, and by which we resolve their Operations, is of nothing (to speak of) but of Accidents: and Accidents are nothing but (as I have touched before, and shall shew again more fully hereafter) the Sentiments we have of things; they being not so much as Grounds or proper Representations of Grounds, but only certain Appearances, under which our several Senses do dress up things, and so show them unto us: and this is enough for Use.

As therefore any person would know but little of this Corporeal World, and nothing usefully, that would not take it in by his Senses, and know it (as he only can) under the Mascarade of Sentiments. that are not without him, but only in Appearances. and in their Grounds; so, he shall know but little of God, that will not condescend to see him in an $\mathrm{Hy}$ - 
pothesis, by way of Analogy and Similitude. What was said by God himself unto Moses, will [115] hold true in every Mortal; Thou shalt see my Backparts, but my Face shall not be seen: All our Knowledge

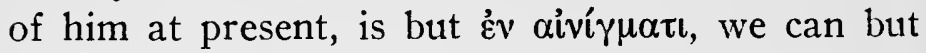
Riddle at him; the Ideas we have of him, are only Attributes; and Attributes are not Qualities really Inherent in him, but only Notions of his Operations, and of the various Relations and Aspects which they bear, to one Another, and to Us, ) that are excited into us, upon the view and considerations which we take of his works. Thus the several Attributes of God, that we conceive and know him under, are, in reference to him, just as the Accidents of things Corporeal, their Colours, their Odors. their Sounds, their Tangible Qualities are unto

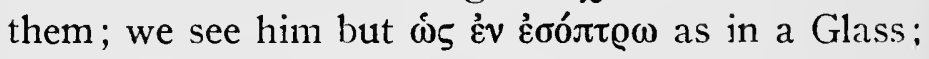
and to see a thing as in a Glass, is not to see the thing it self, but only by Appearances; and yet, he that will look behind the Glass, to see more, shall see nothing at all.

What, then, must be said of those, who think, they See all things in God ?"2 $^{4}$ When God, though in himself he is Pure Light, without any Mixture of Darkness, yet, as to us, in respect of any clear, just, distinct Knowledge of him, He dwells in the thickest Darkness: No [116] Windows in the Sanctum Sanctorum, where the Seat of God was; and the very Heathen, many of them, Adored him with Silence, as one that was Ineffable and Unconceivable: Methinks, it is meer Enthusiasm, to talk of 
Seeing All Things in the Original, when we cannot so much as look upon it; God is Pure Mind, and Pure Mind is Pure Light, of too Transcendent Glory to be immediately beheld by us, but Blear-eyed, Weak-sighted Mortals.

There are two Opinions in reference to the $\mathrm{Na}$ ture of God, that Differ from mine; both of which I will consider.

The First is, that of Spinosa, That he is all Substance, and that Particular Beings (even formally taken) are but Participations of his; as being only so many several Modifications of the Divine Attributes. ${ }^{4}$ But this is a Notion (of the Deity) that I cannot receive, as for other Reasons, so for this particularly, that it makes him to be the Universe, and to be Matter, as well as Mind; whereas. God is neither Matter, nor the World or Universe, but only Pure Mind; for ${ }^{[117]}$ the Great World has a Mind, that made, and Governs it, as well as the Little. Even Mr. Hobbs, has said, He that thinks this World without a Mind, I shall think him without a Mind: $:^{18}$ And says Seneca, Nat. Quast. Lib. I.C. 45. Eundem quem nos Jovem intelligunt, Custodem, Rectoremq; Universi; Animum ac Spiritum, Mundani hujus operis Dominum \& Artificem, cui nomen omne convenit, \&c. ${ }^{43}$ Which I would Render thus; God is the Father All-mighty, All-wise, All good, the Maker of Heaven and Earth, Soveraign Preserver and Governor of All. 
For my own part, I much doubt that those Philosophers, who profess themselves in this Opinion, [that God is all Substance, or that he is the World,] do really believe he has no Being at all, but, only in Fiction of Mind, and by way of Prosopopaeia; and that as Nature Fortune, Chance, which yet are said to do This, and to do That, do, really, only signifie Causes so or so considered; so, God, with them, is only a Notion, a Name, a Mode of Expression, by which they mean all Causes taken together; and so no more the Name of a Real Individual singular Being, than that of Nature, or Fortune. Sunt (says ${ }^{[118]}$ Lucilius in Cicero l.2. de Nat.Deor.) Qui onnia Naturae nomine appellent, ut Epicurus, \&c. ${ }^{45}$

The unwary Expression of some Theologues, and Theologizing Philosophers, who Denominated God Nature Naturing, might give occasion to this improper conceit of him, among the moderns; as might also that mistaken Idea of Infinity (as an Attribute of God) that some have given, which seems to shock his distinction and singularity of Being. For thence it is Argued, how can God, be Infinite Being, if he be not all Beings? And if he be, how can he be One by himself? be a Singular Individual Being, distinct from all others? These were the speculations, that obliged Spinosa to conceive of God, that he is the Ingredient, Immanent Cause of all Things $;{ }^{44}$ and the speculations too, that tempt others, to other mistakes concerning him. But when I come to discourse of the Notions of Finite 
and Infinitc, and to Represent in what Sense the latter is truly Ascribed to God, I hope to manifest, that there is great Mistake in such Speculations and Arguings, and to exempt the true received Notion of Infinity both from these, and from all the like intangling Embarrasments and Difficulties. [119]

The Second Opinion is that of Dr. More and his Followers, who do hold, that God is an Infinite $E x$ iension $;^{46}$ that he is indued indeed with all Goodness, Wisdom, and Power, but he is an Extension so indued; and of this they are so confident, that some require a belief thereof as of an Article as great as any in the Creed; an Article that is the Foundation of all Religion; both revealed and Natural. But as I believe, that no Man hath known the Father except the Son, and he to whom the Son hath revealed him, so, since among all the Revelations that the Son has pleased to make of God the Father, this is none [that he is an Extension] I cannot admit his being so, to be a Notion so Essential unto all Religion, as they would make it; Especially when I consider, that it might as easily have been said, that God is Extension, as, that he is a Spirit; and Christ hath said the latter but not the former. Besides, I cannot understand how Wisdom, Goodness, and Power should be said of meer Extension, which is but space; it seems to me a lesser incongruity (though even this is Incongruity enough) to say that God is Matter so indued, that he is Space so indued; seeing, even in common sense, there is more 
of Reality and Being in meer Matter, ${ }^{[120]}$ than there is in meer Extension or Space. But to urge this Argument more home. By Extension, (which the persons who are in this Opinion do Attribute to God,) they must mean either meer Space, or else a thing that in the Idea of it is Spatious. If meer space is intended; As this does in no ways differ from inane or vacuum, so one may think, it might as well be said (which yet its hard to say) that God is an Infinite inane or vacuum, that is, in plain Eng. lish, an Infinite Nothing indued with Wisdom, Goodness and Power, as, that he is infinite Extension so indued. On the other side, if by Extension is understood a thing that in the Idea and first Con ception of it is Extensive, that is, a thing that does essentially take up space so that it cannot be conceived, but withal space must be Imagined, as an Appurtenant of it; in this Sense, I cannot see how it differs from Matter; and then to say, that God is Extension, is to say, that he is Matter; whereas, God is Pure Mind, not Matter. In fine, as it is certain, that God is Mind, rather than Matter; so likewise it is certain, that in the Ideas that we frame of Mind. and of all the things that properly relate to it, such as Wisdom, Goodness. Thought, \& $c$. We never do once think of Extension or [121] Space: And if at any time we do endeavour to apply Extension or Space unto Mind, or to any thing properly mental, there always arises a Repugnance in us, upon but the thoughts of it; an Inch, a Foot, a Yard of Unrlerstanding, or Goodness, is a Bull. 
I know it is Argued from the Omnipresence of God, that he is Extended; and in truth it is very hard to imagine any presence with things that are extended, but withal, there must be an Imagina. tion of some Extension in the thing that is present: but still, this is but Imagination, which is apt to impose upon us, and therefore it must be examiner? by Reason. And Reason tells us, that we cannot have a distinct and clear conception of the presence of God, if we have not (as we have not) such an one of his Essence, since the presence of God is but a Mode of his Essence; and if we have no distinct and clear Conception of the presence of God, nor consequently of his Omnipresence, or the way how he is present with all his Creatures, where ever they are; I do not see with what Cogency or Force an Argument can be Deduced from it, in this business. In short, since things are present one with another very differently, in proportion to their several $\mathrm{Na}$ tures, it will follow, that [122] things Mental, must be present with others, in much another way than those that are Material, and Consequently that God who is pure $\mathrm{Mind}$, must be present with Material Beings, much otherwise, than these themselves are, one with another. Mind can no more be present the same way that Matter is, than be the same thing with Matter. [123] 
I 18 PHILOSOPHICAL WRITINGS OF BURTHOGGE.

\author{
CHAP. [V. ${ }^{4 T}$ \\ Of Mind in Matter.
}

SECT. I.

Mind as concerned with Matter comes under a double consideration, I As it actuates a most subtle and more than Etherial Matter, that is diffus'd throughout the World. 2ly. As it actuates some particular Vehicle or Body. In the first Notion of it. Mind in Matter is the Idea of the Mosaical Spirit of God. This Spirit according to the Scriptural Hypothesis, is the Immediate cause of all things in the first Creation, and ever since. The Being of this Spirit Evinced, both by Authority and by Argument. Dr. Mores Distinction, between the Spirit of Nature (which he calls Principium Hylarchicum) and the Spirit of God, considered.

\begin{tabular}{|c|c|c|c|c|c|c|c|c|c|c|}
\hline * & * & $*$ & $*$ & $*$ & $*$ & $*$ & $*$ & * & * & * \\
\hline * & $*$ & * & * & $*$ & $*$ & * & $*$ & * & $*$ & $*$ \\
\hline
\end{tabular}

SECT. IJ. [129]

An Inquiry into the Original and Rise of Motion. What is meant by Motion in this Inquiry. That Motion comes from Mind in Matter, or the Mosaical Spirit. This shewed in many instances, by the Connexion between Cogitation and Motion. How Motion comes from a Principle at Rest, and how Matter from Mind set 
out in the Metaphysical Hypothesis, and by other Illustrations.

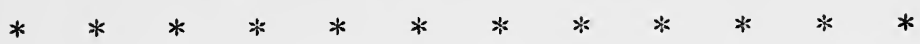

By Finer and Delicater Impressions. I mean such as have less of Local Motion. By Finer and Delicater Faculties, I mean such as are sensible of Finer and Delicater Touches, or Impressions.

In this sense, the Imagination must needs be a finer and more delicate faculty than any external sense, for as much as it receives the impressions of External Objects but by Reflection, or Communication from the Sensories, but these have them directly from the very Objects themselves; and by the same Reason, the Understanding, that receives impressions from the internal sense, ${ }^{[139]}$ must needs be (as indeed it is) a much finer and delicater faculty than That.

Upon the whole, it is evident, that there is a near relation between actual motion and cogitation, and consequently, that it is no unreasonable thought to think, that as they are near of kin, so both are Offsprings of one Original cause, [mind in matter;] but then it will follow also, that motion, and indeed all Energy whatever in the Spring and Principle of it is Rest, for so mind is. But this is the difficulty. For that motion should come from a Principle that is at rest, appears as unintelligible, as that Frost should come from Fire, or Darkness from Light.

Wherefore to make this clear, I must consider things in the Metaphysical Hypothesis, as all are 
understood to come from one, by way of Emanation: and thus, all Created Being is compared to Light, that flows from the Sun; and then its Emanation is in the same manner, as the Radiation of Light, which is from a Center into an Orb or Sphere, in Extenuating Lines. Now in this Hypothesis, as all Beings (even those that are most opposite) do come from one, so they come from it in this way, that the more Removed any is from the Central Being, the more Extenuated it is; that is, as God or pure mind is the Central Being, [140] that Sun, that is the Father of Lights; so all the Being that proceeds from him, has less of Light and more of Darkness, in proportion? to the distance it has, upon the Scale of Being, and in its utmost Elongation or Removal from him, terminates in that, which in Appearance has nothing of Resemblance to the Original Light; but (to be compared with it) is only Darkness and shadow; and this last is the Idea of meer matter, as that of the Central Light is of pure Mind. God is Light; Matter is Darkness; all intermediate Beings are Light and Darkness, in several proportions.

What I have said is sensibly set out in the shades of Colours, and in Colours themselves, which arc but shades of Light; For the Extremes of any Colour, for Example, the Brightest Red, and the Darkest; or the Extreams of all Colours, as White and Black; compare them each with other, and they are so contrary, that nothing can be more, especially the two latter; and yet they do participate, the former not only of Colour in general, but also of Red; and 
the latter, tho' of no particular Colour, vet of Light, which is the Ground of Colour in general; and also the Darkest Red, if it doth not come from the Brightest; and the Blackest Co ${ }^{[141]}$ lour from the Whitest; yet, by the Gradation of Shades, or Participle, intermediate Colours, they are so continued one to another, that the Ascent and Descent from one unto the other is most Agreeable and Delightful, as made by easie steps, without any Patches, or Chasms. It

is true, if we look on Contraries in their Physical Consideration, so they are of opposite Natures, opposite Operations, and one expels the other, when they are immediately set together: but if we look upon them in their Metaphysical Consideration, so they are but degrees of the same nature, and capable of being United and Reconciled: insomuch, that One in a right sense may be said to come from Another; as Darkness from Light. For however contrary Light and Darkness are, each unto other, as to Qualities and Physical Operation, and so in their Physical Consideration, yet as to their Metaphysical, they differ but in degrees; both have the same grounds; for Shadow really is but lesser Light, occasion'd by the interposition of an Opaque Body, and Darkness is but a great Shadow. And thus a Flat and a Sharp, tho' contrary sounds, as to their Physical Consideration, yet as to their metaphysical, they are but different clegrees; the Sharp a greater, the Flat a lesser de ${ }^{[142]}$ gree of Celerity. And thus as Darkness comes from Light, only by the Lessning or Extenuating of it ; so may 
matter come from mind: mind is pure Light, or, all Being in Eminence; but matter, as it doth Participate nothing at all of mind, but only by meer Existence, so it is meer darkness, without the least degree of Vitality or Life; and all Beings between Mind and Matter, are as Colours, in respect of Light, or as Shades, in respect of any particular Colour.

But to add some further cleering to this Subject, and to shew how actual local motion may come from a Principle that is at rest, which being shewed, will shew withall how Matter may come from mind, since there is no greater Repugnance (even to common sense) in the one, than is in the other, I will consider the Relation that the Center of a Circle has unto its Circumference, and how things are in the one, and how in the other; For this will afford it much Illustration. In the Center then of a Circle, or of a moved Sphere, all is at Rest, and out of it all in motion, but in such proportion, that that portion of a Radius which is at a farther distance from the Center, is more in motion, by reason of that distance, and that which is nearer ${ }^{[143]}$ is less.

* $\quad * \quad * \quad * \quad * \quad * \quad * \quad * \quad * \quad * \quad * \quad * \quad * \quad *$

Well then, supposing that the Principle of Energy and Motion is in the Center of the Orb of Being, (and we may well suppose it, since even Nature has its Sphere of Activity, and Acts as from a Center to a Circumference; (so Seeds Act, so Light Acts and Diffuses it self;) it is certain that motion must come from something not in Motion. 
but at Rest; for so that is, which is in the Center: and indeed, else there must be infinite progression in Motions. Again, since in the Orb of being, Pure Mind is in the Center, [146] and matter in the utmost Circumference, it follows, that the nearer things are unto pure mind, and the more they do participate of that, the more they have of Rest, and the less of motion; but the farther off they are from pure Mind, and the nearer to matter, the more in motion they are. And indeed, all Energy in matter is Local Motion. Thus all the Effects of Mechanism, as they are purely material, so they are performed only by Local Motion; but the business of Cogitation, even in the lowest step of it, which is sensation, as it is of nearer Relation unto mind than to matter, so it is performed rather by way of mutation, than of Local motion; the Eye is not sensible of any motion imparted to it, nor is the Ear, or the Nose, or any other of our Sensories, and yet each is sensible of a mutation made therein, (or rather in the Faculty) which comes from motion. But tho' the more refined any Beings are, and the nearer that they are to the Central Mind, the more at rest they be, and the less in motion in their several Actions; and consequently Abstract Spirits that do not live in gross Elementary Bodies, are more at rest, and have less of motion, in the exercises of their several Powers, than Men have, who are imbodied in Elementary Vehi ${ }^{[147]}$ cles; yet no Spirit whatsoever but only God himself, who only is Pure Mind, is so wholly, so Absolutely at Rest, as that it sees all Things at once, by one Entire 
view and Intuition; all Principles and all Conclusions in them; all Ends and all Means and Motives to them; without the least degree of Succession, or any Addition. Only the Central Being sees so, and he doe's.

For seeing all the Circumference is in the Center, so that all the Lines however divided they be in the former, do meet together in the latter; it is plain, that an Eye placed in the Center, must needs see all in the Circle, as clearly as any thing in it; and this too with one Individual, single Intuition, without Succession, or, Addition; seeing there is nothing, of Motion, but all is Rest in the Center. And this properly is to see in Eternity. Thus God sees. But all other Beings beside God, as they are not God, or Pure mind, so they are not in the Center, and not being the Center, but at Distance from it, some at Greater, some at Lesser, but All at some, they All have something of Motion, and consequently cannot Act, or See, in the same manner as Central Pure Mind, by way of Absolute Rest, without Succession, or Addition, [148] and without Distinction of past, present, and to come: For tho' all the Lines do meet in the Center, yet there being no place without it in which they do so, Creatures cannot see as God sees, no more than they can be in the Center as God is. It is too short and Inadequate a way of Arguing to Infer that any Creatures can see All things at once, but from the notions (confused enough) that we Mortals have of Time and Eternity; as that Time is Successive, Eternity a Permanent Duration: to- 
gether with a Conceit, that all Spirits (they being things Abstract and Separate from Bodies,) both Are, and Act, in Eternity, as all Imbodied Beings Are, and do Act, in Time. Certainly every Being but God, is in Time, tho' not in the same Kind of Time; for as God only is in the Center, so he only is Absolutely in Ex.rnity. And if Time is taken for all Duration that is not Eternity, God only is without Time, and so without Succession of Actions. But to Return. [149]

SECT. III.

Of Mind as it Actuates a certain Particular Body: Mind in this Notion called a Soul. Body is a System of Organs. Sonl and Body an Animal. Body Considered two ways. To wit, in Reference to External Objects, and in Reference to the Internal Principal that Acts it. In the First Consideration of Body, the Ends and uses of Organs are shezved, and withal the Reason of their wariety. This illustrated by seweral Instances and Obseriations. The use of Body in Relation to the Intcrnal Principle that Actuates it, is to Individuate and Singularize that Principle. This set out in sensible and plain Resemblances. A Comparison between Vital and Locomotive Energy; with a Recapitulation of the whole Discourse, as it unfolds the Mystery of Animals. 
We have Considered Mind in the first Step of Relation that it carries unto Matter, Namely, as it doe's Actuate a most subtle Matter diffused throughout the Universe, in which Notion is called Spirit simply, as was showed from Malachy, Ch. 2. v. I5. Come we now to Consider [150] it in the next place. as it Actuates some Particular System of Matter. in a Particular Manner; and so it is called a Soul; and that Particular System of Matter, which it doth Actuate, is a Body, or a Particular Vehicle; and the Result of both an Animal. An Animal is nothing but Soul and Body together; or a Body Actuated by a Soul. A Body is a System of Organs; an Organ is Matter framed and Contrived after a Particular Manner for some Animal Use, and End; some Use, End, or Action of a Soul: A Soul is a certain Determinate Vital Energy ; or a certain Portion of the Spirit of the Universe, Vested in a Body, or particular Vehicle; in which Notion all Souls are Spirits; as indeed they are stiled in the Holy Scripture, wherein we Read of the Spirit of the Beast, tho' it.goes Downward, as well as of the Spirit of a Man that goes Upward.

* $\quad * \quad * \quad * \quad * \quad * \quad * \quad * \quad * \quad * \quad * \quad * \quad * \quad *$

We will first Consider a Body in the Relation that it has unto External Objects, and here we must set out the Nature, that is, the Ends and Uses of the Organs which compose a Body, as also the Reason of the Variety, and number of those Organs; why any Organs at all, and why many: both which will 
be done with one Performance. An Organ properly, is Matter Particularly Textured, and Framed for some Particular use: And an Animal Organ is Particularly Textured, and Framed for an Animal use: I will give the Example in only Sensitive Animals, and in the Acts of Sensation, as being best understood; but what is said of Sensation, and of the Organs of it, will, by Proportion, hold in all the other Actions of Animals, and in all other Organs. with a due Alteration. [152]

In all Acts of Scnsation there is first an Affection of the Organ, and then a Perception of that Affection by the Soul; or rather, a Perception Excited in the Soul by means of that Affection; and this is the End of the Organ, and the only Use of it, that the Soul makes, to wit, to come by means thereof unto a Perception of External Objects; as, to see their Colours, to hear their Sounds, to Relish the several Tasts they have, and the like. In short, a Soul cannot but by means of Organs, take any notice of External Objects, nor the Organ be a means of conveying any notice to the Soul, but by being first Affected it self. Now the Affection of the Organ arises from a Perception (may I so express it) or a Reception of the Motions Communicated to it by Objects; and a Capacity for this Reception from the Particular Frame of the Organ. For since all Matter indifferently is not capable of receiving all kinds of Motions and Impressions; but that for some Particular Motions and Impressions (of which sort are sensible ones) there must be Par- 
ticular Textures and Frames of Matter to Catch them; it follows, that there must be Organs; and these too in such Variety and Number: there must be Organs, to Receive the Impression and Motions of Objects, which [153] without a Particular Texture of Matter could not be Received; and there must be Variety of Organs, to Correspond these various Kinds of Notions and Impressions that are in $\mathrm{Col}$ oured, in Sonorous, in Sapid, and in other Species of Objects.

$* \quad * \quad * \quad * \quad * \quad * \quad * \quad * \quad * \quad * \quad * \quad *$

So much concerning Body in its Relation to External Objects: come I now to consider it in the Relation which it has to the Soul, (the Internal Principle that Actuates it, and Acts in, and by it:) and so, the Great work and Business of the Body is to Singulariac and Individuate the Goncral Vital Principle of the Universe, that it may become a Soul, or a Particular Vital Principle of a certain Particular Body. To understand this it must be [155] Consider'd, that the Mosaical Spirit (the Rise and Principle of all Created Cogitation,) as it is Extended throughout the whole Universe; so, to become in Particular a Soul, of any Particular Animal, it must be Singularized, and Individuated, that is, it must be Apportioned (as it were) to that Particular Animal, which it comes to $b c$ by means of the Body. To Illustrate this, it must be Remembred. that a Voice or Sound Diffused throughout the whole capacity of the Medium (as the Mosaica? 
Spirit is throughout that of the universe) is yet in the Phonocamptick Center or object (which is nothing but a place conveniently Disposed for this Purpose.) so Individuated and Singularized (as the Mosaical Spirit is supposed to be by a Congruous fit Body,) that Really it has other Affections and Properties, than those it owns, in all the rest of the Mcdium, insomuch that by Vertue of it, this place instead of being a Medium of Sound, becomes to all Appearance a Principle of it, and so a Speaker, and this is called an Echo. It may also be set out in a Speculum or Looking-Glass, (for a Body is to the Mosaical Spirit, what a Speculum or Looking-Glass is to the Image of an Object in the Medium;) A Speculum Catches the Diffused Image, and so Singularizes it, that [156] it becomes a very Different thing, and puts on other very Different Properties than those it has in the Medium, for in the LookingGlass it doth appear as an Object which it doe's not out of it. But what doe's set it out most naturally, is, that it is so in Man; For the Soul or Cogitative Principle of a Man, as it is Extended throughout the whole Capacity of the Body, in like manner as the Mosaical Spirit is, throughout that of the Universe; so it is Singularized and Individuated, in, and by, the particular Organs: insomuch that the Eye only does Sce; the Ear only does Hear, and only the Tonguc Tasts, in Vertue thereof: for which Reason these are owned to have several particular Faculties, which are as so many several Souls unto them. Now what the Organs are to the Soul in 
I3O PHILOSOPHICAL WRITINGS OF BURTHOGGE.

any Body (that is but a System of Organs, ) Bodies themselves are, unto the Mosaical Spirit, the great Soul of the Universe, of which all particular Bodies are Organs. But since this Notion is of so much Importance, that it will deserve a more particular Consideration, and I design to give it one in another Chapter, I shall dismiss it at present, without fur. ther Insisting on it; and now will only add some Improvement to the former Discourse, by making a Comparison be[157]tween the Vital and the Mechanical Energy.

First then I lay it down as certain, that there is such a thing as a Vital, as well as a Mechanical Energy: by Vital Energy I mean all that is not meerly Mechanical; and therefore do comprehend in that Term whatever is properly Mental; by Mechanical Energy I mean Impulse or Springines, the nearest Physical Principle of Actual Local Motion. Now we are as sure by our senses, and by the Reflection that we make upon our selves, and upon the Notices which we receive from Things without us, that there is such a thing as a Vital Energy, as we are that there is a Mechanical: Because we are as much assured of the Effects of the one, as we are of those of the other; as much assured that there is life, Sensation, and Intellection. that come from a Vital; as we are that there are Actual Local Motions; Motions of Ascent and Descent, Motions Direct, and Motions Circular, \&c. which (as Motions) come from Impulse, the $\mathrm{Me}$ chanical Energy. 
Again; As it is Certain that Local Motion, or that Impulse which is the nearest Physical Principle of it, is not Matter, or Materiate, but yet is in Matter, as United unto it: so by this Consideration we may [158] become as certain, that Vital Energy and the Effects of it, though they be Immaterial, yet they may be in Matter; since there needs no more of Hooks and Crooks to make the Latter, than to make the Former, to stick, and hold together.

In the next place; As the Mechanical, or Locomotive Energy is Diffused throughout the World (for there is nothing in this, that is Entirely at Rest;) so is the Vital: Since it is certain that wherever, and whenever, any Matter becomes Disposed, the Vital Principle is always at hand to Actuate that Matter, and Act in it, according as the Dispositions of it do Invite or Permit: All Putrefaction or Digestion any where, determines in Insects, or little Animals, (as Experience evinces,) the Spirits being Unfettered and let Loose thereby.

And yet as the Mechanick or Loco-motive Impulse is not Received in all Textures of Matter indifferently, but that, (as I have showed already) there must be some certain Modifications of Local Motion. be certain particular Textures of Matter, so neither is the Vital Energy Catcht and Received indifferently by all Textures of Matter; but as all Life consists in Motion, or in something Analogous, so for certain Gradations and Exercises of [159] Life, there must be certain particular Fabricks and Textures of Matter, called Organs, and also certain partic- 
ular Dispositions in the Mechanical Spirits (for so I call the subtle Active Corpuscles in every Concrete) that are the immediate instruments of the Vital Principle in all its Actions of Life, in this Corporeal World.

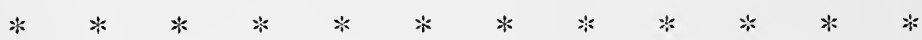

CHAP. VII. [161]

Animals are either Invisible or Visible: in the Former sort I reckon Angels, Good and Bad, which are Etherial: As also the Genii, which are Aerial Animals. Ini'isible. Animals, achy called Spirits. That they are Spirits Evinced, I. From the general Tradition of the WVorld. Mr. Hobbs's Evasion of this Argument Considered. 2. From Operations that camnot be Accounted for but from sucl Causes. 3. From Intelligences and Notifications that cannot be Resolved but upon this Hypothesis. 4. From Spectra or Apparitions. Of the way and manner how' Spirits do Appear, that it is twofold, Real and Visional. That Good Angels zellen they do Appear are

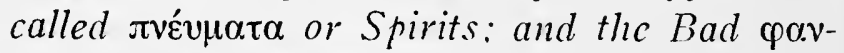

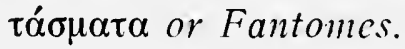

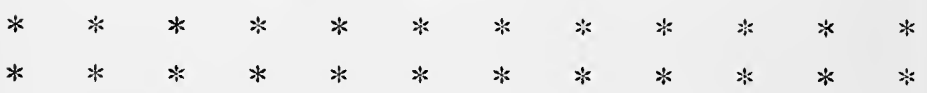

SECT. I [. [171]

That there are Spirits, proved by Gencral Tradition. Mr. Hobls's Answer to this. Argument shezed 
to be but an Evasion, from the Evangelists Natthew and Mark, \&c.

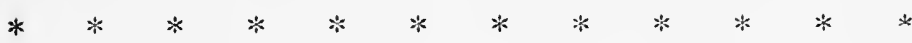

SUB. I. [177]

Another Argument to Proie Spirits. Of the Conversion of an Indian Raja. A Remarkable Story of Witchcraft, out of Mr. Gage's Survey.

* $* * * * \quad * \quad * \quad * \quad * \quad * \quad * \quad * \quad * \quad *$

SUBS. II. [197]

The Third Argument from Supenatural Adver. tisements. An Instance out of Simocatto. Another, of a strange Omen out of Sir W. Rawleigh. Of the Corps-Candles in Wales, \& $c$.

* $* * * * * \quad * \quad * \quad * \quad * \quad * \quad * \quad * \quad *$

\section{SUBS. III. [211]}

The Third Argument from Apparitions. Three Stories of them from the Junior Pliny, in his Epistles. A Recent Story of an Apparition.

* $\quad * \quad * \quad * \quad * \quad * \quad * \quad * \quad * \quad * \quad * \quad * \quad *$

\section{SECT. III. [223]}

The Apparition of Spirits twofold, Real, or Visional; both way's Explained. A Conceit about the Appearing of Ghosts Rejected. That most Apparitions of Spirits are Visional, not Rcal, Evinced by sea'cral Considerations. Some Phaenomena 
I34 PHILOSOPHICAL WRITINGS OF BURTHOGGE.

of Apparitions Salved. Of the Distribution of Spirits.

$\begin{array}{llllllllllll}* & * & * & * & * & * & * & * & * & * & * & * \\ * & * & * & * & * & * & * & * & * & * & * & *\end{array}$

CHAP. VIII. [236]

Another Essay about the Nature of Animals and Spirits.

SECT. I.

The Subject farther Illustrated, by a Comparison of the Universe with a particular.Animal. The Universe a whole; Particular Animals but Members of that whole. A Particular Animal is as an Organ with its faculty; the Universe. as a Body composed of sezeral Organs, with a Soul that endues these Organs with several Faculties. A Demonstration cven to sense, of a common Principle that penetrates throughout the Universe. In what sense a Soul is a faculty. and in what a Principle of Faculties. Two senses of the word Soul, and how in both, it may be conccived as a Principle of Faculties. The Soul in its state of separation becomes a Spirit properly. Soul is the name of a part, a Spirit the name of a whole Substance. God the Central Sun, and Fountain of all Souls and Spirits. The Emanation of Souls and Spirits from God, or from his Spirit, set out in the Comparison of Light and Colours. Not only 
Philosophers, and Poets, but even many Christian Doctors, and particularly St. Augustin, compared God in respect of his influence in and over the Universe, unto the Soul in a Man.

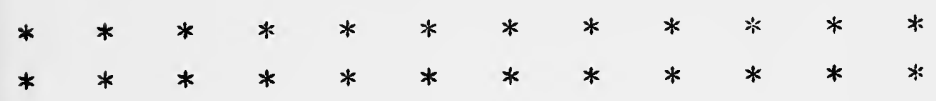

SECT. II. [252]

Several Objections against the Former Hypothesis considered, First, that it makes Souls to be Faculties or Powers, whereas indeed they are Actions, or Acts. This Objection Answered, and the notion of the Souls being a Principle and Faculty, rather than an Action, cleared. The Second Objection, that in this Hypothesis the Deity is considered as an Immanent, and not (what he is) as a Transient cause of all things. Removed; and how he is both the one and the other, shewed, and Confirmed by the Authority of St. Austin, and other Christian Fathers; as well as of the Chiefest Philosophers. The Third Objection, that hereby God and $\mathrm{Na}$ ture are Confounded; Answered, by shewing how God and Nature are Distinguished in this Hypothesis. The Last and strongest Objection, that if there were but one Original Perceptive Principle throughout the Universe, all Animals would hai'e the same Perceptions. 
I36 PHILOSOPHICAL WRITINGS OF BURTHOGGE.

which they have not. This Objection Removed, and the Reason of Different Perceptions in Different Animals cleared.

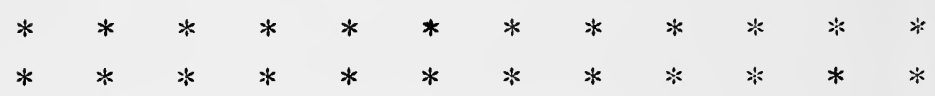

CHAP. IX. [268]

Of Substance in the Scholastical Consideration of it. Substance what, that it is First or Second. Second Substance is called a singular. a suppositum, or subsistent. Of the Principle of Individuation, or that which makes a singular to be so. Dr. Sherlock's Notion of the Individuation of Spirits. Of a Person. The true Idea of it. Laurentius Valla his notion of a Person. the unusefulness of it to the salving of the Holy Trinity shewed. The Trinity a Mystery, and Doctrine of Faith; not a Point of Philosophy: and so the Idea of it to be derived only from Revelation in the Holy Scriptures, and not from bare Discourses of Reason.

\begin{tabular}{|c|c|c|c|c|c|c|c|c|c|}
\hline$*$ & $*$ & $*$ & $*$ & $*$ & $*$ & $*$ & $*$ & *⿰冫⿰亅⿱丿丶丶 & $*$ \\
\hline$*$ & $* *$ & * & $*$ & $*$ & $*$ & ** & $*$ & * * & $*$ \\
\hline
\end{tabular}


OF THE SOUL OF THE WORLD. 



\section{O F T HE \\ $\mathrm{S} \quad \mathrm{O} \quad \mathrm{U} \quad \mathrm{L}$ \\ OF T H E}

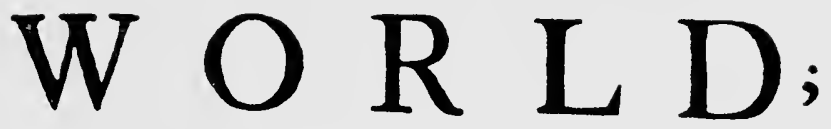

A N D O F

Particular Souls.

\section{I $\mathrm{N}$}

A Letter to Mr. Lock, occafioned by Mr. Keil's Reflections upon an Effay lately publifhed concerning Reaforn.

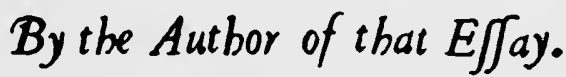

Minut. Fal. in OCtav.

Veritas obvia, fed requirentibus.

Erafmus in Hyperafpift. 1. 2.

Verborum umbris territamur, quàm in re nihil fit abfurdi.

$$
L O N D O N \text {, }
$$

Printed for Daniel Brown, at the Black Swan and Bible without Temple-Bar. M.DC.XC.IX. 



\section{OF THE SOUL OF THE WORLD, AND OF PARTICULAR SOULS.}

TO JOHN LOCK, ESQ;

SIR,

It may seem an improper way of making satisfaction for a former Trouble, to give a new one : yet since you have pardoned the Confidence that made a Present to you of my Essay concerning Reason, and that some very sharp Reflections have been published on a part of that Essay, I hold myself obliged to send you my Defence of it.

My Intention in this Address is not to ingage you in the Protection, or to the Countenance of any Opinion, further than as Reason allows it; nor is it to insinuate that you are of mine, to gain it the more Authority: For though I could not procure a greater Advantage to any Opinion I own, ${ }^{[4]}$ than to have others perswaded that you are of it; yet I must do you the justice to profess that I am wholly ignorant what yours is, as to the Point in debate.

I only appeal unto you now, as I did at first, as tn an Arbiter or Judg, for which your excellent pene. trating Understanding highly qualifies you, without 


\section{PHILOSOPHICAL WRITINGS OF BURTHOLLIL:}

inviting you as a Party to come to my Assistance, which at this time I hope I shall not need.

Mr. Keil ${ }^{30}$ in the Introduction to his Examination of Dr. Burnet's Theory of the Earth, ${ }^{51}$ hath done me the Honor (tho I am not sure he designed it for one) to mention me with several very celebrated Persons; but he doth it in that manner, and with that Abatement, that I have no great cause of being exalted on that regard.

After he had instanced in Spinosa, Dr. More, and $\mathrm{Mr}$. Hobbs, as Authors of great Discoveries, which might well demand Estcem and Vencration. if they were real, he picks out some of their Opinions, which he believed the most obnoxious, that $b y$ them his Readers may see how well they deserve such a Character. He then adds, "But a new Philosopher (naming me, who am not ambitious of that Title) "has much outdone any I have yet mentioned, "in a Book lately printed concerning Reason; there "[5] he assures us that there is but one universal Soul "in the World, which is omnipresent, and acts upon "all particular Organized Bodies, and makes them "produce Actions more or less perfect, in proportion "to the good Disposition of their Organs. So that in "Beasts that Soul is the Principle of the sensitive "and vital Functions; In Men it does not only per"form these, but also all other rational Actions: "just as if you would suppose a Hand of a vast Ex"tention, and a prodigious number of Fingers, play"ing upon all the Organ-pipes in the World, and "making every one sound a particular Note, accord- 
"ing to the Disposition and Frame of the Pipe: So "this unizersal Soul acting upon all Bodies, makes "every one produce various Actions, according to "the different Disposition and Frame of their Or"gans. This Opinion he as confidently asserts to be "true, as other Men believe that it is false; tho it is "impossible he should any other way be sure of it "but by Revelation; and I believe he will find but "few that will take it upon his word".

Mr. Keil, I hope, will give me leave to tell him without offence, that the Representation of my Opinion, had he pleased to make it in my own Terms, would have been less invidious, and withal more just [6] than it appears in his. However, since he hath endeavoured by a Comparison to illustrate, or else to expose [for I cannot well resolve which 'tis] the Sentiment I own, and that this Comparison is capable of being applied unto it to good purpose, I will my self make use of it my own way.

But first I must give a Plan of my true Notion, which in short is this; That the Mosaical Spirit (called Gen. i. v. 2. the Spirit of God) being a Spirit of Life, and present every where, in all the Parts of the Universe, is the Original of all the Energy, Motion, and Action therein, especially of that which is Animal. And that particular Souls [for such I acknowledge there be] are Portions of that Spirit acting in the several particular Bodies in which they are, according to the Capacities, Dispositions, and Qualities of those Bodies. A Sentiment conformable to two received Maxims: Quicquid re- 
I44 PHILOSOPHICAL WRITINGS OF BURTHOGGE.

cipitur, recipitur ad modum recipientis. Actus activorum sunt in patiente disposito.

To make it imaginable, let us suppose a vast Organ, consisting of innumerable Pipes of different Sizes and Fabrick, and this Organ to be filled with Wind blown into it, and the Wind to be received, and some portion of it appropriated by each particu[7] lar Pipe: Imagine also innumerable Fingers playing upon those several Pipes; For then each particular Pipe being played upon, will, by means of the Wind, be made to sound a particular Note, differing from the Notes of all the other Pipes, according as its Qualities, Dispositions, and Fabrick differ.

The World is as such an Organ [an orderly Aggregate;] and the several Sorts of Bodies that compose it are as the several Pipes of that Organ; the Mosaical Spirit present every where throughout the whole World, is as the Wind (which is) blown into the Organ. This Spirit is received and apportioned by the several particular Bodies, as the Wind in an Organ by the several particular Pipes: and as these inspired with Wind, being played upon, do sound different Notes or Tunes; so those animated with their respective Portions of the Mosaical Spirit, being impressed and acted upon by Objects, do perform their several vital Functions, according to their several Dispositions and Fabrick.

Thus far the Comparison plainly holds; but it may be carried a greater length, and made serve to illustrate what I say in my Essay concerning the nature of Animals, of Spirits, and of Souls. For it 
may be [8] added, that as the power of making an Organ sound at all, or the power of making a particular Pipe to sound a particular Note, arises not solely from the frame of the Organ, or from that of the Pipe; for the Organ sounds not at all, if it be not inspired with Wind, and tho inspired with Wind, and consequently tho it gives a Sound, yet it will not sound to such and such a particular Tune, if it be not played upon with the Fingers. In like manner, the Power of making a Body live, or of any particular Instrument of it exercise any particular Action of Cogitation, as of Seeing, or of Hearing, arises not solely from the frame of the Body, or from that of the particular Instrument, the Eye, or the Ear: for the Body lives not, if it be not animated with some Portion of the Mosaical Spirit; and if it be animated, and consequently hath Life, as the inspired Organ hath Sound, yet it doth not exercise that Life in this or that particular manner of Cogitation, by its several Instruments, as in seeing by the Eye, or hearing by the Ear, if it be not acted upon, and impressed by Objects, any more than an Organ which is only inspired, tho it sound, will sound to this or that particular Tune, if it be not played upon with the Fingers. Thus Life originally comes from [9] the Soul: I say, comes from the Soul; for that, speaking properly, it is not in the Soul, consider'd as a Soul, any more than Motion is, which properly is not in the Soul, but from it. And as Life, so Cogitation, which is a Species of Life, proceeds from the Soul, but the Specification of it from the Body. 
146 PHILOSOPHICAL WRITINGS OF BURTHOGGE.

And for the actual exercise of Cogitation in its several Species, whether of Sensation, or of Intellection, it comes originally from the Impressions and Operations of Objects. For Images and Ideas, that is to say, the Sentiments of the Sense, and those of the Mind or Understanding (they) are nothing but different Modifications of Cogitation; the former, Modifications of Sensation, the latter of Intellection; after the same manner as different Notes or Tunes are but different Modifications, or diverse Modulations of Sound.

In this Way of conceiving, the Production of $I \mathrm{~m}$ ages and Ideas is more perspicuous and intelligible, as well as more connatural, than in that of $\mathrm{Mal}$ branch $;^{42}$ which, methinks, in things of Nature, instead of having recourse to natural Causes, doth a little too unphilosophically, too soon repair unto the first Cause, which is the Author of Nature. But (as I said) in the way before set out, the Conception of it is very easy: [10] For Images and Ideas being but the Modifications of Cogitation, they are made by Impressions, and made different by different Impressions of Objects upon the Faculties; as Notes and Tunes are made by the playing, and different Notes and Tunes by the different playing of the Fingers upon the several Pipes of an Organ.

This Comparison of the World animated with the Spirit of God, to an Organ filled with Wind blown into it, cannot but be acknowledged to have much of Resemblance and Agreeableness; and the more, if we consider that this Spirit of God is called 
Ruach in Hebrew, a word signifying Wind; and likewise that Pneumatical or Wind-Instruments of Musick are said (tho but metaphorically) to be animated, as I think they are in Psalm I 50. v. last. For here it is said, Let every thing that hath Neshamah; the same Word that is used for the Soul of Man, Gen. 2. 7. when God is said to breathe into him the Breath of Life: so here, Let every thing that hath Neshamah, every thing that is animated with Wind, let every Wind-Instrument (for the Coherence plainly carries it unto Musical Instruments) Praise the Lord. And as Neshamah comes from Nasham, Anhelare, to pant or breath, so likewise Nephesh, another Word in Hebrew for a Soul, de ${ }^{[11]}$ rives from a Root of the like signification, and often stands for Breath, as well as for a Soul.

Nor was this a particular Sentiment only of the Jezes, but both the Greeks and Romans were in the same: For in Greek the Name for Spirit is $\pi v \varepsilon \tilde{v} \mu \alpha$, and $\pi v \varepsilon \tilde{u} \mu \alpha$ comes from $\pi v \varepsilon \dot{\omega} \omega$ to blow ; and $\psi v \chi \eta$, the Word for Soul, derives from $\psi$ v' $\chi \omega$ to breathe. With the Romans, the word for Soul is sometimes Anima. sometimes Animus; words that come from övenos, which signifies Wind, as in like manner Spiritus does from Spiro.

When I affirm that [Anima] and Animus are often used promiscously in Latin Authors, I have good Authority to support it, since Cotta in Cicero 1. 3. de nat. Deor. saying, Quî magis quam praeter Animam, unde Animantium quoque constet Animus, e.r quo Anima dicitur, ${ }^{52}$ intimates the same: for 
I 48 PHILOSOPHICAL WRITINGS OF BURTHOGGE.

there he calls the vital Principle of inferior Animals Animus, and in effect says, both that it consists of Anima or Breath (which is inspired Air or Wind) and that for this reason the Breath is called Anima. because it is to inferior Animals what the Animus is to Man; [Animus ex quo Anima dicitur.] Anima it is Animus with a little distinction; Anima is the Animus or Soul of Brutes, and Animus is the Anima or Soul of Men; ${ }^{[12]}$ as in the Holy Scripture, where St. Paul speaks of Body, Soul, and Spirit, what he means by Soul may be expressed by Anima, what he intends by Spirit by the word Animus; the former word importing the sensitive Principle, which is common to Beasts, the latter the rational or intellectual which is proper to Men.

To clear this Passage further, which I have quoted out of Cicero, and the sense I have given to it, we ought to consider that the Stoicks held an opinion that all Souls were Fire; and Balbus (who was one of them) taking it for granted, is told by Cotta that he was too forward in assuming so much; for, says he, 'tis the probable Opinion that the vital Principle or Soul is not Breath only as most think, or Fire only as Stoicks think, but a Complex or Result of both; probabilius videtur, tale quiddam esse Animum, ut sit ex igne atque animâ temperatum. ${ }^{\text {'2 }}$

It is true Julius Scaliger ${ }^{61}$ in his ro7th Exercitation against Cardan $^{\circ 2}$ is extream severe upon that wonderfully knowing and learned Man for saying but by implication, that other Souls besides the hu- 
man were called Animi. For Cardan having said, Animi vires praecipuè humani, \&c. Scaliger replies upon him, Quasi verò alius sit Animus ab hu-[13] mano. Insinuating thereby, that to hold that every (or indeed that any) Soul might be called Animus is very absurd, as in truth it would be, if what he says was well grounded, to wit, that all wise Men did ever understand by Animus a Faculty of the human Soul, which he says; tho at the same time he confesses Cicero (who, it seems, for this reason he thought not very wise) to be in a different Opinion: Nam tametsi Cicero (says he) Animal ab Animo dictum scribit, tamen hominis proprium Animum, id est, Animae vim, sapientes omnes intellexêre.

And to lessen Cicero's Authority in this particular, he impeaches him of Inconstancy, telling us that at another time, speaking of Apronius, he uses such Expressions as do evidently so distinguish between Anima and Animus, that no room is left to imagine but that he took the latter for only a Power or Faculty of the former. At (says Scaliger) non servabit [Cicero] constantiae opinionem invitis doctis viris, ejus enim verba de Apronio sunt, qui non modo Animum integrumi, sed ne Animam quidem puram conservare potuisset, ubi apertè Animae facultatem innuit Animi appellatione.

But our Hypercritick has not exercised his Talent to advantage in this place: for tho it must be acknowledged that Animus is [14] very often used for a Faculty of the Soul, and not always taken for 
the Soul it self; yet when Cicero says of Apronius that he could not conservare animam puram, he does not mean by Anima his Soul (of which the Animus, that he distinguishes from it should be a Faculty) but he understands his Breath, which was impure. foul, and stinking. This is evident from the Orator himself, who in Verrem lib. 3. describing this Apronius, says of him, that his Breath was so fetid, that, as some affirmed, the very Beasts could not endure its Stink: Ut odor Apronii teterrimus oris \& corporis, quem, ut aiunt, ne bestiae quidem ferre possent.

In truth, nothing more surprizes me on this occasion, than to find Scaliger (a very extraordinary Man, and a great Critick) so positive in this Opinion, that none of the Antients who had any Wit, ever denominated the Souls of inferior Animals Animi, or even that of Man Animus. For Seneca Epist. I I3. tells it to Lucilius, as the Opinion of the Antients, that the Animus is an Animal, for that it makes us Animals; and that Animals receive their name from ANIMUS: Quae sint (says he) quae Antiquos moverint dicam; Animal constat Animum esse, cum ipse efficiat ut simus Animalia, \& cum ab illo Animalia nomen hoc traxerint. ${ }^{52}[15]$

However (to note it by the by) it must not be said neither that the Antients never gave the name [Anima] to the Soul, or that Anima of old did only signify the Breath: For tho Anima was us'd to signify the Breath, it was so but in a secondary Sense, the Breath being therefore called Anima, 
because the Anima or Soul was generally understood to be contained therein, or to consist thereof. This is manifest not only from what is said already. but (to omit others) from a Passage in Seneca l. de provid. where $A s$ he says, sive haustus ignis cursum Animae remeantis interscidit, \&c. where [Anima remeans] signifies Respiration or Breathing: So he likewise says, Id quod rocatur MORI, quo Anima discedit a corpore, $\&$ c. For here [Anima] is taken for the Soul. But to put it out of question, that even the human Soul is called Anima by antient Authors, I need to cite but Seneca his I 7 th Epistle; where, writing of the Immortality of Souls, and saying that the Consent of Mankind in that Point is a cogent Argument for the truth thereof, he uses the Word [Anima] not [Animus] for a Soul; cum de ANI$M A R U M$ aeternitate disserimus, says he, non leve momentum apud nos habet consensus hominum, aut timentium Inferos, aut Colentium.

I have a fruitful Subject before me, and [16] could add a great deal more, if I believed it proper; but it may suffice at this Time to have shewed that both Anima and Animus are Names for a Soul, and that both derive from a Word that signifies Wind or Breath: for this evinces that the Comparison I have made between the animated World and an inspired Organ, is not any remote one, or (as we usually speak) farfetch'd but very fitting and agreeable.

However, tho this Comparison between the World and an Organ is well enough imagined, and 
carries much resemblance; yet since an Organ is but a Machin, and only artificial, and that Animals are Works of Nature, and more than mere Machins. I chose in my Essay to illustrate and set out my Notion by Comparisons taken from Nature, as from Sound and Echo, from Light and Colours; but more particularly from our own Souls, and their different Operations in the several Organs of Human Bodies, by means of their several Faculties.

In that Treatise I have shewed at large, that there is a universal vital Principle diffused throughout the World; and withal have shewed how that Principle comes to be singularized, and individuated, so as that there be particular Souls. I have also endeavour'd to satisfy Objections, and have instanced in the Theodosian and Scotish [17] Monsters, as sensible Demonstrations of the truth of what I affirm in Reference to this Subject.

I have shewed likewise that the Jewish Doctors. many Philosophers, some Fathers, and several Schoolmen, were in the same Sentiment as to the main: for tho perhaps they all agreed not either each with other, or with me, as to particular explications; yet all held a vital Principle that doth permeate the whole World; and that, unto the Universe, is what the Soul of Man is to his Body. And if common Language does signify a common Senti. ment, this must be owned to be one. For why else is Man called a Microcosm or little World, but because he is like the Great, and has Soul and Body? And tho this Expression is appropriated unto Man, 
yet if we believe Galen, the Antients held that every Animal is a Microcosm, a World in little; and then surely, in their Opinion, the World itself is, after a sort, an Animal in great.

Upon the whole it is evident, that for any to imagine I exclude particular Souls, because I do affirm a general (one,) is to do me injury; and in effect. the same as to infer that I deny there are Colours, because I affirm there is Light; or that I deny there is Echo, because I affirm there is [18] Sound. In sum, he might as fairly conclude that all those deny the Powers of Seeing, of Hearing, of Feeling, $\mathcal{G} c$. to be in any Animal, who do affirm that the Animal has a Soul which is the Principle of those Powers; for those Powers in divided Bodies would be so many Souls, that in the same Body are only so many Faculties of one Soul. This way of Reasoning goes on the same Ground that Seneca's does, when, in another case, he says, Epist. II3. Animal sum \& Homo, non tamen duos esse dices: Quare? quia separati esse debent. Ita dico alter ab altero debet esse diductus, ut duo sint.

Yet, after all, it has pleased Mr. Keil to make a sharp Reflection upon me for this Opinion (but with how much Equity or Candor, our Readers must determine) and he doth it in these Terms:

"This Opinion he as confidently asserts to be "true, as other Men believe it is false; though it is "impossible he should any other way be sure of it "but by Revelation; and I believe he reill find but fero "that will take it upon his Word. 
I54 PHILOSOPHICAL WRITINGS OF BURTHOGGE.

First he says, I confidently assert, \&c. As for Confidence, I acknowledge that a Confidence like his in this Reflection, that does only assert but not prove, cannot merit $\mathrm{a}^{[19]}$ ny great Commendation: But otherwise I know no fault in being of any Opinion or in a confident asserting of it, (which however I am no way conscious of) if there is reason for that Confidence, and that the Opinion be well grounded.

But this he supposes mine is not; for he says, $I$ confidently assert, \&c. tho it is impossible I should any other way be sure of it but by Revelation. If he mean it is impossible I should be absolutely sure of it but by Revelation, and that for this reason 'tis a Presumption in me to assert the Opinion, since I an not assured of it that way, he must excuse me if I differ from him. For, in the first place, I will take the liberty to tell him what I believe most others who consider, would upon occasion, that there are many Degrees of a just Confidence, that yet do all fall much beneath Infallibility, or absolute Certainty. Besides, methinks it should content him, as being a sufficient ground of asserting any Opinion, even with Confidence, that there is Reason for the Opinion, tho he that asserts it cannot be absolutely sure of it without a Revelation; especially since Mr. Keil himself, I dare say, will not affirm he had a Revelation for all he confidently asserts in his Book, of which yet he cannot be absolutely sure [20] without one: but what there is of Revelation in the Question between him and me, he may be told hereafter, and 
might have learned somewhat of it from the Essay, where also he might have seen that there was some reason for the Opinion.

And whereas he says, that I as confidently assert my Opinion to be true as other Men believe that it is false: If I should yield him so much, what would follow but this, That if this be all, 'tis only Confidence on either side; I confidently assert it to be true, other men as confidently believe that it is false? And when equal Confidence and nothing else is in both the Scales, what shall turn them? But certainly, tho other Men (if but other Men) believe an Opinion to be false, that any one affirms to be true, it will not necessarily follow that 'tis false indeed; for if it should, Mr. Keil himself, who writes in opposition to other Men (and those very worthy Men) must believe himself in the wrong Box, till he can convince them, ay, and all the rest of Mankind that think otherwise than he does; for till then other Men will believe that what he says is false. Indeed, if my Opinion went contrary to common Sense, and that all other Men, or but all considerate, wise, and thinking [21] Men were in another belief, I should be very apt to suspect I was imposed upon by false Appearances; but there is nothing of this in the matter, as will be manifest presently.

Mr. Keil closes up his Censure (for all he says against me is Censure only, not Argument) with telling his Readers his Belief, which is, that I will find but few that will take the Opinion upon my word. In truth it is not my desire, as it is not 
I56 PHILOSOPHICAL WRITINGS OF BURTHOGGE.

reason any should; nor as it falls out, is there any need they should: for if a Revelation in the Holy Scriptures, if the Authority of some of the most thinking and sagacious Philosophers, and if Reasons taken from the Phaenomena of Nature, can put any Sentiment beyond the Misfortune of being precarious, mine is safe enough from that Imputation.

As for Revelation, what Interest it hath in this Opinion, I have shewed in my Essay from Genesis Ch. I. v. 2. compared with Psalm I47. v. 15, I6, \&c. which I will not repeat, only I will add that I think it abundantly confirmed by an Evidence I find in the Book intituled, The Wisdom of Solomon, where it is said, Ch. I. v. 7. The Spirit of the Lord filleth all the World; and the same that maintaineth all things hath Knowledge of the Voice. [22]

This Spirit, as it hath in the Holy Scriptures the Denomination of the Spirit of God, because it comes from him, and is his hand in all his Influences upon the World; so it hath that of the Spirit [or Soul] of the Creatures, whether these be Plants, Sensitives, or Men, as being that vital Principle that acts and actuates them all. Thus in Psal. I04. v. 29. that which is called the Breath of the Creatures, or the immediate Principle that makes them live, and is their Soul, upon whose Departure they are said to die, and to return to their Dust, is, in the zoth verse of the same Psalm, called the Spirit of the Lord, which being sent into them, makes them live: Thou sendest forth thy Spirit, and they live; and thou reneruest the face of the Earth. 
This is particularly affirmed as to Man by Elihu. Job 33. 4. The Spirit of God hath made me, and the Breath of the Almighty hath given me Life: By Job himself, Chap. 27. v. 3. All the while my Breath is in me, and the Spirit of God is in my Nostrils: And by Elihu again more comprehensively, Job. Chap. 34. v. I4, I 5. If he set his Heart upon Man [to take notice of him, and remark his Iniquities] and [consequently] gather unto himself his Spirit and his Breath; all Flesh shall perish together, and Man shall [23] turn again unto Dust. Plainly intimating that the Spirit of God (as if it were a common Soul) is the Original Principle of Life and vital Operation in Man, as well as in all things else that have life. See Isa. 42. 5 .

The Prophetical Scheme in Ezekiel, Ch. 37. concerning the dry Bones, is very pertinent, and full to the same purpose. For when the dry Bones are to be made to live, God is introduced saying to them, v. 5. Behold, I will cause Breath to enter into you, and you shall live. And he effects it by the same steps, and in the same manner as he created Man at first. For first he organized Bodies, v. 7,8 . The Bones came together, Bone to his Bone, the Sinew's and the Flesh came upon them, and the Skin covered them above. But tho the Bodies were organized, yet being not inspir'd, [for there was no Breath in thein] they were not made to live as yet; and therefore to make them living Bodies, and put Soul into them, the Prophet had a Commission to the MUNDANE SPIRIT to come and animate 
I 58 PHILOSOPHICAL WRITINGS OF BURTHOGGE.

them, v. 9, Io. Then said he unto me, Prophesy unto the Wind, prophesy, Son of Man, and say to the Wind, Thus saith the Lord God, Come from the four Winds, O Breath, and breathe upon these slain, that they may live: So I prophe ${ }^{[24]}$ sied, as he commanded me, and the Breath came into them, and they lived. Where it may be observed, that the Spirit that quickneth and giveth Life to those Bodies is compared to inspired Wind or Breath; that this Spirit of Life or quickening Breath is diffused throughout the Universe in all the Quarters thereof; and that it is intirely at the Command and Beck of God: For it is Breath is called upon to come and quicken those Bodies; and it is called upon to come and quicken them from the four Winds; and it is no sooner called upon, but it comes forthwith, and quickens them.

It may also be observed that the Breath or common Spirit of Life, that blew upon those Bodies, as it came upon them all, so it was apportioned by each; for the Breath must be in them: And where the Breath is in all, each hath his Portion of it in particular, and then may say as $J o b$, Chap. 27. v. 3. All the while my Breath is in me, and the Spirit of God is in my Nostrils, \&c. So long his Breath is in him. as the Spirit of God is in his Nostrils.

Thus every Man hath his own Soul, but this Soul is only a Portion of the Spirit of God that, as a Soul, does permeate the Universe; so that it is (as in Pythagoras's Expression, which I find in Lucre-

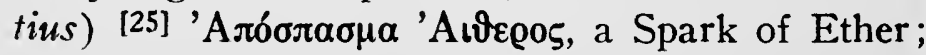


or as others choose to express it, particula Aurae Divinae: which, according to the grounds that I have laid in my Essay, I would render a Portion of Mind in Matter. So much for my Opinion from the Authority of Revelation.

As for that of Philosophy, I produced in my Essay as Vouchers of my Hypothesis, not only the great Philosopher last named, who was Founder of the Italick Sect, but also Zeno, Seneca, Plutarch. Marcus Antoninus, and Apuleius. To all which, from as many as would fill a Volume, I will add a few more.

Thales the Father of the Ionick Sect, held (as Laertius tells us ${ }^{63}$ that Water was the Principle of all things, and that the World was animated [ $\tilde{\varepsilon} \mu$ uvxov] In which Doctrines (as is very probable) he was instructed by the Mosaick Tradition [of the Waters, and the Spirit that moved upon them 7 for unto this his Dogmata are very conformable.

There are in Plato so many Testimonies of a mundane Soul, and his Opinion is so generally known, that it were to overdo to instance Particulars.

I have mentioned Zeno Citticus in my Essay:" but seeing he was Founder of the [26] Stoick Sect, and that I find in Laertius, who wrote his Life, a fuller State of his Opinion, and in more particulars consonant to mine than what I have mentioned already, I will produce him again. He then, as Laertius tells us, asserted a Mind that permeated every Portion of the World, after the same manner that the Soul 
I6O PHILOSOPIIICAL IVRITINGS OF BURTHOGGE.

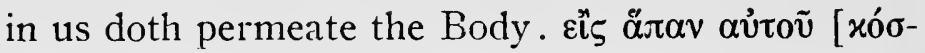

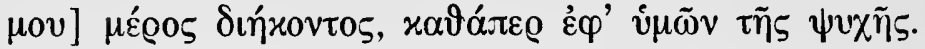
But through some more, through others less $\alpha \lambda \lambda$ '

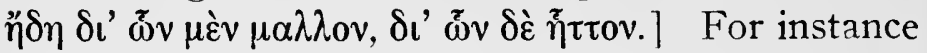

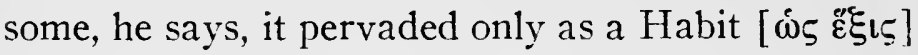
as through the Bones and Nerves; but through others as a Mind [ $\omega_{\zeta}$ Noṽ $]$, as through the under-

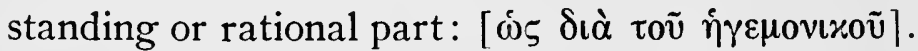

This Sentiment of a Divine Virtue that pervaded the whole Universe, was in antient time so generally received, that even the Tyrant Phalaris, in an Epistle Consolatory written by him to the Children of Stesichorus (if indeed he was the Author of those Epistles passing in his name $)^{54}$ mentions it as such

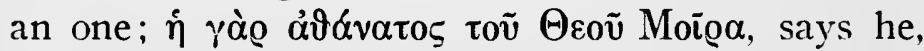

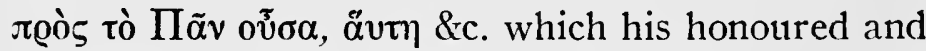
very learned Translator renders thus: Immortalis quippe Dei vis, quae per unic'ersum diffunditur, mihi nihil [27] nisi hace ipsa harmonia videtur. He is also understood by that excellent Person in his Annotations, to mean the mundane Soul of the Pythagoreans, when in his I04. Epistle, which is to the

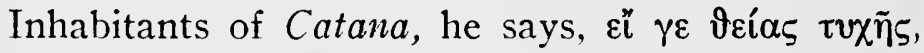

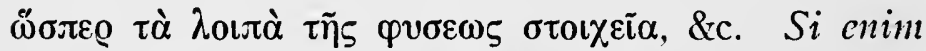
Divinae fortis, quemadmodum caetera naturae elementa, \& $c$.

And even Aristotle, tho a great Opposer of the Platonick Soul (yet) being prevailed upon by irresistible Experience (he) in a Paragraph quoted out of him by Julius Scaliger, ${ }^{\text {B1 }}$ in his 26 th Exercitation against ardan, $^{62}$ comes somewhat near to my Opin . 


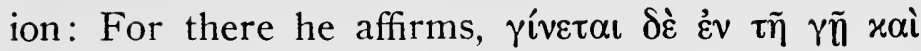

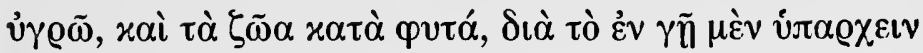

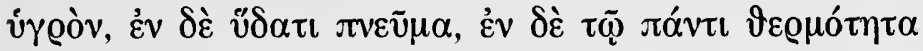

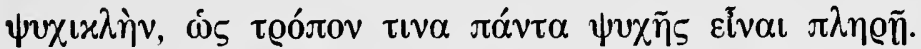
That both Animals and Plants are produced in the Earth and in the Waters, for that there is, as in the Earth Moisture, so in the Water Spirit, and throughout the Universe an animating [vivifick] Heat; insomuch that after a sort [it is true that] all things are full of Soul. [28]

To those Philosophers I will add the well-known Testimony of a philosophical Poet, Virgil AEn. 6.

Principio coelum, ac terras, camposq: liquentes, Lucentemq; globum lunae, Titaniaq; astra, Spiritus intus alit, totamq; infusa per Artus Mens a gitat molem, \& magno se corpore miscet.

Rendered by Eugenius Philalethes ${ }^{55}$ thus:

The Heavens, the Earth, and all the liquid Main, The Moon's bright Globe, and Stars Titanian, A Spirit within maintains, and their whole Mass A Mind, which through each Part infus'd doth pass, Fashions and works, and wholly doth transpierce All this great Body of the Universe.

I begin to be fatigued with the unpleasant Drudgery of quoting and transcribing; and therefore wholly omitting modern Testimonies, I will add but one more of the antient, and that shall be 
I62 PHILOSOPHICAL WRITINGS OF BURTHOGGE.

from Cicero, who l. 2. de natur. Deor. introduces Balbus de ${ }^{[29]}$ monstrating that all things in the World are subject to a sentient perceptive nature. and are administered and governed by it. This he evidences by shewing, that particular works of $\mathrm{Na}$ ture have infinitely more of the Beauties of Art and Contrivance than the most noble Productions of Human Skill, and yet that no particular Operation of Nature, for example, the Production of a Vine, of a Tree, or of that of the Body of any Animal, can shew as to Conformation, Order, and Situation of Parts, or as to Adjustment and Fitness of them for ends and uses, that wonderful Sagacity, that Subtilty of Invention, or that wise Contrivance that shines with great brightness in the general frame of the World; whence he confidently, but justly infers that the whole World is under the Conduct and wise Administration of a sentient and perceptive Nature, or else that nothing at all is so. Aut igitur. says he, nihil est quod à sentiente Naturâ regatur, aut mundum regi confitendum est.

This last Testimony, as it is an Evidence, so it is also an internal Argument; and being taken from the Phaenomena of Nature, reminds me of what I undertook to do in the third place, which was to shew that my Opinion had Reasons for it in Nature, and [30] grounded upon things themselves: And these I will now produce.

The First is taken from the Uniformity even in Difformity, the mutual Relation and the Harmony of Parts that is in the World in its general Fabrick, 
if it may be allowed to make a judgment of the whole Frame by that of a particular Systen, which we our selves belong unto: But I will not now insist any longer on this Argument, because it is set out at large in my Essay in many Instances, and the learned Reader will find more in Nemesius de nat. Humanâ.

Again, this Hypothesis accounts for another Phaenomenon that cannot be so well accounted for any other way, that whenever any Matter becomes disposed for Animal Life, this is presently afforded to it; which how it should come to pass, is easily conceived, on supposal of a mundane Soul, or a Principle of vital Energy diffused every where; but otherwise one must imagine particular Souls, and those too to be Spirits (that are) always every where in waiting for an Office, which is hard to be admitted. I say [and those too to be Spirits] for that 'tis certain that mere corporeal Souls (as some call them) suffice not for Animal Operations, even tho we should conceive [31] them (as those do) to consist of Flame for vital Actions, and of Light for the sensitive ones: for if Matter be not radically vital, and so there be no need at all of Spirit or Mind, and then there is no such thing, it will be absolutely unconceivable how Flame and Light (which are only Matter under greater comminution of its parts of a particular Texture, and in rapid Motion) can of themselves be vital and perceptive, or make other things become so. But to return.

Mr. Lewenhoec's $s^{\text {se }}$ Experiment of pepper'd Wa- 
I64 PHILOSOPHICAL WRITINGS OF BURTHOGGE.

ter, every Drop whereof affords (as he says) so many Thousands of Animalcules, ${ }^{57}$ is a sensible Demonstration of an omnipresent vital Principle that acts as occasion is; and a sensible Demonstration too of spontaneous equivocal Generations: for so I call the Productions of Animals that do not come from Seeds in the common Acceptation of this word. I acknowledg it almost a Scandal but to name equirocal Productions at this time, they are now so generally disbelieved and exploded; but for my part, I am not ashamed to confess that as yet I have not observed so much said by the excellent Redi, ${ }^{58}$ or by any other Author against the Reality of them, as to oblige me to depart from a Sentiment that [32] hath been the common Belief of most Inquirers into Nature, in all Ages before this last. And the Hypothesis of a mundane Soul will make Productions of that kind conceivable; without which indeed it will be hard to apprehend how they can be.

Dr. Cox, in a Process of extracting volatile Salt and Spirit out of Vegetables, which is described in the Philosophical Transactions, intimates this $\mathrm{Ob}$ servation; That many of the Herbs putrefied and fermented after his way, did swarm with Maggots, especially at the Bottom, and in the Middle, where (he tells us) Flies and other Insects could have no access to deposite their Eggs, ${ }^{50}$ and where the Heat is so violent that they could not possibly subsist. Some years after that learned Person, I find another, the experienced Juncken, in Processes of much a like nature, making the like Observation, 
that in the Putrefaction and Fermentation of the Vegetables, great numbers of Insects and little Animals were generated, tho (as he says) the Vessels were never so close stopp'd: And indeed it is commonly observ'd that Putrefactions do terminate in Animals of one sort or other. [33]

The Relations of Barnacles, that are said to be Birds arising out of the putrefied Relicks of shipwrack'd Planks, ${ }^{\text {Bo }}$ which Relations have been confirmed to me by an Eye-witness of unsuspected Credit, are further confirmed by the Testimony of an Eagle-eyed Philosopher, who tells us he hath seen a Creature of that kind; for so I understand Julius Scaliger, ${ }^{61}$ when in his 59 Exercitation against Cardan $^{62}$ he says, In Oceano Britannico magis mireris ignotam avem, anatis facie, rostro pendere de reliquiis putridis naufragiorum, quoad absolvatur, atque abeat quaesitum sibi pisces, unde alatur: hanc quoq; vidimus nos.

To the former Story Scaliger in the same Exercitation adds another, which he calls miraculous; it is of an Oyster-shell not very great, that was presented unto Francis, King of France, and contained in it a little Bird, almost finished with Pinions, Feet, and the Bill, sticking to the Extremities of the Shell. This Bird he says, some Learned Men believed a Transformation of the Oyster. His own words are these, Singularis nunc Miraculi subtexenda historia est, ubi de Aquis agimus. Allata est Francisco regi opt. max. Concha non admodum magna. cum aviculầ intus penè perfectâ alarum 
I66 PHILOSOPHICAL WRITINGS OF BURTHOGGE.

fastigiis, ro ${ }^{[34]}$ stro, pedibus, haerente extremis oris ostraci. Viri docti mutatum in aviculam Ostreum ipsum existimarunt.

My Lord Bacon, in his natural History, Century 4th, Exp. 228. tells us, That if the Spirits be not merely detained, but protrude a little, and that Motion be confused and inordinate, there followeth Putrefaction, which ever dissolveth the consistence of the Body into much inequality, as in Flesh, rotten Fruits, shining Wood, $\mathcal{E} c$. and also in the Rust of Metals; but if that Motion be in a certain order. there followeth Vivification and Figuration, as both in living Creatures bred of Putrefaction, and in living Creatures perfect: But if the Spirits issue out of the Body, there followeth Desiccation, \&c.

In Experiment 339, his Lordship further tells us. that all Moulds are Inceptions of Putrefaction, as the Mould of Pyes and Flesh, the Moulds of Oranges and Lemmons; which Moulds afterwards turn into Worms, or more odious Putrefactions, \& $c$.

And methinks the Production of Plants without Seed affords a very weighty $\operatorname{Ar}^{[35]}$ gument for the like Production of Animals. My Lord Bacons gives us many Instances of the former in the 6 th Century of his natural History, where he tells us, Experiment 563 . That it is certain that Earth taken out of the Foundation of Vaults and Houses, and Bottoms of Wells, and then put into Pots, will put forth sundry kinds of Herbs: but some time is required 
for the Germination; for if it be taken from a Fathom deep, it will put forth the first year, if much deeper, not till after a year or two. And in the $565^{t h}$ Experiment, adds, that the nature of the Plants growing out of the Earth so taken up, doth follow the nature of the Mould it self; as, if the Mould be soft and fine, it putteth forth soft Herbs. as Grass, Plantane, and the like; if the Earth be harder and coarser, it putteth forth Herbs more rough, as Thistles, Furs, $\mathcal{E} c$.

Scaliger, ${ }^{01}$ in his 323 d Exercitation against $C a r$ dan, ${ }^{\circ 2}$ speaking of the Production of Frogs, ${ }^{64}$ that sometimes have been rained in great abundance, of which there he gives several Instances, tells Cardan, who affirmed them to be bred of Frogs-Eggs or Spawn, that they were spontaneous or equivocal, as being Productions of a gene ${ }^{[36]}$ ral Nature, and not seminal ones; which kind of Animal Productions he evinceth to be possible the same way that I have, by shewing that there are the like in Plants: Quid multa, says he, nonne quotidiana foetura coelestis genii, quae natura est potentiam declarant Plantae. nullis ortae seminiis?

My Lord Bacon assures us for a certain truth, that Toads have been found in the middle of a Freestone, ${ }^{05}$ where it cannot be imagined that an Animal of that Kind should come and lay her Eggs; and I have been credibly informed, that very lately a living Toad was found in the Heart or Middle of a large Oak when it was felled. 
I68 PHILOSOPHICAL WRITINGS OF BURTHOGGE.

The Animation of Horse-hairs ${ }^{68}$ lying in the Summer time in Pools, has been observed of many, some of which I have discoursed concerning it; and an understanding Man of my acquaintance assured me, that more than once he hath made an Experiment which very much confirms the truth thereof. He takes a Hair with the Root, pluck'd from the Main or Tail of a Mare that is proud, and in a warm Season puts it into a wooden Dish full of Water, where letting it lie two or three Days, the Hair in that space will, for the most part, be ${ }^{[37]}$ come quickned with a strong Motion, and a Head like that of a Serpent grow out of its Root.

The infectious Water of the Showers that accompany the Tornadoes on the African Coast, standing any where, do (as Mr. Terry tells us in his Relation of a Voyage to East-India) presently bring forth many little offensive Creatures; which is likewise affirmed by Mr. Herbert.

The Vermination in Human (as well as other Animal) Bodies, ${ }^{67}$ of which there are innumerable Instances in Medical Writers, as in Bartholinus's Centuries, in Borellus's, in Tulpius's Observations, \& c . is another weighty Argument for spontaneous Generations; but I will mention only one: A Worm of an unusual Figure, with Head of a Serpent, found in the left Ventricle of the Heart of a Gentleman. whose name was John Pennant. The Relation well attested, together with the Figure of the Worm, was in the year 1639. printed at London by one 
George Miller, to which Relation I refer the Reader. This Phaenomenon of Vermination is a good Evidence of SPONTANEOUS GENERATION ; and this, a weighty Confirmation of the Existence of a mundane Soul. [38]

Another Argument for it may be taken from the Difficulties that the admittance thereof will remove, as to the Production of Human Souls; which some conceive to come, as they express it, ex traduce; not indeed by way of Eduction from the Power of the Matter, for they acknowledg no such Power therein, but by propagation. But others think them immediately created by God, either all at once, as those do who hold the Doctrine of Praeexistence, or (as most imagin) on occasion, according to the exigence of Matter.

As for the first Opinion, that of Traduction, I find it in Nemesius, lib. de nat. human. cap. 2. where he tells us, it was the Sentiment of Apollinarius, that Souls do propagate Souls, as Bodies do Bodies; and Julius Scaliger concurs with him, affirming that Souls may come from Souls, ut lumen de lumine. that is, that Souls do propagate one another, after the same manner as Candles light one another. Poiret believes as the two former, that Souls are propagated, but extends the business of Propagation somewhat further than they do, and upon other Grounds. For in his $\mathrm{Co}^{\left[{ }^{[39}\right]}$ gitat. rational. l. I. c. 5 . in Annot. he affirms that all things are Prolifick, and that as Matter produces Matter, and Motion 
I7O PHILOSOPHICAL WRITINGS OF BURTHOGGE.

is productive of Motion, so in like manner one Soul or Spirit may generate and produce another.

But there are many Difficulties in this Opinion, of all which I will insist on this only; That a Soul, if it be an immaterial Substance (as most conceive it to be) is as uncapable of Propagation (otherwise than by a Metaphor) as it is of Discerption or actual Division. For even the Propagation of Light is by Discerption; some Effluvia or Emanations of the enlightning Candle passing into that which is lightned. And for the Propagation of Motion, the way thereof is so obscure, it cannot afford Light to this Subject. Only this is certain, that in local Motion derived from Body to Body, so much of it as is imparted unto one, departs from the other; which (I suppose) will not be admitted in the Propagation of Spirits. And as to the Prolifickness of Matter, I should think but few will allow thereof, who consider, that there is no more of Matter in the World now than ever was, and that Matter is ingenerable and incorruptible, being a Subject of [40] all substantial Mutations, but not the Term of any: So that if the Generation of Souls has no other, or no better Foundation than this, That Soul is productive of Soul, as Matter is of Matter, I conclude the belief thereof will never become general with knowing Men.

As for Creation of Souls (an Opinion generally held by Divines, and among our late Philosophers, 
particularly embraced by des Cartes) many Objections lie against it; of which I will touch but one or two, as sticking most with me.

The first is, that it seems a little unphilosophical to call in a supernatural Agent for a Business and Work of Nature, such as is (if any is) the Propagation of Kind: My full consent is with Julius Scaliger, when he says Nihil quod est in naturâ praeter naturam est: Nothing is in Nature that hath not a Cause in Nature.

Again, it may be further argued, that if human Souls are immediately created by God, it must be admitted that those of Beasts are so too, since nothing can be clearer, even to Sense, than that Men and Beasts do propagate their kinds the same way, [41] whether that way be by Creation, by Traduction. or by any other whatever. There is in Mankind, as well as in the kinds of Beasts, a Distinction of Sexes for the Business of Generation; a Furniture and Disposition of Organs for it in both: and in both a like Use and Application of Organs. All Men and Beasts are alike conceived in their respective Wombs, alike nourished and augmented, and both come out in the same manner: and therefore there being the same Evidence, it is but reason to make the same Conclusion for both.

I know this Argument will have but little effect upon Cartesians. who, against the testimony of 
I 72 PHILOSOPHICAL WRITINGS OF BURTHOGGE.

Sense, believing that Beasts are only Machins, without any conscious Perception or Knowledg, do not own them to have Souls as Men have, in the proper Sense of the Word. But yet it cannot want its due Weight with all others, who, believing their own, refuse not Senses unto Beasts; as thinking they have reason to conclude that Beasts see and hear, $\mathcal{F} c$. as Men themselves do, because they have Eyes and Ears, $\mathcal{F} c$. as Men themselves have, and, to all appearance, make the same use of them upon occasion, as Men themselves upon the like would do. And all these will find the same ${ }^{[42]}$ reason to infer that Men and Beasts beget their like the same way, because there are the same Appearances to make us think they should.

These Appearances are obvious, and they ought to be considered; nor are they capable (I think) of being solved, or the other Difficulties, that do lie in both the ways of Creation and Traduction, capable of being removed otherwise than on the Hypothesis I have proposed, by acknowledging a Mundane Soul, that, according to the Exigence and Disposition of the Matter, is always ready with a Portion of it self to animate and actuate it; so that there is no need of any new Creation, of Praeexistence, or of any Traduction of particular Souls. But to proceed.

There is another Phaenomenon very obvious, that is better solved on this Hypothesis of a munclane 
Soul, than it can be on any other; to wit, that certain Animals do move and stir, and give other Tokens of Life and Sensation, tho cut in several pieces, such as Eels, Snakes, Earthworms, Butterflies, \&c. This in the common way is hard to be conceived, since it must infer either that there is a Discerption and actual Divi[43] sion of Souls, of which, if Souls be immaterial, they are absolutely uncapable; or else that vital Effects may remain in being after that the Soul, which is the next immediate Cause of those Effects, is departed ; contrary to the Maxim, Sublata causa, tollitur effectus.

But the Reason of this Phaenomenon, if we suppose an universal mundane Soul, will be very plain: for since the Parts of those divided Animals do retain for some time the same Qualities and Dispositions that they had before their Separations, there not being in them, as in those of other Animals, that sudden Dissolution of the Texture, or of the Spirits; it follows that they must receive the same Influences which they had before from the mundane Soul, and consequently, that for some Time they must continue to live, and in convenient Circumstances would longer; for like Reasons as the Parts of Vegetables do, which, tho separated from their Wholes, yet continue to live in Slips, in Buds, in Grafts, when inserted into other Wholes. Nor do I see but that the Parts of Animals might be inoculated, or ingrafted into Animals, as well as those of Vegetables are into Vegetables, if the Qualities and Dispositions of Ani- 
mal Parts, when separat ${ }^{[44]}$ ed, could be as well preserved as those of Vegetables, and a Coalition of them as well made: a Sentiment that is confirmed by the Experiment of Taliacotius, and by all the others that the Chirurgia Curtorum affords.

Thus I have instanced in a few Phaenomena of Nature, to which I might have added many others of a higher Quality; but these sufficiently confirm my Hypothesis, against which I cannot imagine any Objection of moment, capable of being rais'd, except this, that it does seem to render the Distinction between human and inferior Souls less conceivable, and in consequence the Immortality of the former.

But this Objection will soon vanish, if we but suppose there is a firm and indissolvable Union between the Spirit of God and its Vehicle in Man, and that there is not the like Union between it and its Vehicle in inferior Animals. And this Supposal is not without ground. For such a firm indissolvable Union betwixt the Spirit of God and its Vehicle. must be admitted to be in Angels, if they are (as they are) immortal; and then the Ligament or Bond of that Union, provided it be natural, must consist in a natural, but a naturally immu[45] table, Congruity. Now the System of Spirits, that in Man is the Vehicle of the mundane Soul, must be owned to have more Alliance unto that of Angels than the Vehicles of it in inferior Animals have, if we consider the advantage the Human Understanding hath 
in excellency of Operations, above the Imagination of Beasts; and also consider that the Souls of Men are capable of the Divine Image, which those of Beasts are not: for thence it will evidently follow that the former have more of a natural congruity to the Spirit of God, which is the Soul of the World, than the latter have; those as to their Vehicles being of a celestial, but these of a terrestrial and elementary matter. No wonder then if the Spirit of a Man, when he dies, goes upward, but that of a Beast goes downward.

Thus Sir, I think I have evinced from the holy Scriptures, and from several Plaenomena of $\mathrm{Na}$ ture, that there is a Principle of Life diffused throughout the Universe; and I have likewise evinced that it was the Sentiment of many great Philosophers: so that tho I am not very fond of any Opinion, I hope I may say of this, without Injustice to Mr. Keil, that what he hath offered in contradiction to it, does in no degree impeach its Credit, or lessen mine for [46] asserting it. However I do own I am obliged to that ingenious Gentleman for the occasion he hath given me of further explaining and confirming my Hypothesis, and thereby too of professing a second time before the World, that

I am with the greatest Respect, Sir,

\section{Your Devoted Humble Seriant}

\section{Rich. Burthogge}

June 13. 1698 

OUTLINE. 



\section{OUTLINE OF BURTHOGGE'S PHILOSOPHY.}

\section{A. THE DOCTRINE OF KNOWLEDGE.}

1.

The Faculties of Knowledge: "Conceptive, Cogitative Faculties" (Essay, Ch. I, Sect. 1, pp. 3-4; cf. Ch. III, Sect. 1, pp. 58-59. Organum, Sects. 3, 10,13).

a. Sense, affected directly by the external thing (Org., Sect. 24; Essay, Ch. III, Sect. 1, p. 60), furnishes the perceptual element. which is the beginning of knowledge (Org., Sects. 6, 24, 32; Essay, Ch. I, Sect. 1, pp. 9-10; Ch. III, Sect. 1, p. 59) :

"I am apt to think that person who should never have seen. nor heard, nor tasted, nor smelt, nor felt any thing, would have his minde as little furnish'd with Idea's or Notions, as his Memory with Images, and would understand as little as he had sensed" (Org., Sect. 74²).

b. Reason, stimulated by sense perception (Org., Sect. 24; Essay. Ch. I, Sect. 1, p. 8), apprehends the "meaning" of the object through the notion (and in no other way) :

“....as the Eye has no Perceivance of things but under Colours.... So the Understanding Apprehends not things.... but under Certain Notions" (Essay, Ch. III, Sect. 1, p. 57, cf. Ch. I, Sect. 1, p. 10; Ch. III, Sect. 1, p. 62, Sect. 2, p. 68)

II.

The Object of Krowledge is

a. Complex, made up of

1. The sense factor (Org., Sects. 63, $74^{2}$; Essay, Ch. I, Sect. ?. pp. 9-10; Soul of the World, p. 10).

2. The notional factor (Org., Sects. 6, 8, 63; Essay, Ch. II, Sect. 1, p. 23; Ch. III, Sect. 1, p. 57 ; Soul of the World, p. 10).

b. Dependent upon mind: no object apart from the knower. 
1. The parts of the object known through sense (i.e., the "sentiments of sense") have no existence apart from the "cogitative powers":

"No such thing as Colour but in the Eye, nor as Sound but in the Ear,.... These, though they seem in the Objects, and without the cogitative Powers, yet are no more in them than the Image that seemeth in the Glass is there indeed" (Org., Sect. 10; cf. Essay, Ch. III, Sect. 1, pp. 57-59).

2. The parts known through the notion, i. e., the notions of things (substance, entity, etc.) and about things (cause. effect, etc.) exist in the mind only:

a) If it be admitted that "sentiments of sense" have no external existence it must be admitted also that notions have none:

1) Notions are dependent upon "sentiments"; "sentiments are grounds to notions" (Org., Sect. 24; Essay, Ch. III, Sect. 1, 60).

2) Notions are themselves "sentiments," i. e., "Intellectual Sentiments"; "Reason... is refined, Sublimated Sensation" (Essay, Ch. I, Sect. 1, p. 10; Ch. III, Sect. 1, p. 62).

b) If notions give only an inadequate knowledge of things (as all admit), they cannot exist in things themselves but only in the mind (Essay, Ch. III, Sect. 1, p. 60).

c. Phenomenal, not real:

"....the immediate Objects of Humane Cogitation.....are Entia Cogitationis, All Appearances; which are not properly .... in the things themselves" (Org., Sect. 10).

"... the immediate Objects of cogitation.... are entia cogitanionis, all Phaenomena; Appearances that do no more exist without our faculties in the things themselves, than the Images that are seen in water, or behind a glass, do really exist in those places where they seem to be" (Essay, Ch. III, Sect. 1, p. 60).

III.

The Thing (or Cause of Knowledge).

a. Real, i. e., independent of mind:

"That which is without the thinking of any one upon it,.... is a real Thing" (Essay, Ch. IV, Sect. 1, p. 78; cf. Sect. 3, p. 90).

b. Virtually Unknown: we have only a very inadequate knowledge of the thing. 
1. Our senses communicate directly with the external object (Org., Sect. 24; Essay, Ch. I, Sect. 1, p. 10; Ch. IV [VI], Sect. 2, p. 138), but do not give even a true copy of it (Org., Sect. 9; Essay, Ch. III, Sect. 1, p. 59; Sect. 2, p. 66).

2. Reason gives us notions of the thing, but these notions are not like the reality itself :

".... few, if any, of the Ideas which we have of things are properly Pictures; our Conceptions of things no more resembling them....than our Words do our Conceptions, for which yet they do stand" (Essay', Ch. III, Sect. 1, p. 56; cf. pp. 59,63 ; Sect. 2 , p. 66 ).

c. Essential to Knowledge: though outside the realm of knowledge the thing directly impressing the organs of sense is the cause of sensation :

"....things without us, are the Causes that do excite.... Images and Notions in us" (Essay, Ch. III, Sect. 2, p. 73; cf. p. 70).

B. THE DOCTRINE OF TRUTH.

2

The Definition of Truth.

a. Negative Statements.

1. Truth cannot be defined as that which corresponds exactly with its original model, for

a) We have not the original with which to compare the copy (Org., Sect. 65) :

1) The original is in the mind of God (Org., Sect. 65).

2) We have no "anticipations," no innate notions, either of God (Org., Sect. 39), or of things (Org., Sect. 73) :

a) If we did have innate notions, knowledge would not be founded, as it is, on impressions and images of sense (Org., Sect. $74^{3}$; cf Essay, Ch. III, Sect. 1, p. 62).

$\beta)$ Although immediate assent to certain principles and immediate action under certain circumstances seem to indicate "innate notions," both assent and action are really due to previous learning (Org., Sect. $74^{2}$; Essay, Ch. IIl, Sect. 1, pp. 53-55). 
$\gamma$ ) "Beings are not to be multiplied without $\mathrm{Ne}$ cessity": there are no original images in the eye or ear and there is no reason for supposing original notions in the mind (Org., Sect. $74^{8}$; Essay, Ch. III, Sect. 1, p. 52).

b) Even if we did have "anticipations" or innate notions they would be "particular" and therefore too narrow a test of truth which is infinite (Org., Sect. $74^{3}$ ).

2. Truth cannot be defined as that which is "congruous" with our faculties, for

a) Congruity between object and faculty gives merely knowledge of the object (Org., Sect. 72).

b) A "falsity" as well as a truth may be congruous with our faculties (Org., Sects. 7, 63).

\section{b. Positive Definitions.}

1. "Truth.... is objective Harmony," i. e., that which is congruous with itself and which fits in with the whole objective scheme of things is true (Org., Sect. 75; cf. Sect. 17).

2. That is true which conforms to the "notion" or "form" of truth which is in the mind, independent of the sensuous percept to which it is applied (Org., Sects. 63, 69, 72, $74^{3}$ ).

II.

The Relation of Truth to Knowledge: knowledge of the object as object precedes knowledge of the object as true, for

a. Knowledge of the object as object follows bare congruity between object and faculty (Org., Sect. 72), while

b. Knowledge of the object as true comes only

1. After the reasoning, i. e., the forming of a judgment, about the object already known (Org., Sects. 7, 56, 82, 83, 86).

2. After the "form" of truth is perceived in the object already apprehended or known (Org., Sects. 63, 68, 69, 72, 74 $4^{3}$ ).

\section{THE DOCTRINE OF SUBSTANCE.}

Note: Burthogge's teaching about substance is inconsistent. He says not only (1) that substance is a notion of the thing (or, as he sometimes phrases it, "a thing conceived under a certain notion"-Essay, Ch. V, Sect. 1, p. 97), in other words, that substance is merely the way we think of reality, but also (2) that substance is the thing itself, the reality about which we have notions. 
I.

\section{Substance as Notion.}

“.... Substance and Accident....; what are they, but likewise Modi concipiendi?....notions, that.... are not without grounds, but yet that have, themselves, no Formal being but only in the Mind, that frames them; there being no such thing in the World as a Substance, or an Accident" (Essay, Ch. III, Sect 1 , p. 64 ; cf. p. 57 ; Sect. 2 , pp. 67,69 ; Ch. V, Sect. 1 , p. 96 ).

x.

Swbstance as Thing.

a. Its Nature:

1. In itself unknown: what substance is itself, "stript of all... Accidents, is no wise known" (Essay, Ch. V, Sect. 1, p. 97. cf. p. 101).

2. Certain facts about it known:

a) That it is subject of accidents :

"All we know of any substance is, that it is the subject of such and such Accidents" (Essay, Ch. V, Sect. 1, p. 97 ; cf. pp. 99,101 ; also Ch. III, Sect. 2, p. 67).

b) That it is self-subsistent :

"...that which is a subject of Accidents [i. e., substance], is it self in no subject; that is, it is self-subsistent" (Essay, Ch. V, Sect. 1, p. 98; cf. p. 102).

Note: Burthogge often implies (Essay, Ch. III, Sect. 1, p. 64 ; Sect. 2 , pp. 70,71 ), and sometimes positively asserts that the "attributes," (1) of being subject of accidents, and (2) of self-subsistence, are only notions; and that we can not say whether substance itself is possessed of these attributes:

"....a substance is nothing but a subject, or a thing that has other things in it as Accidents; whereas in truth, neither Accident, nor Substance hath any being but only in the mind, and by the only vertue of cogitation or thought" (Essay, Ch. III, Sect. 1, p. 65; cf. Ch. V, Sect. 1, p. 98).

c) That it is real, i. e., independent of mind (Essay, Ch. V, Sect. 1, p. 97 ; cf. p. 108).

d) That there are two kinds of substance. (1) Mind and (2) Matter:

"That which is without the thinking of any one upon it.... is a real Thing, or a Reality ;.... and such a thing is matter.... and such a thing also is Mind" 
(Essay, Ch. IV, Sect. 1, p. 78). "Mind .... is Cogitative, thinking.... substance," "Matter is Extensire, spacious, substance" (Essay, Ch. V, Sect. 1, p. 106).

Note: There are passages where Burthogge says that we distinguish two kinds of substance only "notionally," i. e., as phenomena (Essay, Ch. V, Sect. 1 , pp. 106, 107). But this teaching is not inconsistent with his general teaching about substance as thing. Burthogge's meaning seems to be that therc are two kinds of substance, in themselves unknown, but distinguished "notionally," i. e., in our representations of them, as mind and matter (Essay, Ch. IV, Sect. 1, p. 78; Ch. V, Sect. 1, p. 107).

b. Classification and Description of Substance.

1. Principles, "substances that are causes of other things, but are themselves uncaused" (Essay, Ch. V, Sect. 1, p. 101) :

2) Matter: "Passive substance" (Essay, Ch. V, Sect. 1, pp. $103,106)$.

b) Mind: "Active substance" (Essay, Ch. V, Sect. 1, pp. 103, 106) :

1) "Pure Mind", i. e., God (Essay, Ch. V, Sect. 2. pp. 110, 111, 112).

2) Mind in matter:

a) Soul of the World (Essay, Ch. IV [VI], Sect. 3, pp. 149, 150, 154f).

B) Particular Souls (Essay, Ch. IV [VI], Sect. 3, pp. 149, 150, 154f).

2. Principiates, "substances that are caused" (Essay, Ch. V, Sect. 1, p. 101) :

2) Matter (Essay, Ch. V, Sect. 1, pp. 103, 106).

b) Mind (Essay, Ch. V, Sect. 1, pp. 103, 106). 
NOTES. 
The Notes which follow to Burthogge's Organum, ESSAY UPON REASON and SOUL OF THE WORLD, are historical, bibliographical and philosophical in character. The pages referred to by the Notes are those of the original editions (the bracketed numerals of the present edition). The cases in which a given note elucidates not merely one but several passages are shown in the Index. 


\section{NOTES.}

\section{NOTES TO "ORGANUM VETUS \& NOVUM."}

1. (Note to p. 1.) Andrew Trevill to whom the Organum is addressed is undoubtedly Burthogge's father-in-law. In Lyson's Magna Britannia, London, 1814, Vol. III ("containing Cornwall"), p. cxviii, under the head of "Extinct Families," appears the following note: "Treville of Ethy or Tethe in St. Winnow-extinct in the latter part of the seventeenth century. The coheiresses married Burthog, Savery, and Arscot." Furthermore, in both the Organum and in the Taratov (1670, dedicated also to Andrew Trevill), Burthogge signs himself "Your most humble Servant and Son." It is interesting to note that in the year 1651 "Andreus Trevill" was "High Sheriff of Cornwall" (cf. Hitchins, History" of Cornivall, Vol. II, p. 685).

2. (Note to pp. 2 et al.) No criticism of Burthogge's Causa Dei as a whole could have called forth the Organum in reply. The Causa Dei is a long-drawn-out attempt to. show that the everlasting torments to which the wicked are condemned are not inconsistent with God's goodness. (Cf. pp. 12-13 for Burthogge's statement of his aim in writing.) The book is a fair example of Burthogge's theological writings embodying the current views of his day and bearing little resemblance to his more original philosophical works. The criticism to which Burthogge refers may have been 
made upon a short section (pp. 395-407), ${ }^{1}$ more or less incidental to the main purpose of the essay, in which Burthogge discusses the role of reason in conduct. Reason, he says, is an "intellectual Sense," a "Light within" by which we know good and evil, just as white and black are "sensible ones," by which we recognize things as white or black. (Cf. Burthogge's theory that the "form" of truth is an innate notion which we apply to objects to determine whether they are true or false, Organum, Sects. 63, 69, 72, 74.) Reason, unassisted, does not, however, point out "duty." To know duty, the good must be recognized as the "will of a Superior." And the principle which shows it to be the "will of a Superior" is "conscience," which is an instinct.

The fact that the Causa Dei was written in answer to a still earlier essay, Tayatov, 1670 (cf. letter following "The Epistle Dedicatory" in Causa Dei), lends further emphasis to the introductory paragraph of the Organum.

3. (Note to p. 6.) Burthogge can not mean to refer to the Jewish historian as a chronicler of the persecutions of the Christians by the Jews. Josephus mentions the Christians but once throughout his writings, and that in a merely casual manner. (Cf. his so-called "Testimony," Antiquities of the Jews, Bk. XVIII, Ch. III, par. 3, translation by William Whiston; in some of the older translations the chapter divisions differ, and the "Testimony" appears in Ch. IV, par. [2].) Burthogge's reference is evidently merely to Josephus as an historian who "hath left on Record" "what manner of men" the "zealous" Jews were, zealous not in persecuting the Christians but in maintaining their own independence of Roman authority. (Cf. Antiquities and The Jewish Wars.)

4. (Note to p. 13.) In the original this word is misprinted: Uuderstanding.

1 All citations are from the first edition, noted in the Bibliography. pp. $227 \mathrm{ff}$. 
5. (Note to pp. 13 et al.) Burthogge uses the terms "formal" and "objective" in the sense generally accepted in the seventeenth century. The thing itself was said to exist "formally," i. e., independent of mind. Cf. Descartes, Meditations, III and VI; cf. also Fleming's "Vocabulary of Philosophy" (in Krauth's Vocabulary of the Philosophical Sciences, New York, 1878) for a brief history of the use of the term "objective."

6. (Note to pp. 19 et al.) Jacob Behmen, 1575-1624 (variously spelled Behm, Behme and Behmen by his English translators in the seventeenth century). For a clear and sympathetic treatment of the significance of Behmen's teaching as an outgrowth of the Reformation and a forecast of the Quaker movement, cf. R. M. Jones, Spiritual Reformers in the I6th \& I7th Centuries, London, 1914. A complete bibliography of first editions of the works of Behmen will be found on p. xii of the Everyman edition of The Signature of all Things. For a bibliography of English translations cf. Jones, op. cit., p. 213.

Burthogge rightly characterizes the works of Behmen as obscure. In the Aurora (1612) Behmen's first and most widely known work, he frankly admits the unintelligibility of his writings even to himself, when the dictating "Spirit" has left him. "....this work," Behmen says (p. 54 of translation by Sparrow, 1656), "comes not from his [the author's] Reason, but from the impulse of the Spirit," and ".... if the Spirit were withdrawn from me, then I could neither know nor understand my own Writings" (p. 73).

7. (Note to pp. 20 et al.) Robert Flıdd, Oxford, B.A. 1596. M.A. 1598, M.D. 1605 , is perhaps most widely known for his connection with the fraternity of the Rosicrucians. He has been called the "English Rosicrucian." ( $\mathrm{H}$. Jennings, The Rosicrucians, Their Rites and Mysteries, New York, 1879, Ch. 38.) He probably got his first knowledge 
of this fraternity of mystics from his friend Michael Maier who introduced Rosicrucianism into England. (Cf. A. E. Waite, The Real History of the Rosicrucians, New York, 1888, Ch. X.)

On two points, at least, the biographers of Robert Fludd agree, (1) that he was a man of great erudition, but (2) that his writings are. for the most part, so obscure as to be quite unintelligible. Granger says of him (Biographical History of England, London, 1775, Vol. II, pp. 3-4) : “.... a vein of unintelligible enthusiasm runs through his works." In Wood's Athenae Oxonienses, London, 1815, Vol. II. pp. 618-19, we read: ". . . as he [Fludd] wrote by clouding his high matter with dark language.... so he spoke to his patients, amusing them with I know not what, till by his elevated expressions he operated into them a faith-natural, which consequently contributed to the well working of physic." And again Chalmers (General Biographical Dictionary, London, 1814, Vol. XIV) says of him: "He did not begin to publish until 1616, but afterwards became a voluminous writer, being the author of about twenty works, mostly written in Latin, and as dark and mysterious in their language, as in their matter" (p. 418). "All the mysterious and incomprehensible dreams of the Cabbalists and Paracelsians, he compounded into a new mass of absurdity.... he... describes the whole mystery of production and corruption, of regeneration and resurrection, with such vague conceptions and obscure language, as leaves the subject involved in impenetrable darkness" (p. 419).

For an annotated bibliography of Fludd cf. F. Leigh Gardner, A Catalogue Raisonné of Works on the Occult Sciences, Vol. I, "Rosicrucian Books," London, 1903, pp. 23-28. Other bibliographies will be found in (1) Wood, Athenae Oxonienses, Vol. II, p. 619; (2) Dictionary of National Biography, Vol. XIX; (3) A. E. Waite, Real History of the Rosicrucians, New York, 1888, pp. 287-88; (4) H. Jennings, The Rosicrucians, Their Rites and Mys- 
teries, New York, 1879, pp. 363-64; (5) Chalmers, General Biographical Dictionary, London, 1814, Vol. XIV, pp. 418-19.

8. ${ }^{2}$ (Note to p. 20.) Gnosticism (c. 100-300 A. D.) is a form of mystical religion grounded in dualism. The Gnostics believed themselves to be endowed with a peculiar and mysterious sort of knowledge hidden from the uninitiated and imparted to them by special revelation.

Burthogge's knowledge of the "Whims of Basilides, of Valentinus and the Gnosticks" was probably not first-hand. Very little of the writings of the early Gnostics has survived (for an annotated collection of the fragments cf. Hilgenfeld, Ketzergeschichte des Urchristentums, Leipsic, 1884, pp. 195-218). And Burthogge's acquaintance with the Gnostics was made, more probably, through their contemporary opponents: Irenæus, Hippolytus, Clement of Alexandria and Tertullian. There were three early systems of Gnosticism: (1) the Egyptian, (2) the Asiatic, (3) the Syrian. And it is generally conceded that although these early systems arose simultaneously with Christianity their ideas were borrowed from various sources much older, e. g., from Greek philosophy, from Buddhism, from Parseeism and from Jewish-Alexandrine philosophy. It was only later, when Gnosticism was declining and could find nothing in the older philosophies to bridge the gap between spirit and matter, that it incorporated Christian beliefs in order "to bolster up a crumbling fabric." Gnosticism began to wane in the second half of the third century running more and more into mysticism.

Basilides and Valentinus were both leaders in the early Egyptian school of Gnostics. Basilides, born in Alexandria, was the founder of that form of Gnosticism known as the "Abraxas" religion, based, as all forms of Gnosticism were, upon a fundamental dualism. For an exposition of the

2 Notes 8 and 21, in part, and Notes 14, 17, 23, 27 and 42, entire, were written by Professor Calkins. 


\section{I92 PHILOSOPHICAL WRITINGS OF BURTHOGGE.}

teaching of Basilides cf. Mansel, Gnostic Heresies of the First and Second Centuries, London, 1875, Ch. X, and for a shorter statement of his theory of the creation of the world cf. Kramer, Sources of Gnosticism. Princeton, 1896, pp. 8-10, also Irenæus's summary in C. W. King, The Gnostics and Their Remains, London, 1864, pp. 34-35. Basilides died about 133 A.D. He published twenty-four volumes of "Interpretations upon the Gospels," besides "Odes" and "Spiritual Songs."

Valentinus, born also at Alexandria, but of Jewish origin. followed Basilides and elaborated his system of emanation. Of the two, Valentinus was the more prominent leader of the Gnostic movement. $\mathrm{He}$ was the founder of a great number of subordinate schools. For a statement of the system of Valentinus cf. Mansel, op. cit., Chs. XI and XII. Valentinus died in $158 \mathrm{~A} . \mathrm{D}$.

9. (Note to pp. 20 et al.) The religious sect known as the "Familists" or "Family of Love" was founded about the middle of the sixteenth century, by Henry Nicholas (or Niclaes, fl. 1502-80), and was in existence as late as the opening of the eighteenth century. The teaching of these mystics is closely allied to that of their successors the Quakers. Many of the doctrines generally supposed to have originated with the Quakers were probably borrowed from the "Familists." The central idea in the teaching of Nicholas, called by Henry More "the begodded man of Amsterdam." is that real righteousness is reached not through conformity to any external law or ceremony, but through the attainment of a spiritual union with God, a union in which the man becomes "godded." For an excellent sketch of the life of Henry Nicholas, "Father of the Familists," cf. the Dictionary of National Biography. A bibliography of his works (all written originally in Low German) will be found there also. For an exposition of the teaching of Nicholas. with quotations from his writings, cf. R. M. Jones. Studies 
in Mystical Religion, London, 1909, Ch. 18. The names of the various contemporary opponents and an account of the charges which they brought against the "Family of Love" will be found on pp. $442-48$ of the same book.

10." (Note to p. 20.) The terms "demoniacal" and "complexional" are very common terms for types of enthusiasm. by which is meant the claim to direct divine guidance. I give one illustration from Cornelius Agrippa's Occult Philosophy which was translated into English in 1651. Agrippa says, in speaking of "enthusiasm": "Melancholy men, by reason of their earnestness, do far better conjecture, and quickly conceive a habit, and most easily receive an impression of the celestials. And he [Aristotle] in his Problems saith that the Sibyls, and the Bacchides, and Niceratus the Syracusan and Ammon, were, by their natural melancholy complexion, prophets and poets. The cause, therefore, of this madness, if it be anything within the body, is a melancholy humor; not that which they call black choler, which is so obstinate and terrible a thing, that the violence of it is said, by physicians and natural philosophers (besides madness which it doth induce), to draw or entice evil spirits to seize upon men's bodies" (p. 186).

I have also run across the following passage in Holland's translation of Plutarch's Morals (1603): "The Daemons use to make their Prophets and Prophetesses to be ravished with an enthusiasm or divine fury."

A great number of writers who followed Paracelsus used "complexions" for combinations of the so-called four "humors," the "choleric," "phlegmatic," "sanguine" and "melancholic." Dreams and revelations of one sort and another were believed by these writers to be the result very often of "complexions," or, as we should say to-day, of emotional conditions. From the time of the Renaissance it

3 Extract from a letter from Prof. R. M. Jones, of Haverford College, to Miss Calkins. 
was customary either (1) to treat "enthusiasm" as an invasion by a good or bad spirit, or (2) to consider it to be a result of "temperature" or "tincture" or "complexion," these being various terms which cover pretty much what we mean by a psychical or emotional condition of the subject. Abundant illustrations can be found in the writings, for instance, of the English Platonists, especially in those of Henry More.

11.4 (Note to p. 21.) It is extremely difficult to be absolutely sure about the "upstart sect." There are three sects to which Burthogge might be referring: the Quakers, the Behmenists and the Muggletonians. I feel very sure that he is referring to the Quakers. They were far and away the most numerous and they had aroused far greater interest and comment than any other "upstart sect" of the time. There were probably thirty thousand Quakers in England at the time this tract was written and they had made very sweeping claims to the possession of the direction of the Spirit. The Muggletonians came into notice about 1652 and claimed to have a wholly fresh and new revelation from God. They were, however, always few in number and are not nearly as likely to be meant as are the Quakers. I hardly think Burthogge can be referring to the Behmenists, though they, too, claimed to have full guidance of the Spirit, and they were striking examples of "enthusiasm." The "Familists" and the "Seekers" had so greatly waned in numbers and in influence by 1675 that they, I think, are eliminated.

12.5 (Note to p. 21.) Despite the vast amount which has been written in praise and in disparagement of Paracelsus, the famous iatrochemist and physician (1493-1541), the facts definitely known regarding his life are few. He was

4 Extract from a letter from Prof. R. M. Jones to Miss Calkins.

- For this Note the editor is indebted to Dr. Charlotte Fitch Roberts, late professor of chemistry at Wellesley College. 
born at Einsiedein in Switzerland, led for the most part a wandering life, though he was settled for about three years at Basel as city physician and lecturer in the University; and he died in Salzburg. His constant attempts at reforms and innovations brought him many enemies. "That you other physicians are angry," Paracelsus writes (in the Preface of Das Buch Paragranum), "because I write differently' from your books, is something which depends upon your unreasonableness, not mine. No one cries out who is not wounded, and no one is wounded who is not vulnerable. The art of medicine does not cry out against me, for it is invulnerable and immortal." Though ranked as an alchemist, his principal work in the development of chemistry consisted in turning away attention from the attempt to prepare gold and silver, and in applying chemistry to medicine, thus founding the school of iatrochemists. As a physician, many brilliant cures were attributed to him in his lifetime, but his claim to recognition now lies not so much in the contribution of new discoveries as in the introduction of the empirical method in the study and practice of medicine. "All things," he writes, "are possible to science" (De Natura Rerum, Huser edition, Basel, 1589-90). He did a real service to the advancement of science in general by his emphasis on investigation and on independence in work. This idea of independence is brought out in the motto which he adopted for himself, which appears in connection with many of his portraits: "Alterius non sit qui suus esse potest." Another favorite saying which recurs in many forms in his writings is: "Lehren und nicht tun, das ist klein; lehren und tun, das ist gross und ganz." Again, he writes: "At the basis of a good physician is fidelity-not halved nor divided. For, as little as the truth of God can be divided or limited, so also is it with fidelity" (Paramirum, Strassburg folio edition, 1616-18).

$A$ vast number of writings on many and varied subjects are extant which have been published under the name of 
I96 PHILOSOPIICAL WRITINGS OF BURTHOGGE.

Paracelsus, but in many cases the books were published after his death and are of doubtful authenticity.

13. (Note to p. 21.) Jean Baptiste van Helmont (15771644), was a Belgian chemist and physician and a disciple of Paracelsus, although he repudiates some of his master's teachings. (Cf., e. g., his "Nativity of Tartar in Wine," tr. by Charleton in A Ternary of Paradoxes, etc., London, 1650, Sects. 1, 13, 15: and Oriatrike, tr. by Chandler, London, 1662. Ch. 115, on "The Arcanums or Secrets of Paracelsus.") Helmont was a curious paradox, both mystic and scientist. He was "a careful observer of nature and an exact experimenter who in some cases realized that matter can neither be created nor destroyed," yet at the same time he resorts to supernatural agencies in solving his physiological problems. His works were collected by his son and published at Amsterdam, in 1668, under the title of Ortus Medicinae. For the facts of his life cf. Encyclopadia Britannica, 11th ed., also the Catholic Encyclopadia. A bibliography of French and German works on Helmont will be found in the former. For English translations cf. Charleton, op. cit., and Chandler, op. cit.

14. (Note to pp. 24 et al.) Burthogge's "Light of Nature" is only roughly parallel to Descartes's. For Descartes does not make the contrast between the "Light of Revelation" and the "Light of Nature," whereas he distinguishes the "natural light"-by which he means self-evident truth (cf. Meditations, III, par. [3]) - from "natural impulse" which he describes as "only a certain spontaneous impetus that impels me to believe in a resemblance between ideas and their objects, not a natural light that affords a knowledge of its truth" (ibid., par. [9]). Natural light, not natural impulse. is described by Descartes as "clear and distinct perception." 
15. (Note to p. 32.) The gods of Epicurus were "unknown" in the sense of being unrevealed, which is apparently Burthogge's meaning. In a region of perpetual calm and serenity, in the space between the worlds, they lived in perfect happiness, aloof from men, and "not concerned, nor concerning themselves with things below them." These gods resembled men, but were immortal and of a superior nature. Like men they feasted and conversed together. And their bodies were of human form, though of a more ethereal substance. They required food (of a kind suited to their bodies), but no sleep.

This conception of the gods was a result of Epicurus's attempt to prove the absurdity of the two opposing views -alike intolerable to him-which were current at the time. (1) the theory of divine interference, and (2) that of Stoic fatalism. According to his conception of the gods, both views become impossible. The gods cared nothing for men and their affairs, and were content to let them guide the course of nature as well as their own fortunes. For a statement of the theology of Epicurus cf. Wm. Wallace. Epicureanism, London, 1880, Ch. IX; E. Zeller, Stoics, Epicureans and Sceptics, tr. by O. J. Reichel, London, 1892, Ch. XVIII ; and R. D. Hicks, Stoic and Epicurean. New York, 1910, Ch. VII.

16. (Note to p. 33.) It is interesting to note that the conception of God as unknown is, in the view of Hobbes. the natural outcome of a materialistic system (cf. Leviathan. Pt. I, Chs. XI and XII; Pt. II, Ch. XXXI: Pt. III, Ch. XXXIV). Hobbes conceived of the whole universe as "corporeal substance." On this materialistic view of the universe, God (if he exist at all) must be either "corporeal" or unknown. Unwilling to deny $\mathrm{His}$ existence, but unwilling also to make Him merely a part of the material universe, Hobbes makes God the unknown "cause." To this unknown God, he teaches, we apply the attributes of cor- 
poreal substance, as well as the "indefinite" attributes: "good," "just," "holy." (Cf. Leviathan, Pt. II, Ch. XXXI.) But what He really is in Himself we do not know. The doctrine of an unknown God is the natural development of Burthogge's doctrine of knowledge. If our knowledge of the material world is subjective, that is, if we can know objects only as they exist in the mind, and never as things in themselves outside of the mind, how much more true must it be that we can know God only "as $\mathrm{He}$ stands in our Analogy," and not "as He is in Himself." It is inconceivable that our "Notions" which are inadequate for knowledge of things, should be adequate for a knowledge of God.

17. (Note to p. 40.) Prof. Arthur O. Lovejoy has pointed out ${ }^{8}$ that this is the earliest use of an argument best known in the form which Kant gave it in his Second Antinomy. From the opposition between the "common Notion" of Quantity and "the composition of the Continuum," Burthogge argues that quantity is a "Phenomenon" or "Appearance," not a "Reality." For Arthur Collier's use of the same argument cf. his Clavis Universalis, p. 63 of the Open Court edition, edited by Ethel Bowman, and also A. O. Lovejoy in his essay "Kant and the English Platonists" (in Essays Philosophical and Psychological in Honor of William James, New York, 1908).

18. (Note to p. 43.) For an analysis of Aristotle's logic and the history of its use cf. Ueberweg, System der Logik, Bonn, 1857, par. 16; Brandis, Handbuch der Geschichte der griechisch-römischen Philosophie, Berlin, Vol. II, Pt. II (1853), Sect. III, pp. 148ff; Zeller, Die Philosophie der Griechen, Leipsic, Vol. II, Pt. II (3d ed., 1879), pp. 67ff; Prantl, Geschichte der Logik im Abendlande, Leipsic, Vol. I (1855), Sect. IV ; Vol. II (1861). Sects. XIII-XIV : Vol. III (1867), Sect. XVII.

- In a private letter. 
19. (Note to p. 48.) Burthogge refers here to Cicero's discussion, in the second book of his Academica (inscribed Lucullus in the first edition), of the role of sense-perception in knowledge. The chief characters in the dialogue are Lucullus and Cicero himself. Cicero, as spokesman of the Academy, upholds the view that the senses are wholly untrustworthy, and offers in support of his position the old illustration of the oar in water and the colors on a pigeon's neck. Lucullus, on the other hand, while he admits that the senses can not under all circumstances be trusted, holds that there is the "very greatest truth in the senses, if they are in sound and healthy order, and if everything is removed which could impede or hinder them." Or, as Burthogge interprets Lucullus, not everything that is perceived through sense is true, but only that which is clearly and distinctly perceived.

20. (Note to p. 52.) Edward, Lord Herbert of Cherbury (1583-1648) was the author of the first purely metaphysical treatise written by an Englishman. The De Veritate (published first in Latin, Paris, 1624. England, 1633, and in French translation 1639, and criticized by Locke in his Essay, Bk. I, Ch. III, pars. 15-19), is his most important philosophical work, embodying not only a methodology for the investigation of truth, but a theory of knowledge and a scheme of natural religion as well. Truth, according to Lord Herbert, is the agreement between faculty and object. For every object in the world there is a corresponding faculty in the mind. And each faculty reacts only to its own object. The faculties of the mind, though infinite in number, may be reduced to four general classes: (1) natural instinct: (2) internal sense or conscience, by which good and evil are distinguished; (3) external sense; (4) reason. Of these four, "natural instinct" is the most reliable and reason the least reliable in determining truth. (Cf. Spinoza's theory of truth. Ethics, Pt. II. According to Spinoza, the true idea is the 
idea which "agrees with its ideal" or "is adequate." And of the three types of knowledge, opinion, reason and intuition, only the last two are efficacious in determining true ideas. Prop. XL, Note II,--Prop. XLIII.)

For the facts of his life and for an introduction to Lord Herbert, the gallant English nobleman, soldier and diplomatist, the reader is referred to his autobiography. In his own opinion his contributions to literature and philosophy, his only real claim to fame, were merely incidental to a career filled with valiant deeds and hairbreadth escapes. Bibliographies of his historical and philosophical works will be found in the Encyclopadia Britannica, 11th ed., and in the Dictionary of National Biography.

21. (Note to p. 55.) Burthogge here, of course, refers to the theory, then current, of innate ideas-the theory so sharply criticized twelve years later by Locke. (Cf. Essay, Bk. I; also p. xxiii of this book.) It is interesting to note that Burthogge, though he implies that the doctrine of innate ideas arose from a conviction that we have certain universal concepts which we could not have got through the senses, had another account also, of their origin. The theory of innate ideas, he suggests, was the invention of those who, while admitting the fallibility of the senses, were yet unwilling to deny the possibility of knowledge. Innate ideas were thus hit upon as the deus ex machina, to be relied upon to lend assistance to knowledge on all occasions where the senses proved incompetent.

22. (Note to p. 55.) Modern scholars have decided that the author of the Celestial Hierarchy is not Dionysius the convert of Paul, but a pseudo-Dionysius writing in the fourth or fifth century. (For arguments against this view cf. Parker, The Celestial and Ecclesiastical Hierarchy of Dionysius, the Areopagite, London, 1894, Introduction.) The works of the pseudo-Areopagite (four in all: Celestial Hier- 
archy, Ecclesiastical Hierarchy, Divinc Names and Mystic Theology) were probably not known in the East until 533 A. D., and in the West they were not known, to any extent, until the ninth century when Erigena made a Latin translation of them. Borrowing from Judaism, from Christianity and from Oriental philosophy, but chiefly from neoPlatonic philosophy, Dionysius combined his material into a system which had an enormous influence not only on the philosophy but on the art and literature of the Middle Ages as well. In poetry his influence is seen in Dante, in Spenser and in Milton; in philosophy, in the works of Albertus Magnus and Thomas Aquinas. Indeed, so faithfully did Aquinas reproduce the Dionysian conceptions that it has been said that if the writings of Dionysius had been lost "they could be almost reconstructed from the works of Aquinas." A good summary of Dionysius's conception of the threefold hierarchy of celestial beings through whom man rises to a mystic experience of God, and a statement of the place of Dionysius in the history of medieval thought, will be found in R. M. Jones, Studies in Mystical Religion, London, 1909. Ch. VI. Cf. H. O. Taylor, Classical Heritage of the Middle Ages, New York, 1911. For an English translation of the Celestial Hierarchy and the Ecclesiastical Hierarchy cf. Parker, op. cit.

23. (Note to p. 57.) Evidently Burthogge here refers to Locke; and Locke (Essay, Bk. II, Ch. XXVII) defines an animal as a "living organized body" (loc. cit., par. 8); teaches that "the same successive body must, as well as the same immaterial spirit, go to the making of the same man" (ibid.) ; and, finally, contrasts both spirit (or soul) and man with person (or self) which he conceives as "a thinking intelligent being, that....can consider itself as itself" (ibid., par. 9).

24. (Note to p. 62.) Claudius Galen (130-200 A.D.), the greatest of the ancient medical writers, was born at 
Pergamus, in Mysia. At the age of sixteen he began to study medicine and later studied at Smyrna under the anatomist and physician Pelops. About 160 he went to Rome where he gained great reputation for his learning and success in the medical profession. During the years of a later visit to Rome, at the invitation of the emperor Marcus Aurelius, Galen greatly extended his already wide reputation as a physician and wrote at this time most of his important works. $\mathrm{He}$ is said to have written nearly five hundred treatises on various subjects, including not only medicine, but logic, ethics and grammar as well. Of the original works on logic, only one remains: the treatise on "Fallacies in dictione." Many points of logical theory are discussed, however, in his medical and scientific writings. A brief statement of the logical theories of Galen will be found in Prantl, Geschichte der Logik, Vol. I, pp. 559-77. Down to the seventeenth century the Arabian physicians. and the European through the Arabian, borrowed largely from Galen. And most of the descriptive terms in physiology, pathology and anatomy, now in use, were employed by Galen in the sense in which they are now employed by modern authors. Burthogge's reference is evidently to Galen's seventeen books De Usu Partium Corporis Humani (cf. Opera Omnia, ed. by D. Carolus Gottlob Kühn, Leipsic. Vols. III-IV, 1822). For a bibliography of the various translations and editions of Galen's works and critical works about them cf. Encyclopadia Britannica.

25. (Note to p. 64.) In the original this word is misprinted: enqure.

\section{NOTES TO "ESSAY UPON REASON."}

26. (Note to p. 6.) The quotation is from the passage (De Natura Deorum, I, 29, 80) on facial distinctions among the gods: "Ecquos si non tam strabones, at paetulos esse 
arbitramur? ecquos naevum habere? ecquos silos, flaccos, frontones, capitones ; quae sunt in nobis? an omnia emendata in illis? Detur id vobis. Num etiam una est omnium facies? nam, si plures, aliam esse alia pulchriorem necesse est: igitur aliquis non pulcherrumus deus. Si una omnium facies est, florere in coelo Academiam necesse est. Si enim nihil inter deum et deum differt, nulla est apud deos cognitio, nulla perceptio."

27. (Note to p. 6.) Cf. Meditations, II, end: “.... it is now manifest to me that bodies themselves are not properly perceived by the senses nor by the faculty of the imagination. but by the intellect alone."

28. (Note to p. 6.) Honoratus, or Honoré, Fabri, S. J. (1607-88), was a French writer and teacher. For fourteen years he taught philosophy at the Collège de la Trinité at Lyons. He was later called to Rome as grand pénitencier, and died there. The works of Fabri, many of which were written pseudonymously (under at least six different pseudonyms), include treatises on mathematics, logic and medicine, as well as on philosophy. Fabri has been called "the pleader of lost causes." He is recognized as a great worker but one whose loud promises were seldom fulfilled, and one whose writings have to-day not even an historical significance. A bibliography of his works and an account of his life will be found in Michaud's Biographie universelle: also in Jöcher's Allgemeines Gelehrten-Lexicon.

29. (Note to p. 37.) The quotation is from the Leviathan. Pt. I, Ch. IV, and reads: “.... words are wise men's counter's, they do but reckon by them : but they are the money of fools, that value them by the authority of an Aristotle, a Cicero, or a Thomas, or any other doctor whatsoever, if but a man." (Cf. Concerning Body. Pt. I. Ch. II, "Of Names.") 
30. (Note to p. 57.) In the original this word is misprinted: Enity.

31. (Note to p. 62.) The quotation is from the Academica, II, 10, 30. The chief speakers in the dialogue are Lucullus and Cicero; the subject under discussion is sense. Lucullus has argued against the untrustworthiness of the senses, but for the sake of continuing the discussion, he grants to the Academicians the invalidity of sense in reference to knowledge and turns to a consideration of sense in relation to the affections, desires and thought: "Sed disputari poterat subtiliter, quanto quasi artificio natura fabricata esset primum animal omne, deinde hominem maxime, quae vis esset in sensibus, quem ad modum primo visa nos pellerent, deinde adpetitio ab his pulsa sequeretur, tum ut sensus ad res percipiendas intenderemus. Mens enim ipsa, quae sensuum fons est atque etiam ipsa sensus est. naturalem vim habet, quam intendit ad ea, quibus movetur."

32. (Note to p. 68.) In the original this word is misprinted: perceptlon.

33. (Note to p. 71.) This seems to be Burthogge's only suggestion, in any of his philosophical writings, of the fact that he was a physician.

34. (Note to p. 74.) For Plato's allegory of the cave see Republic, Bk. VII, 514-18.

35. (Note to p. 91.) In the original this section is wrongly numbered II.

36. (Note to pp. 94 et al.) Up to this point Burthogge has referred to external reality simply as "the Thing" or "things without us," or as "grounds" or "cause" of sensations (cf. Essay, Ch. III, Sect. 2, pp. 73-75). Here, how- 
ever, in discussing this reality not primarily in its relation to knowledge but in and for itself, he names it substance. Burthogge's conception of substance is Lockian rather than Spinozistic. Self-subsistence, the essential character of Spinoza's substance, is, according to Burthogge, not fundamental, since it is involved in or derived from the main character of being "subject of accidents." Burthogge agrees with Locke in holding that substance is primarily the unknown substratum of sense-phenomena, "a supposed I know not what to support those ideas we call accidents." (Cf. Locke's Essay, Bk. II, Ch. XXIII.) The idea of substance is then according to both, a "Relative Idea" only. Substance is known only as that which is related to its accidents. What it is absolutely and apart from those accidents can never be known. (Cf. Notes 41 and 44.)

37. (Note to p. 103.) The quotation reads more fully. "Nempe universa ex materia et ex Deo constant: Deus ista temperat, quae circumfusa rectorem sequuntur, et ducem. Potentius autem est ac pretiosius est quod facit, quod est Deus, quam materia, patiens Dei. Quem in hoc mundo locum Deus obtinet, hunc in homine animus: quod est illic materia, id nobis corpus est."

From Plato directly, but not improbably from Seneca's borrowed Platonic conceptions as well, Burthogge derives his conception of God as "pure mind," a substance utterly different from matter. Burthogge does not, however (as he himself points out, p. 112), follow Seneca in identifying God with the Soul of the World.

38. (Note to pp. 103-04.) The quotation is from the Lives of the Philosophers of Diogenes Laertius, Bk. VII,

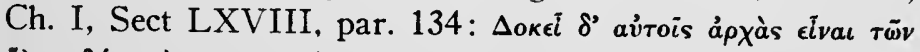

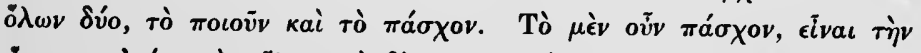

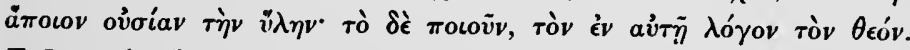

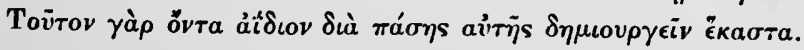


39. (Note to p. 107.) Descartes does not, any more than Burthogge, identify cogitation with mind, or extension with matter. He merely holds, with Burthogge, that thinking is the principal attribute of mind, and extension that of matter. (Cf. Descartes, Principles of Philosophy, Pt. I, LII-LIV.)

40. (Note to p. 108.) Burthogge probably had Hobbes in mind, for the polemics of the seventeenth-century idealists in England were almost sure to be hurled at Hobbes. A genuine passion for the revival of the study of Plato was. to be sure, the primary factor in the origin of the Cambridge movement. But the desire to refute Hobbes certainly furnished an added impetus, without which the writings of the Platonists would have lacked definite purpose. (Cf. Culverwel, Discourse of the Light of Nature, and Smith, Select Discourses.)

Cudworth, and More only less violently, attacked the "atheistic arguments" of Hobbes against the existence of "spiritual substance." Although the materialism against which Cudworth argues is the "atomic" materialism of the ancient philosophers, Democritus and Epicurus, he has in mind constantly his contemporary Hobbes. He scorns even to mention his name, referring to him simply as "a modern writer," or "a late writer," and sometimes as "a late pretender to Politics" and "the author of the Leviathan," who has outdone his masters in the "sottishness" and "impudence" of his atheism. The fury of the Platonists against Hobbes is easily understood. The denial of the existence of spiritual substance was a teaching long made familiar to them through the "Democritic and Epicurean Atheists," whose arguments, based on the "atomic" theory, appeared to them futile and antiquated. But the denial of the soul's existence on the ground that it can not be perceived by sense was a new and startling teaching, and one which to the Platonists was simply exasperating. Sense, according to them, never could be the criterion of any truth, and least of 
all of spiritual truth, yet here was "a modern atheistic writer" boldly asserting that we must deny the existence of "spiritual substance" because we can not perceive it through sense.

For the attitude of the Cambridge Platonists toward Hobbes cf. Cudworth, True Intellectual System of the Universe, Ch. V, "A Confutation of Atheism." and More. Af Collection of Several Philosophical Writings, esp. Immortality of the Soul. Cf. also Tulloch. Rational Theology and Christian Philosophy in England in the Seventeenth Century, London, 1874. Vol. II.

41. (Note to p. 109.) Whether or not Spinoza's definition of the human mind as the "idea of a thing actually existing" (cf. Ethics, Pt. II. Prop. XI) be accepted, it must be admitted that it is consistent with his system as a whole. As thought and extension are but two attributes of one substance, God, so the human mind and body are but two aspects of a single individual. The statement that the mind is the "idea of the body" means to Spinoza not only that it is the idea coexistent with the body. but also that it is the idea whose object is the body. (Cf. Ethics, Pt. II. Prop. XXI. Note: also Prop. XV, Proof.)

42. (Note to pp. 109 et al.) Malebranche teaches that we know God immediately: that we know ourselves "through internal sense." and other selves, as well as "pure intelligences," through "conjecture" (Recherche de la vérité, Bk. III, Pt. II, Ch. VII) ; and, finally, that we have ideas of things "in God," i. e., that God by his will continually furnishes us with ideas of things. Yet Malebranche, though he can not argue with Descartes that an extended material world exists in order to explain our perception, none the less holds that an extended material world exists. He therefore protests against the identification of his teaching with that of Spinoza. who makes the material world, with all its "dés. 
ordre," an aspect of the infinitely perfect Being, God. (Cf. Entretiens sur la métaphysique, IX, Sect. II ; also Euvres. ed. by Simon, Vol. I, Introd., pp. 33f.)

43. (Note to pp. 112 et al.) The first quotation is from Naturales Quaestiones, I. Praefatio: "Quid est Deus? Mens universi. Quid est Deus? Quod vides totum, et quod non vides totum. Si demum magnitudo sua illi redditur, qua nihil majus excogitari potest, si solus est omnia, opus suum et extra et intra tenet. Quid ergo interest inter naturam Dei et nostram? Nostri melior pars animus est : in illo nulla pars extra animum. Totus ratio est...."

The second quotation, from Ep. 65, reads: "Sed nos nunc primam et generalem causam quaerimus: haec simplex esse debet: nam et materia simplex est. Quaerimus, quae sit causa, ratio scilicet faciens : ista enim, quaecumque retulistis. non sunt multae et singulae causae, sed ex una pendent, ex ea quae faciet."

Burthogge agrees with Seneca in holding that God is not only necessary cause of the universe but efficient cause as well. He denies, however, Seneca's teaching that God is immanent cause. The Soul of the World, he admits, may be the immanent cause, but God must be the transcendant cause of the universe. (Cf. Note 37.)

44. (Note to pp. 116 et al.) At least three conceptions of the nature of substance were current in the seventeenth century. These conceptions are not mutually exclusive, and as a matter of fact two of the three are found in the teaching of most of the seventeenth-century philosophers. The first is that which holds substance to be the self-dependent. This conception is suggested, but not logically carried out, by Descartes. (Cf. Principles of Philosophy. Pt. I, LI : cf. also Hobbes's definition of substance as "any thing that has existence or subsistence in itself..... in which sense God is properly.... substance....having subsistence 
not only in himself, but from himself," in "An answer to Bishop Bramhall," Works, Molesworth edition, Vol. IV, p. 308.) This doctrine is consistently developed by Spinoza (Ethics, Pt. I, Defs. III and VI, and Props. XIV and XV). The second conception is that taught by Locke, according to which substance is the unknown, "a supposed I know not what, to support those ideas we call accidents" (Essay, Bk. II, Ch. XXIII, par. 15). According to the third conception. substance is that which is subject of accidents. This last view was the most wide-spread of the three. It was held by Descartes and by Locke, as well as by the Cambridge Platonists. The Cambridge Platonists, to be sure, do not define substance as the subject of accidents, but their characterization of the different kinds of substance implies this conception. Spinoza and Locke also hold that substance is the subject of accidents, though neither regards this as the fundamental character of substance. (Cf. Burthogge's teaching about the nature of substance, Note 36. )

As regards the kinds of substance and the characters which differentiate them, there are again three doctrines which were current in the seventeenth century. By far the most common was the dualistic. Descartes, Locke and the Cambridge Platonists hold that there are two kinds of substance: (1) spiritual, and (2) corporeal. According both to Descartes and to Locke, the chief attribute of spiritual substance is thought, but Locke also regards "a power of action" as one of the "primary qualities or properties of spirit” (Essay, Bk. II, Ch. XXIII, par. 30). The attribute which distinguishes corporeal substance is extension, to which Locke adds solidity, and the "power of being moved" (op. cit., Ch. XXIII, par. 15). More teaches that all substance is extended. but distinguishes between corporeal and spiritual substance by characterizing the first as "impenetrable" and "discerpible," the second as "penetrable" and "indiscerpible" (cf. Note 46). Cudworth regards "Life, Cogitation and Understanding" as the "Peculiar Attributes 
and Charackteristicks of Substance Incorporeal," as contrasted with "Sensless Matter" (True Intellectual System of the Universe, Bk. I, Ch. III, Sect. XXXV, pp. 145f). Hobbes holds a materialistic view of substance. All substance, he teaches, is corporeal; substance is synonymous with body; to speak of incorporeal substance is meaningless. Spinoza, finally, holds an absolutistic view of substance. Substance, as he conceives it, is one.' but can not be identified either with mind or with body. Extension and thought are, he teaches, but two "attributes" or aspects of a single fundamental substance which he calls God (Ethics, Pt. I, Props. $\mathrm{XIV}$ and $\mathrm{XV}$ ).

45. (Note to pp. 117-18.) The reference is to Cicero's De Natura Deorum, II, 32, 82. Lucilius concludes his résumé of the various views held about nature, with that of Epicurus. "Sunt attem," he says, "qui omnia naturae nomine appellent, ut Epicurus; qui ita dividet, omnium, quae sint, naturam, esse corpora et inane quaeque his accidant."

46. (Note to p. 119.) For More's doctrine of substance cf. especially Epistola Prima H. Mori ad R. Cartesium, also Immortality of the Soul, Bk. I, Ch. 2, Axiomes VIII-IX. All substance, More held, whether corporeal or incorporeal, is possessed of two characters: (1) extension, and (2) motion. To deny that substance is extended is to deny, he said, that it exists. Incorporeal substance, however, while sharing with corporeal substance the attribute of extension, is distinguished from it by being "penetrable" and "indiscerpible." Corporeal substance, he held, is "impenetrable and "discerpible." It is not unlikely that the Platonists as a whole (though none but More includes this teaching in his writings) held that incorporeal substance is extended. It was the common belief in the seventeenth century that spirits have bodies, extended but of a more ethereal nature than human bodies. Burthogge's criticism that to hold that 
NUIKS rO "OF THE SOUL OF THE WORLD." 2 I I

incorporeal substance is extended is to make it either a "vacuum" or "matter," could thus have been easily met, in More's opinion. (Cf. Notes 36 and 44.)

47. (Note to p. 123.) It will be noted that this, the sixth chapter, is wrongly numbered.

\section{NOTES TO "OF THE SOUL OF THE WORLD."}

48. (Note to title-page.) The quotation is made from the Octavius of Felix Marcus Minucius, one of the earliest Christian apologists. The dialogue, which seems to be modeled on Cicero's De Natura Dcorum, dates back to the second or third century A. D. It first appeared in the Adversus Gentes of Arnobius. The quoted words are supposedly spoken by the Christian Octavius who accuses pagan writers of corrupting youth by fictitious tales of the origin of the Greek gods. The passage reads: "His atque hujus modi figmentis, et mendaciis dulcioribus corrumpuntur ingenia puerorum et hisdem fabulis in haerentibus, adusque summae aetatis robur adolescunt et in iisdem opinionibus miseri consenescunt: cum sit veritas obvia sed requirentibus" (Arnobii Disputationum adversus Gentes Libri Septem: M. Minucii Felicis Octavius, Paris, 1595, p. 353; cf. Octavius, ed. by A. Baehrens, Ch. 23, par. 8).

49. (Note to title-page.) The quotation is from Erasmus's "Hyperaspistes Diatribae adversus servum Martinii Lutheri," Lib. II. (Cf. Opera Omnia, Leyden, 1706, Vol. X. p. 1531.) "Et si poterat Augustinus," he says, "per vim liberi arbitrii audire concionantem Ambrosium, legere libros sacros, erogare stipem in pauperes, vacare precibus ac meditationibus, confabulari cum piis hominibus, eosque rogare ut Domino salutem ipsius suis precibus commendarent, quid 
est cur sic exsibiletur opinio Scholasticorum, quae tradit hominem per opera moraliter bona promereri de congruo gratiam justificantem? Verborum umbris territamur, cum in re nihil sit absurdi."

50. (Note to p. 4.) John Keill (1671-1721) was a mathematician and astronomer, noted mainly for his exposition of the Newtonian principles and for his opposition to the theory of "natural philosophy" upheld by Whiston and Burnet. Keill received the M.A. degree, with "distinction in mathematics and natural philosophy." from the University of Edinburgh and in 1694 was "incorporated M.A." at Oxford. Here he at once distinguished himself by his lectures on Newton's Principia. His Examination of $\mathrm{Dr}$. Burnet's Theory of the Earth, published 1698 (cf. Note 51), increased his reputation, although the seriousness with which he opposes the "Theory," using long trigonometrical proofs to overthrow some fanciful detail of the "Hypothesis," appears to the modern reader ridiculous. Burthogge's protest against Keill's presentation (in the Introduction of his Examination) of Burthogge's Soul-of-the-World theory seems rather ill-founded. Keill's account, so far as it goes, is accurate, and Burthogge himself, in presenting his theory anew. finds the metaphor of the "vast Organ" illuminating. In 1701 Keill's Introductio ad Veram Phy'sicam, considered at that time his "best performance," was published. In 1712 he was elected Savilian Professor of Astronomy at Oxford. and in 1713 the degree of D.M. was conferred on him by the University. The later years of his life were occupied mainly in a defense (begun in 1705) of Newton as inventor of fluxional calculus against the claims of Leibniz. For a more detailed account of Keill's life. cf. Dictionary of $\mathrm{Na}$ tional Biography. An interesting, though brief. estimate of his personal character will be found in Thomas Hearne's Remarks and Collections, edited by C. E. Doble, Oxford, 1885, Vol. VII. p. 273. (Cf. also scattered references ibid., 
NOTES TO “OF THE SOUL OF THE WORLD.”. 213

Vols. I-VI.) For a bibliography of Keill's works cf. the British Museum Catalogue.

51. (Note to p. 4.) Thomas Burnet (1635?-1715) was an English divine educated at Northallerton and at Clare Hall, Cambridge, where in 1654 he became master. In 1658 he received the M. A. degree from Christ's College and in 1667 became senior proctor of the University. He was chosen master of the Charterhouse in 1685. Later, Burnet became "chaplain in ordinary and clerk of the closet of William," but was removed in 1692 on account of the opposition to his Archaeologia Philosophicae in which he treats the Mosaical account of the fall of man as allegorical and professes to reconcile his own "Theory of the Earth" with the Mosaical account. Part I of Burnet's Theory was first published in Latin in 1681 under the title Telluris Theoria Sacra. An enlarged English version followed in 1684. The second part of the Theory, together with a second edition of the first, and an English translation of the whole appeared in 1689. The work passed through a number of later editions, the seventh appearing in 1759 .

Burnet's Theory of the Earth is a fanciful account of the evolution of the world, originating in an attempt to explain how it was possible for the Mosaical deluge to have taken place. In his own words, it "is an Account of the Original of the Earth, and of all the great and general Changes that it hath already undergone, or is hence forwards to undergo, till the Consummation of all things" (p. 3). Burnet's science is crude even for his own time. His "Hypothesis" is borrowed from Biblical sources and is bolstered up by a vivid imagination. The present world, he holds, is but the "ruins" of an antedeluvian "Paradisiacal" world. The projections of the broken shell of that first world form our mountains, and our seas are a part of the great "abyss" uncovered by the break. As the first world was destroyed by water, so it will be restored by fire in all 


\section{I4 PHILOSOPHICAL WRITINGS OF BURTHOGGE.}

its "Paradisiacal" perfection. Like the Phœnix, he says, "it will be consum'd in the last Fire: And from its Ashes... will arise another World."

Burnet's Theory, taken seriously in his own time, although it did not lack supporters (e. g., Whiston), met with a good deal of opposition. Two of the most formidable opponents were Erasmus Warren and John Keill (cf. Note 50). Burnet's “Answer" to Warren's Exceptions.... against the Sacred Theory of the Earth and to Keill's Examination of the Theory will be found appended to the fifth edition of the Theory, London, 1722.

52. (Note to pp. 11 et al.) Burthogge has correctly made and interpreted these quotations.

53. (Note to p. 25.) Cf. August Heinrich Ritter and Ludwig Preller, Historia Philosophiae Graecae, 7th ed., Gotha, 1888, "Thales," pp. 6-11.

54. (Note to p. 26.) Phalaris, tyrant of Agrigentum. Sicily (c. 570-554 B. C.), was notorious for his horrible cruelty. According to tradition he was entrusted with the building of the temple of Zeus and took advantage of his position to make himself despot. Until the seventeenth century it was generally believed that Phalaris was the author of the Epistles which bear his name. Politian, in the fifteenth century, had, to be sure, attributed the Epistles to Lucian. Not, however, until 1690 when Sir William Temple revived the interest in Phalaris by naming his Epistles one of the greatest masterpieces of antiquity, was any serious question of their genuineness raised. And by 1698, the year in which Burthogge published his Soul of the World, the controversy between Charles Boyle and Richard Bentley over the authorship of the Epistles was at its height. In the Preface of his new edition (1695) of the Epistles, Boyle presents the various views regarding the authorship without 
presuming to decide in favor of any. In 1697 Bentley's Dissertation on the Epistles of Phalaris appeared, appended to Wotton's Reflections on the Ancient and Modern Learning. Bentley believed the Epistles to be spurious, arguing mainly from the anachronisms to be found in them. Towns are mentioned, for example, which were not in existence until long after the time of Phalaris, and men are spoken of who lived centuries later. Early in 1698 Boyle replied with Doctor Bentley's Dissertation....examined. And later in the same year Bentley published a reply to Boyle in a second enlarged edition of his Dissertation. A full account of the controversy will be found in R. C. Jebb's Richard Bentley, New York, [1882]. The epistle to which Burthogge makes reference is numbered 103.

55. (Note to p. 28.) The Eugenius Philalethes referred to is probably Thomas Vaughan (1621-66), twin-brother of the poet Henry Vaughan. The psendonym Philalethes was fashionable in the seventeenth century and Anthony à Wood names three others, all contemporary with Vaughan, who use it. Yet, although it has been impossible to verify the quotations, there are several considerations which make it almost certain that Thomas Vaughan is the poet referred to by Burthogge. For Thomas Vaughan more consistently than any one else, wrote under the pseudonym Eugenius Philalethes. Moreover, he wrote both English and Latin verse and translated several of the Latin poets.

56. ${ }^{7}$ (Note to p. 31.) Leeuwenhoek, Antony van (16321723). A Dutch naturalist and microscopist, perhaps best known as the investigator who completed Harvey's work on the circulation of the blood by the discovery in 1686 of the capillary connection between arteries and veins. Leenwenhoek's enthusiasm in the use of the newly inventerl

7 For Notes 56 and 58-67 the editor is indebted to Dr. Alice Robert. son, formerly professor of zoology at Wellesley College. 
microscope led him to experiment in grinding lenses, so that he possessed the best microscopes of his day with powers ranging from forty to two hundred and seventy diameters. In 1675 he discovered the protozoa, the one-celled animals so abundant in water containing decaying organic substance, his so-called "peppered water." Twelve years later he discovered bacteria.

Belief in spontaneous generation had declined somewhat during the seventeenth century. The experiments of Redi (cf. Note 58) had confirmed the truth of Harvey's epigram. "Omne vivum ex ovo." After the discovery of these onecelled organisms, however, although spontaneous generation could no longer be affirmed of the larger animals, belief in its possibility was revived in regard to these minute animals. And, indeed, it must be admitted that such a theory of generation was not wholly unreasonable as long as the life histories of protozoa and bacteria were unknown. For the life and work of Leeuwenhoek the reader is referred to W. A. Locy, Biology and Its Makers, New York, 1908, pp. 77-88.

57. (Note to p. 31.) In the original this word is mis printed: Animalcles.

58. (Note to p. 31.) Redi, Francesco (1626-97). An Italian physician living at Arentine. In 1668 he first performed an experiment which, in the minds of scientists. dispelled all doubt of the untenability of the theory of spon. taneous generation. The experiment was so simple that it is astonishing that it had not been tried before. He set three jars containing fresh meat in a place where all would be subjected to the same environmental conditions. One jar remained uncovered, a second was covered with parchment, a third with wire-netting. The first soon showed signs of putrefaction accompanied with visible animal life. The second also putrefied but no animal life was apparent. 
On the wire-netting covering the third jar flies had deposited many eggs, but the putrefying meat in the jar gave no signs of life. The conclusion was evident that the organisms found in the first jar were not spontaneously generated, but had hatched from eggs which flies had laid on the meat. This experiment weakened the belief in spontaneous generation revived by the discoveries of Leeuwenhoek. Cf. Locy, Biology and Its Makers, pp. 277-82.

59. (Note to p. 32.) The larvæ of insects that feed on fermenting material instinctively seek darkness. Hence, although such larvæ (maggots) were found, as reported, at the bottom of the fermenting mass, the eggs were probably laid on the top, the larvæ, after hatching, seeking the darker places. It is not necessary, therefore, to assume that the adult flies had to endure the high temperature of fermentation, since the eggs were laid before or at the beginning of fermentation. The eggs, however, require a high degree of heat in order to incubate and hatch rapidly, and the larvæ are adapted to endure this high temperature. Redi's experiments with meat, both shielded and unshielded from flies, apply to any putrefying or fermenting masses, and the assumption of spontaneous generation in such cases as the above is thus shown to be invalid.

60. (Note to p. 33.) The myth of birds arising from barnacles is extremely old and wide-spread, dating back to the twelfth century and extending from Britain to Ceylon. Max Müller has studied this myth and gives an interesting and amusing account of his research in the second volume of Science and Language (New York, 1891). pp. 659-82.

61. (Note to pp. 33 et al.) Julius Cæsar Scaliger (14841558) was an ardent believer in, and supporter of, the theory of spontaneous generation. He is best known to-day as the author of an unwarranted attack upon Cardano (cf. Note 
62) in a brilliantly written Latin work entitled Exortericarum Exercitationum Liber $X V$ de Subtilitate ad Hieronymum Cardanum, first published in 1557, and followed by numerous later editions: 1576, 1592, 1612, 1634 and 1665. At the time of this attack Scaliger was a physician of repute living in the home of the Archbishop of Agen as his medical adviser. Roused by envy at Cardano's success, and jealous of the attentions he received on his triumphal return to Milan, it is said that Scaliger aspired to be talked of as the rival of Cardano. Much color is given to this belief when it is remembered that Scaliger wrote his book three years after the second edition of Cardano's work was printed, without ever reading this second edition, in which Cardano had laboriously expunged many erroneous statements. G. Naudé, who had no love for Cardano, says, writing of Scaliger's attack: "Scaliger undertook this work not in the interest of learning, but rather for disputation, and a comparison of the works of the two men will show that Scaliger committed more errors in his than he found in Cardano's." According to this authority, Scaliger's purpose seemed to be to deny all that Cardano affirmed and to affirm all that Cardano denied. This quarrel seems to have been widely known and the dogmatic nature of Scaliger's criticisms fully appreciated, especially in the countries Cardano had so recently visited. In one of his Commonplace Books, Sir Thomas Browne quaintly observes, "If Cardan saith a parrot is a beautiful bird, Scaliger will set his wits on work to prove it a deformed animal." Cardano kept his temper admirably during the whole dispute. He published a short and dignified reply, Actio prima in Calumniatorem, in which the name of Scaliger never once occurs. His attitude of dignified indifference won him approval by contrast to the raging fury of his adversary.

62. (Note to pp. 33 et al.) Cardano, Girolamo (15011576). A notable and picturesque personality of the six- 
teenth century. Possessed of a highly imaginative mind as well as of a highly emotional nature, he was as a child moody, misunderstood and neglected. In youth he early showed unusual power of abstract thought and distinguished himself in mathematics, dialectics and philosophy. Much against the desire of his father, who wished him to follow the profession of law, he entered the University of Padua in 1520 , bent on the study of medicine, and in 1524 received his degree. An eager student, a voracious reader, greedy for knowledge of all kinds, he grew to manhood self-assertive, irascible, disregarding the conventions of society, and what was more important, neglecting the cultivation of the rich and powerful. Few patients called on the services of the young physician who started on his medical career offending his colleagues in Milan by the publication of a book entitled De Malo Recentiorum Medicorum Medendi Usu. This book proved a great financial success but brought the enmity of the medical profession. Turning to mathematics, a favorite study, he published works in arithmetic and algebra which early carried his fame far beyond the bounds of Italy. He not only raised algebra to a point it had never before reached, but his name as a mathematician became known throughout Europe and the success of his mathematical writings was remarkable.

Between 1547 and 1551, holding a professorship in Pavia, teaching besides several young men in company with his own son, he brought out his great work, De Subtilitate. (Later editions appeared in 1554, 1560, 1563 and 1582.) In this treatise the author ambitiously wished to treat of the cosmos. It is said that he produced the richest and at the same time the most chaotic collection of the facts of natural philosophy that had yet issued from the press. The book displays amazing erudition and industry, for not only did Cardano collect vast masses of information, but much of it he verified by experiment. Thus he was one of the earliest scientists to use the experimental method. In speaking of 
one of his discoveries in medicine he remarks, "In the matter of invention Reason will be the leader, but Experiment the Master." Cardano, paradoxically enough, was an earnest student of astrology, even though the fact of his indulging in this study was quoted by his enemies as reflecting on his fair name as a physician. However, Cardano's medical fame arose partly out of his literary effort in De Subtilitate, and partly out of his knowledge of astrology and his power to cast horoscopes.

In 1551, through the reading of De Subtilitate, which inflamed him, it is said, with a desire to become acquainted with everything Cardano had ever written, Cassanate, a Franco-Spanish physician who was in attendance upon Archbishop Hamilton of St. Andrews, invited Cardano to meet the Archbishop in Paris in order to prescribe for the prelate's asthma. Eventually Cardano went to Edinburgh and there staid five weeks in attendance upon his illustrious patient. The fame of Cardano spread rapidly and the nobility of Scotland flocked to him paying him most liberally for his advice. On leaving Scotland he was entreated to visit England to give an opinion on the health of Edward VI, and to cast his horoscope. His journey homeward was a continuous ovation, and on his return to Milan he stood the acknowledged head of his profession. He was flooded with invitations from the wealthy and powerful, each desiring his exclusive attention. All of these invitations. he steadily refused, being satisfied to hold an honored place in his favorite city, Milan.

His own words written on his return from this famous journey reveal the spirit of the man: “....I, who was born poor, with a weakly body, in an age vexed almost incessantly by wars and tumults, helped on by no family influence, but forced to contend against the bitter opposition of the College at Milan, contrived to overcome all the plots woven against me, and open violence as well. All the honours which a physician can possess I either enjoy, or 
have refused when they were offered to me.... What I have written has been lauded; in sooth, I have written of so many things and at such length that a man could scarcely read my works if he spent his life therewith....I have refused always to flatter the great; and over and beyond this I have often set myself in active opposition to them.... I have been most fortunate as the discoverer of many and important contributions to knowledge, as well as in the practice of my art and in the results obtained; so much so that if my fame in the first instance has raised up envy against me, it has prevailed finally and extinguished all ill feeling."

Cardano, unlike his adversary Scaliger, opposed the doctrine of spontaneous generation as held in his day, maintaining that the facts urged in support of this theory could be better explained by natural than by supernatural processes. For the life and work of Cardano cf. Henry Morley, Life of Girolamo Cardano of Milan, 1822, and William George Waters, Jerome Cardan: a Biographical Study. 1898. Cf: also Encyclopadia Britannica, 11 th ed.

63. (Note to p. 35.) Whether Lord Bacon believed that plants may be spontaneously generated it is difficult to say. As Burthogge quotes, Bacon mentions instances in which he says that plants were produced without seeds. (For Bacon's experiments cf. his Sylva Sylvarum: or a Natural History. in Ten Centuries, London, 1627. Burthogge's reference to experiments in Century IV are wrongly numbered 228 and 339 instead of 328 and 329.) Considering Bacon as an authority not to be questioned, our author reasonably infers the possibility of animal production without eggs. However, the instances cited can not be urged as evidence of spontaneous generation. It is well known that ants, earthworms and other burrowing animals disseminate seeds long distances under the ground, and it is further known that seeds retain their vitality for long periods of time, and may even withstand unfavorable environments. The instances cited by 
Bacon may, therefore, be accounted for by normal and natural processes. As to the power of seeds to withstand unnatural environment, it will be remembered that a few ounces of mud, collected by Darwin from under the water of a pond where no vegetation was visible, when brought into his study and given suitable environment produced no fewer than 537 plants. As evidence of the vitality of seeds. Professor Cowles of the University of Chicago reports experiments in which dried seeds not less than twenty-five years of age, have germinated, and refers to other experiments in. which seeds have been shown to retain their viability for 150 to 250 years.

64. (Note to p. 35.) No instance of a rain of frogs or of other creatures can be accepted as proof of spontaneous generation. Although some apparently authentic stories are told of such occurrences, even these must be received with incredulity. If true, the animals must have been transported by the wind from some near-by body of water, and it is not impossible perhaps that such transportation might take place during or following a severe storm. This may be especially true in tropical regions. The phenomenon of the sudden appearance of a surprisingly large number of animals, frogs or fish, is not uncommon after heavy rains in the tropics. In these regions, during the dry season, many kinds of aquatic animals are known to bury themselves in the mud from three to twelve or sixteen inches, and on the return of the rainy season to reappear with such rapidity and in such multitudes that it is not surprising that mythical stories have arisen. For an account of instances of the belief that fishes fall during heavy showers and for the probable explanation of the phenomenon cf. Edward Terry's A Voyage to East India, London, 1777, p. 6; also Sir J. E. Tennent's Ceylon, an Account of the Island, Physical, Historical and Topographical, London, 1860, Vol. I, pp. $211 \mathrm{ff}$ and Notes (A) and (B), pp. 226-27. 
65. (Note to p. 36.) The hibernation of toads, their ability to do without food for long periods if temperature conditions are relatively cool and constant, together with the natural credulity of the ignorant, have contributed to the longevity and persistence of this myth. Actual experment has shown that toads may live for over a year in sandstone hermetically sealed and buried three feet in the ground In more porous stone. such as limestone. they live a few months longer. If permitted an almost infinitesimal amount of food and air, in a cool place where escape is impossible. they might live a much longer time, but not indefinitely. For further details regarding the hibernation of toads and tortoises the reader is referred to Hans Gadow's Amphibia and Reptiles (Vol. VIII of The Cambridge Natural History, London, 1901), esp. pp. 68. 347, 354, 363, 369. 376: also to Sir J. E. Tennent's Ceylon, Vol. I. p. 218.

66. (Note to p. 36.) The horse-hair myth, like those of the goose barnacle and toad-in-hole. is difficult to eradicate since even to-day there are people who regard it with credulity. The so-called "horse-hair" worm is threadlike, five or six inches long, found in water-troughs, ditches and pools of stagnant water and known to science as Gordius. The life history of Gordius comprises three distinct stages: two of them are larval and parasitic, the third is adult, aquatic and free living. The eggs are laid in water and hatch into minute larva possessing an effective boringapparatus. Gordius larva bores its way into the body of the larva of an insect, that of the Alder fiy, and passes into a resting-stage in its muscles or fat body. During the next few months the Alder fly larva metamorphoses into the adult fly, and Gordius larva then passes over into its body. The Alder fly falls an easy prey to a certain predacious beetle which haunts its habitat, and which thus becomes the host for the second larval stage of Gordius. Here it lives several months and after consuming a large 
part or all of the internal organs of the beetle, it bores its way out and becomes adult. If the beetle host has chanced to fall into water or has been carried into water by the wind, Gordius lives a free life as the "horse-hair" worm. If, on the other hand, the beetle host falls on dry land, as doubtless often happens, Gordius dies.

For the classification, anatomy and life history of Gordius the reader is referred to Arthur E. Shipley, Nemathelminthes \& Chaetognatha (Vol. II of The Cambridge Natural History, London, 1910).

67. (Note to p. 37.) Modern biological investigation has shown that worms of various kinds may infest the organs of persons living under unsanitary conditions, or eating infested food not properly cooked. The hookworm infestation of certain regions of this country, and the sporadic cases of trichina in man are modern examples. 


\section{BIBLIOGRAPHY.}





\section{BIBLIOGRAPHY.}

\section{THE WORKS OF BURTHOGGE.}

Note: The appended lists of libraries in which each book may be found are based on inquiries addressed to about fifty university and city libraries in the United States. (The British Museum Library is the only European library to which reference is made.) The follow. ing abbreviations have been used:

Amh. Amherst College Library.

Ath. Athenæum Library, Boston.

B. M. British Museum.

C. U. Columbia University Library.

Chic. Chicago Public Library.

Cor. U. Cornell University Library.

H. U. Harvard University Library.

L. C. Library of Congress.

Lib. Co. Library Company, Philadelphia.

P. I. Peabody Institute, Baltimore.

U. P. University of Pennsylvania Library.

U. Theol. Union Theological Seminary Library.

Y.U. Yale University Library.

\section{PHILOSOPHICAL. WORKS.}

1678 Organum Vetus $\mathcal{E}$ Novum, or a Discourse of Reason and Truth; Wherein the Natural Logick common to Mankinde is briefly and plainly described.

London, Printed for Sam. Crouch, at the Princes Arms a Corner-shop of Popeshead ally in Cornhil. Pp. 73. Ath., B. M., H. U., L. C., U. Theol. 
1694 . An Essay upon Reason, and the Nature of Spirits.

London, Dunton. Pp. 280. Amh., B. M., Cor. U. H. U., I.. C.. Lib. Co., P. I., U.P., Y. U., U. Theol.

1699 Of the Soul of the World: and of Particular Souls. In a Letter to Mr. Lock, occasioned by Mr. Keil's Reflections upon an Essay lately published concerning Reason.

London. Printed for Daniel Brown at the Black Swan and Bible, without Temple-Bar. Pp. 46. B. M., C. U., H. U.: 1748 (in [Somers Tracts] A Collection of Scarce and Valuable Tracts, Vol. II), C. U., H. U., U.Theol., Y.U.: 1809 (in Somers Tracts, Vol. XII), B. M.; 1814 (in Somers tracts, Vol. XII), Ath., C. U., Chic., Cor. U.. L. C., Y.U.

II. WORKS ON RELIGIOUS SUBJECTS.

1670 Divine Goodness explicated and vindicated from the Exceptions of the Atheist; wherein also the Consent of the gravest Philosophers, with the holv and inspired Penmen, in many of the most important Points of Christian Doctrine is fully vindicated.

London, 1671 (Pp. 133+), H. U.; 1672, B. M. (The title in the editions of 1671 and 1672 reads : TaraOov, or Divine Goodness, etc.)

1675 Causa Dei, or an Apology for God: Wherein the Perpetuity of Infernal Torments is Evinced, and Divine both Goodness and Justice (that notwithstanding) Defended. The Nature of Punishments in General, and of Infernal ones in Particular Displayed. The Evangelical Righteousness Explicated and Setled. The Dirinity of the Gentiles both as to things to be 
Believed, and things to be Practiced. Adumbrated; and the wayes whereby it was Communicated, plainly Discover'd.

London, Imprinted for Lewis Punchard Bookseller in Totnes in Devon.... Pp. 422. B. M., L. C., U. Theol.

1683 An Argument for Infants' Baptism, deducted from the Analogy of Faith and Harmony of the Scriptures: in which, in a Method wholly ncw', and "pon Grounds not commonly observed, both the Doctrine of InfantBaptism is fully asserted, and the Objections against it are obviated. ${ }^{2}$

London.

1685 Vindicice Pado-Baptismi: or, a Confirmation of an Argument lately emitted for Infant-Baptism. ${ }^{1}$

London.

1687 Prudential Reasons for repealing the Penal Laws against all Recusants, and for a general Toleration. ${ }^{2}$

London.

1691? The Nature of Church-Government, Frecly Discussed and set out. In Three Letters.

London. Pp. (4), 52. U. Theol.

1702 Christianity a Revealed Mystery: or, The Gracious Purpose of God toward the Gentiles, set in a clear Light, in some Reflections on Rom. viii. 28, 29, 30. To which is added, A Brief Discourse concerning Perseverance in Grace.

London. B. M.; 1755, Ath., H. U.

${ }_{1}^{1}$ Title taken from Athenae Oxonienses, Vol. IV, p. 581.

${ }^{2}$ The following note is added after the title in the Athenae Oxonienses: "There is no name set to it, only said in the title to have been pen'd by a protestant person of quality." 
230 PHILOSOPHICAL WRITINGS OF BURTHOGiE.

III. MEDICAL WORK.

1662 Disputatio de Lithiasi et Calculo.

Leyden. B. M.

OTHER WORKS TO WHICH REFERENCE IS MADE IN THE INTRODUCTION.

Smith, John (1618-52),

Select Discourses.

London, 1660.

More, Henry (1614-87),

A Collection of Several Philosophical Writings of Dr. Henry More, Fellow of Christ's College in Cambridge. As Namcly

His $\left\{\begin{array}{l}\text { Antidote against Atheism } \\ \text { Appendix to the said Antidote } \\ \text { Enthusiasmus Triumphatus } \\ \text { Letters to Des-Cartes \&c. } \\ \text { Immortality of the Soul } \\ \text { Conjectura Cabbalistica }\end{array}\right.$

Culverwel, Nathaniel (d. 1651?),

An Elegant and Learned Discourse of the Light of Nature.

Oxford, 1669.

Cudworth, Ralph (1617-88),

The True Intellectual System of the Universe.

London, 1678.

Locke, John (1632-1704),

Essay Concerning Human Understanding.

London, 1690. (Quotations from Bohn edition.) 
Kant, Immanuel (1724-1804),

Critique of Pure Reason.

1781, 1787. (Quotations are from Max Müller's translation, New York, 1896.)

Calkins, Mary Whiton.

The Persistent Problems of Philosophy, 4th rev. ed.

New York, 1917.

Lovejoy, Arthur O.,

"Kant and the English Platonists," in Essays Philosophical and Psychological in Honor of William James.

New York, 1908.

Lyon, Georges.

L'idéalisme en Angleterre au XVIITe siècle.

Paris, 1888.

Ueberweg, Friedrich.

History of Philosophy from Thales to the Present Time, tr. by G. S. Morris. Vol. II.

New York, 1892.

Wood, Anthony à (1632-95).

Athenae Oxonienses, an Exact History of all the Writers and Bishops who have had their Education in the University of Oxford, to which are added the Fasti, Annals of the said University. A new edition. with additions and a continuation by Philip Bliss. Vol. IV.

London, 1820.

Dictionary of National Biography. 

INDEX. 



\section{INDEX OF PERSONS.}

[This Index does not make reference to the Bibliography.]

Agrippa, Cornelius, 193.

Antoninus, Marcus Aurelius, 159, 202. Apollinarius, 169.

Apronius, 149, 150.

Apuleius, 159.

Aquinas, $201,203$.

Aristotle, 30, 160, 193, 198, 203.

Arnobius, 211 .

Arscot, 187.

Augustine, St., 135, 211.

Aust in, St., 135.

Bacon, Francis, 166, 167, 221 .

Baehrens, A., 211.

Balbus, 148, 162 .

Bartholinus, 168.

Basilides, 16, 191, 192.

Behmen, Jacob, 16, 17, 189.

Bentley, Richard, 314f.

Borellus, 168.

Bowman, Ethel, 198.

Boyle, Charles, 214f.

Brandis, C. A. B., 198.

Browne, Sir Thomas, 218.

Burnet, Thomas, 142, 212, $213,214$.

Calkins, M. W., xviii, xix, xx, 191 , 193. 194.

Cardano, Girolamo, 148, 149, 160, 165 , $167,217 f f$.

Cassanate, 220.

Chalmers, Alexander, 190, 191.

Chandler, 196.

Charleton, Walter, 196.

Cicero, 34, 36, 44, 59, 79, 114, 147, $148,149,150,162,199,202,203$, $204,210,2 \times 1$.

Clement of Alexandria, $19 x$.

Collier, Arthur, 198.
Cotta, 59, $147,148$.

Cowles, H. C., 222.

Cox, 164

Cudworth, Ralph, xiii, xiv, xvii, xviii, 206, 207, 210.

Culverwel, Nathaniel, xiii, xv, 206.

Dante, 201.

Dat win, Charles, 222.

Democritus, 206.

Descartes, René, xvii, 55, 59, 105. 171. 189, 196, 206, 207, 208, 209.

Dionysius, convert of Paul, 200 .

Dionysius, Pseudo-, 38, 200.

Noble, C. E., 212.

F.dward, Lord Herbert of Cherbury, $35,168,199 \mathrm{f}$.

Edward VI, of England, azo.

Epicurus, 23, 114, 197, 206, 210.

Erasmus, 139, 211.

Erigena, 200.

F.ebri, H., 55, 59, 203.

Felix Marcus Minucius, see Minucius Felix.

Fleming, William, 189.

Fludd, Robert, 16, 17, 69, 189, 190.

Gadow, Hans, 223.

Gage, 133 .

(ialen, Claudius, 42, I53, $201,202$.

Gardiner, F. L., 190.

Granger, James, 190.

Hamilton, Archbishop of St. Andrews, 220.

Harvey, argf.

Ilearne, Thomas, 212. 


\section{PHILOSOPHICAL WRITINGS OF BURTHOGGE.}

Helmont, J. B. van, 17, 196.

Henry VIII, of England, 46.

Herbert, Lord. See Edward, Lord Herbert of Cherbury.

Hicks, R. D., 297.

Hilgenfeld, 191 .

Hippolytus, 191 .

Hitchins, 187.

Ilobbes, Thomas, $65,68,113,132$, 142, 197, 203, 206, 207, 208, 210.

Holland, Philemon, 193.

Irenzus, 191, 192.

James II, of England, xii.

Jebb, R. C., 215 .

Jennings, H., 189, 190.

Jöcher, C. G. J., 203.

Jones, R. M., 189, 192, 193, 194, 201.

Josephus, 8, 188.

Juncken, 164 .

Kant, Immanuel, Burthogge's relation to, xiii, xvff, xxii, 198.

Keill, John, 142, 143, 153, 155, 175 , 2 I $2,214$.

King, C. W., 192.

Kramer, 192.

Krauth, C. P., 189.

Kühn, D. C. G., 202.

Laertius, Diogenes, 103, 159, 205.

Leibniz, Gottfried Wilhelm von, 212.

Leeuwenhoek, Antony van, 163, $215 f$.

Lccke, John, Burthogge's relation to, xi, xvff; 139, 141, 199, 200, 201, 205, 209.

Locy, W. A., $216 \mathrm{f}$.

Lovejoy, A. O., xviif, 198.

Lucian, 2 I 4.

I.ucilius, II4, I50, 210.

Lucretius, I 58.

Lucullus, 34, 199, 204.

Lyon, Georges, xi.

Lyson, 187 .

Magnus, Albertus, 20 .

Maier, Michael, 190.

Malebranche, Nicolas, 107, 207.

Mansel, H. L., 192.

Marcus Aurelius Antoninus. See Antoninus.

Michaud, L. G., 203.

Miller, George, 169.
Milton, Jobn, 201.

Minucius Felix, Marcus, 139, 211.

More, Henry, xiii, xiv, xvii, I15, 118 , 142, I92, 194, 206, 207, 209, 210 , 211.

Morley, Henry, 221.

Mïller, Max, 217.

Naudé, G., 218.

Nemesius, 163,169 .

Newton, 212.

Nicholas, Henry, 17, 192.

Paracelsus, 1 7, 193, 194, 195, 196.

Porker, 200, 201.

Pelops, 202.

Ycnnant, John, 168.

Phalaris, 160, $214,215$.

Philalethes, Eugenius, pseud. See Vaughan, Thomas.

Plato, Xiv, 88, 1 59, 204, 205, 206.

Pliny, the Younger, 133.

Plutarch, I 59, 193.

Poiret, 169.

Politian, 214.

Prantl, 198, 202.

Preller, Ludwig, 214.

Pythagoras, I 58, I60.

Raleigh, Sir. W., 133.

Redi, Francesco, 164, $216,217$.

Reichel, O. J., 197.

Ritter, A. H., 214.

Roberts, C. F., I94.

Robertson, Alice, 2 I 5.

Savery, 187 .

Scaliger, Julius, 148, I 49, I 50, 160 , $165,167,169,171,217,218,221$.

Seneca, 102, 109, I13, I50, I 51,153 , 159, $205,208$.

Sherlock, 136.

Shipley, A. E., 224.

Simocatto, I 33.

Smith, John, xv, 206.

Sparrow, John, 189.

Spenser, Edmund, 201.

Spinoza, Baruch de, Substance as conceived by, 92f, 95, 97f, 205, 209f; mind as conceived by, 107, 207; God as conceived by, 108. 113f, 208; truth as conceived by, I $99 f$.

Stephen, Leslie, $\mathbf{x i .}$

Stesichorus, I60. 
Taliacotius, 174 .

Taylor, H. O., $20 x$.

Temple, Sir William, 214.

Tennent, Sir J. E., $222 f$.

Terry, Edward, 168, 222.

Tertullian, 191.

Thales, xi, 259.

Trevill, Andrew, 5, 187.

Tulloch, John, 207.

Tulpius, 168.

Ueberweg, xi, xiii, 198.

Valentinus, 16, 190, 192.

Valla, Laurentius, 136 .

Vaughan, Henry, 215.
Vaughan, Thomas, 161, 215 .

Virgil, $16 \mathrm{r}$.

Waite, A. E., 190.

Wallace, William, 197.

Warren, Erasmus, 214.

Waters, W. G., 22 I.

Whiston, William, 188, $212,214$.

William the Conqueror, 46.

William III, of England, xii.

W'olff, Christian, xviii.

Wood, Anthony à, xi, 190, 215.

Wotton, William, 215.

Zeller, Eduard, 197, 198.

Zeno of Citium, In3, 159. 



\section{INDEX OF SUBJECTS.}

Accidents, Phenomenal nature of, 24, 60, 68, 75, 77, 79ff, 85, $90 \mathrm{ff}, 97 \mathrm{ff}, 106$, $111,112,183,205,209$; Spinoza's conception of, 92, 93, 95, 205, 209: Locke's conception of, 205, 209; the Cambridge Platonists' conception of, 209. See Attributes.

Action (or Activity), the fundamental attribute of inind, rozf, 106f, 335, 142 , $143,145,163,184$. Sec Energy.

Affection, of apprehension, 19, 25, 27, 66; conceived as emotion, 23, 72, 110 . 204; conscious sense affection, $57 \mathrm{ff}, 91,127,129$.

Analogy, 12, 33, 38, 48, 73; regarded as test of truth, 35, 43. Sec Congruity and Harmony.

Angels, 132, 174 .

Animals, Faculties of, 10, 134; souls of, $125 \mathrm{ff}, 143 \mathrm{f}, 148,150$ 1 $52 \mathrm{f}, 16 \mathrm{ff}, 172 \mathrm{ff}$; kinds of, 132; spontaneous generation of, $163_{3} \mathrm{ff}$; Locke's definition of, 201 ; sensations of, like those of man, 6of.

Anticipations, 28, 37, 39, 40, 7x. Sec Innate ideas.

Apparitions (appearances), 84, 93; (spectra or spirits), $132 \mathrm{ff}$. See Appearance.

Appearance, contrasted with "grounds" or reality, 12, 24, 28f, 4If, 47, 76, 77, 82, 85, 87, 88, 93, 111, 155, 180, 198. $S c c$ Phenomena and Apparitions.

Apprebension, an act of the understanding or reason, soff, $37 \mathrm{ff}, 65,69,74$; the object of, $18 \mathrm{f}, 66,7 \mathrm{of}, 75,80$; clearness and distinctness, the affections of, 19, 24, 25f, 66; conditions of clearness and distinctness in, $27 \mathrm{ff}$; not 2 criterion of truth, $33 \mathrm{ff}, 40$.

Apriorism, xx, xxiii.

Assent, an act of judgment, $11,30,32,37$; as related to truth, 33f, 36, 37, 41, $45 \mathrm{f}, 48$; as related to falsity, 48 .

Attention, necessary for conception or understanding, $29,61,64$.

Attributes, of God, 24, 112f, $114,197 \mathrm{f}, 207,210$; of things, 26; phenomenal nature of, 84, 112; as related to substance, 98, 183, 209; Spinoza's conception of, 95, 113,207, 210; thought and extension conceived as attributes, 206, 207, 210. See Accidents.

Barnacle myth, 165, 217, 223.

Being, Objective or cogitable, 14, 33, 80, 82, 94, 183 ; formal or real, 13, 14, 8n, $82,94,183$, cf. $99 \mathrm{f}, 113 \mathrm{f}$; mind and matter as related to, $120 \mathrm{ff}$. See Existence.

Body, 99, 168f, 170, 197, 201, 203; as related to mind or soul, 107, 118, 125f. $128 \mathrm{ff}, 134,142 \mathrm{ff}, 152 \mathrm{ff}, 157 \mathrm{ff}, 207$, cf. $123,325,148,166,211$; as related to external objects, $126 \mathrm{ff}$; Hobbe's identification of substance with, 210 .

Breatb, identified with soul, $147 \mathrm{ff}, 156 \mathrm{ff}$. 


\section{PHILOSOPHICAL WRITINGS OF BURTHOGGE.}

Cambridge Platonists, The, xiii ff, 194, 206f, 209, 210; Burtbogge's relation to, xiii ff; Soul of the world as conceived by, xiv; human souls as conceived by, xiv; nature of truth as conceived by, xv; materialism opposed by, 206f; substance as conceived by, $209 \mathrm{f}$.

Cause, 34, 72, 76, 107, 109, 114, 118f, 135, 146, 171, 173; a notion of the mind, $13,75,84,85,91,92,94,180$; of sensations and notions, regarded as things, $87,18 \mathrm{r}, 204$; Principles conceived as uncaused causes, rorf, 184; God conceived as primary, $197,208$.

Clear and distinct perception, see Perception.

Clearness, an affection of apprehension, 19, 24, 27, 28, 66. See Perception, clear and distinct.

Cogitables (or Cogitable beings), $13,14,89 f$.

Cogitation, 68, 118f, 128; includes sensation and intellection, $12,13,18,55 \mathrm{ff}$, $61 \mathrm{f}, 76,77,8 \mathrm{r}, 85 \mathrm{ff}, 92,123$; as related to mind, $105 \mathrm{ff}, 206$; gives knowl. edge of phenomena only, $12,77,180,183$.

Cogitative Faculties, see Faculties.

Coherence, see Congruity.

Colour, xvi, 112, 120ff; related to eye as meaning is to understanding, I1ff, $15,18,24,32,34,58,67 \mathrm{f}, 7 \mathrm{r}, 74 \mathrm{f}, 77,83 \mathrm{ff}, 88,92 \mathrm{ff}$.

Conception, 16, 29, 65, 80, 97, 100, 146; role of, in knowledge, 12, 13f, 25, 26 . $57 \mathrm{ff}, 67,70,74,77 \mathrm{f}, 82,117,181$.

Conduct, Role of Reason in, 188 .

Congruity, between the object and the understanding, $15,36,42,182 ;$ cf. 174 . 175; objective congruity as test of truth, 41ff, 182. See Aanalogy and Harmony.

Conscience, $48,188$.

Consciousness, Relation of, to knowledge, $58 \mathrm{ff}$.

Consistence, see Congruity.

Continuum, 29. 198.

Creation, of souls, $170 \mathrm{ff}$.

Deity, 5, 23. See God.

Discerption, conceived as attribute of material stibstance, 170, 173, by More. 209, 210.

Dissent, an act of judgment, $30,32,4^{1}, 45$.

Distinctness, an affection of apprehension, 19, 25ff, 66. See Perception, clear and distinct.

Duration, 124, 125; eternity conceived as permanent duration, 124 .

Effect, conceived as a notion of the mind, $13,75,84,85,90,9 x, 92,94,180$, cf. $45,72,87$, ror, 173 .

Energy, Vital, distinguished from mechanical, xv, $125 \mathrm{f}, 830,13 \mathrm{I}, 143,163$. See Action.

English Platonists, see Cambridge Platonists.

Enthusiasm, 16f, 69, 112, 190, 193, 194.

Entity, of sense, 13; of reason or understanding, 13, 75, 80, 85, 89, 90, $91,92$. 180 .

Epistemology, see Knowledge.

Errour, 6, 8, 24, 25, 26, 28, 34, 35, 37, 45, 48, 49. See Falsity.

Essence, 80, $1 \times 7$.

Evil, a notion of the mind, 13,81 ; distinguished from good by reason, 188 .

Existence, 80, 96, 169, 197, 206, 207; objective, 13, 75, 180; real, 75, 84, 93, 99, 100, 122 , 209. See Being.

Experience, Role of, in knowledge, Burthogge's teaching compared with that of Locke, xvii, $x \times \mathrm{f}$. 
Extension, conceived as attribute of matter, 95f, 99, 100, 105, 106f, I 16,206 , 209; Spinoza's conception of, 95, 207, 210; substance conceived 2s, 99; God conceived as, 108, by More, Ir $5 \mathrm{ff}, 209$.

Eye, The, $15,19,20,21,24,28,32,33,34,37,39,40,145,172$; related to seeing as the understanding is to meaning, If $, 37,60,63,66,72,74 \mathrm{f}, 87,88$; an organ of sense, $64,76,83,84,123,129$.

Faculties, 15, 20, 26, 31, 36, 42, 77, 82, 93, 94, 102, 104, 105, 107, $119,129,134$ 135, 146, 149, 152, 153, 182; of sense (i. e., perceptive), 10, $12,13,56$, $76,77,180$; of reason (i. e., conceptive and cogitative), 10, 12, 13, 14, 56f, 76, 86, 91, 180, 299. See Powers.

Faith, opposed to reason, 10, $21,47,48$. See Light, of Faith.

Falsity, 13, 32ff, 37, 41, 43ff, 48, 69, 182. See Errour.

Familists, 16, 17, $192 \mathrm{f}$, 194 .

Form (or Notion), of truth, 35, 37, 40, 182 , 188.

Formal (or formally), 11, 12, 13, 14, 80, 82, 94, 183; Burthogge's use of the term, 189.

Gnostics, 16, 19 rf.

God, 7, 99. 103, 192, 201 ; nature of, $8,19,28,47,48,94,102,108 \mathrm{ff}, 118,120$, $123 \mathrm{ff}, 134,135,143,146 f, 156 \mathrm{ff}, 169,171,174 f, 18 \mathrm{r}, 184,187,195,205$; Burthogge's teaching about, compared with that of Cambridge Platonists. xiv; according to Malebranche, 107, 108, Iraf, to Spinoza, ro8, 113f, $207 \mathrm{f}$, 209, to More, $115 \mathrm{ff}$, to Hobbes, $197 \mathrm{f}$, 209, to Seneca, 208 ; revelation of, Igff, 28, 194; purpose of, 21, 23; conceived 2s unknown, 24, Ixif, 197 , as source of truth, 33 .

Good, conceived as a notion, $13,8 \mathrm{r}$, as the "will of a Superior," 188.

Goodness, an attribute of God, 19, 108, 115f, 198.

Gordius, see Horse-hair myth.

Grounds, reality, or things-in-themselves, conceived as "grounds" or cause of Notions, 14, 18, 80, 85,87, 93, 180, of sentiments, 17, 19, 88, 93. I Ix, IaI; reason, the "ground" of judgment, 30, $3 x$, objective harmony, of assent, 33, 34, 4I, falsity, of dissent, 41 ; of truth, 36, 40 .

Harmony, External, the test of truth, xxiii f, 15, $4 \mathrm{tff}, 262,182$; of things to our faculties, conceived as test of truth, $35 \mathrm{f}, 42$, 199 . See Congruity.

Horse-hair myth, 168, 223 f.

Idealism, of seventeenth century, xiii ff; of eighteenth century, $x v$ ff.

Ideas (or Notions), the objects of understanding, $18,62 \mathrm{ff}, 73,78,90,146,179$. 196; derived from sensation, 39; original, in the mind of God, 33; role of, in knowledge, $57 \mathrm{f}, 74,18 \mathrm{r}$, 205, 207; innate, xviii, xxiii, 200. Ideas of substance, 92, 205; mind and motter, 92, 96f, ro7; cogitation. and extension, 106, 116; God, 108, 112; accidents, 209. See Notions.

Image, $13,14,35,39,57,58,60,62,63,64,73,77,84,87,88,129,146,175$, 179, $180,181,182$. See Phenomena and Representation.

Imagination, 12, 13, 14, 17, 39, 76, 96, 117, 175; a Conceptive Cogitative Power, 55, 57f; a Mental and Spiritual Power, 6If; conceived as internal sensation, 55, 62f, 119 ; acts of, 65 ; role in knowledge, 77 ; inadequacy of, for knowledge, according to Descartes, 203 .

Impressions, of sense, 12, 17f, 24, 26, 34, 39, 60, 62, 63, 76, 87, 88, 119, 127, $128,146,181$; see Representation and Image; of the mind, 34, 35, 59 , Ir9; see Notions.

Innate Ideas (or Innate Notions or Native Notions), xviii, xxiii, 70, 71, 881 , 182,188 , 200. See Anticipations and Notions. 


\section{PHILOSOPHICAL WRITINGS OF BURTHOGGE.}

Instinct, warding off of blow not an instinct but habit, 71 ff; conscience conceived as, 188; "natural instinct," a faculty of the mind, 199.

Intellect, $11,33,42,203$. See Mind.

Intellection, $55,57,76,130,146$. See Reasoning.

Intuition, as criterion of truth, $x v, x \times i i i$; God sees universe in single, 124: conceived as a type of knowledge, by Spinoza, I99f.

Jews, 7, $147,352,188$.

Judgment, an act of reason or understanding, 11, 20, 29ff, 37, 44, 45, 65, 69, 163,182 ; of sense, 20 .

Knowledge, 6, 7, 26, 33, 40, 43, 48, 66, 73, 156; Burthogge's doctrine of, compared with that of Kant and Locke, $x v$ ff; roble of notions in, $18,80,8 z$, 90, $179 \mathrm{ff}$; ròle of sense in, 20,47, $57 \mathrm{ff}, 61,179 \mathrm{ff}, 198,200,204$; reason and, 55 ; inadequacy of human, $12 \mathrm{f}, 67,76,80,82 \mathrm{ff}, 110,111 \mathrm{f}, 198,205$, 221, cf. ro6; faculties of knowledge or understanding, 10, 12, 14, $56 \mathrm{ff}$ 76f, 179; relative of truth to, 182; Spinoza's true types of, 200.

Life, derived from motion in the soul, 13off, 145; God, the original principle of, $157 \mathrm{f}$; of the universe, 163, 175; conceived by Cudworth as attribute of incorporeal substance, 209-2 10.

Jight, of Revelation or Faith, I9ff, 24f, I 96 , cf. 10; of Nature or Reason, $19 \mathrm{ff}$, 24f, 188, 196; intellectual, 19; of Discourse, 27; innate notions conceived as light of understanding, $37 \mathrm{ff}$; necessary for vision, $74,83,84,88,152 \mathrm{f}$, for sensitive actions, 163 ; God, conceived as source of, 120 ff, 134; nature of propagation of, 170 .

Logic, a method of reasoning, 3off, 44; subject of, 66 .

Matter, 191, 196, 211 ; nature of, 24, 91, 96f, 102ff, 11 1, 113, 115f, 120ff, $188,13 x, 169,170,172,175,183 f, 205,206,210$; "mechanik and material" powers of, 61 ; as related to mind, ro8ff, $118,126 f, 163$.

Meaning, the immediate object of the mind, $11 \mathrm{ff}, 15 \mathrm{f}, 27,64,66$, 68 . See Sense.

Metaphysics, Subject of, 66. See Philosophy.

Mind, $27 \mathrm{ff}, 44 \mathrm{ff}, 59,60,598$, 199, 210 ; nature of, $9 f, 55,61,64,65,91,96 \mathrm{f}$, $100,102 \mathrm{ff}, 184,206$; faculties of, 12; apprehension, an act of, 11,19 ; notions of, $12 \mathrm{ff}, 24,32 \mathrm{ff}, 38 \mathrm{ff}, 70,73,75 f, 78,80 f, 85,90,92,346$, 1 $79 \mathrm{ff}$; pure mind (i. e., God), $110 \mathrm{f}, 113 \mathrm{f}, 116 \mathrm{f}, 122 \mathrm{ff}, 184,205$; in matter, $118 \mathrm{ff}, 125 \mathrm{f}, 159 \mathrm{ff}, 184$; Spinoza's conception of, 207.

Mosaical Spirit, xiv, $110,138,128 \mathrm{ff}, 143 \mathrm{ff}$. See Spirit, of the universe.

Motion, 17, 36; a reality, 24, 103, 104, III; conccived as related to mind and matter, 72, 118f, $122 \mathrm{ff}, 127 \mathrm{f}, 130 \mathrm{f}, 163$, by More, 210; source of, 143 ; conceived as related to soul, 145 ; necessary for spontaneous generation, 166, 168; self-perpetuating, $169 \mathrm{f}$.

Muggletonians, 194 .

Mysticism, of Rosicrucians, $189 f$; of Gnostics, 191; of Familists, 192f; of Helmont, 196.

Naturc, Light of, $19 \mathrm{ff}$; innate notions conceived as gift of, $37 \mathrm{ff}, 72$; harmony in, 42f, 162 ; key to, 48 ; life of, 104, 175, cf. 156, 164; activity of, 122; relation of God to, I14,135, 146, 171; animals a part of, 152, 174: Epi. curus's concention of, $197,210$.

Noemata, 13, 14. See Notions. 
Notions, Burthogge's teaching about, compared with that of Kant, xvi ff; kinds of, $9 f, 18,21,28,73 f, 89,92$; rôle of, in knowledge, 12ff, 22ff, 27, 29, $33,62,67,73,75,77,79,83,105,179,181$; dependent upon sense, 17, 18, 20, 82, 179, 180; as objects of apprehension, 19, 25, 66, 70; innate, xviii, xxiii, $38 \mathrm{ff}, 7 \mathrm{of}, 18 \mathrm{If}, 188$; of reason or understanding, $58,62 \mathrm{f}, 70$, $75,78 f, 90,181$; subjective nature of, $14,68,74 \mathrm{ff}, 80 f, 84 \mathrm{ff}, 92,93 \mathrm{ff}$, $105,180,198$; of sense, $79,85,92$; things conceived as cause of, 45,87 , 89, 93, 181. Notions of truth, xxiii f, 35, 37, 41, 44f, 48f, 182, 188 ; entity, xvi, 75, 85, 90, 180 ; substance, xvi, $75,77,80,82 \mathrm{f}, 84,8 \mathrm{~s}, 90$, 92, 93f, 95, $96 \mathrm{ff}, 100,180,182,183$, as conceived by Spinoza, 95 ; accident, xvi, 75, 77, 8o, 82f, 85, 90, 92, 93, 94, as conceived by Spinoza, 95; whole and part, xvi, 13, 39, 75, 84, 85, 90; cause and effect, xvi, 13 , $75,84,85,90,92,94,180$; quality, 77, 82f, 84, 93, 94; action, 77 ; subject, 80 ; adjunct, 80 ; thing, 89, 90, 180 ; reality, 90; time, 92, 124; place, 92; relations, 13, 93, 94; measuse, 94; God, 110, $112 \mathrm{ff}, 198$; eternity, 124; self-subsistence, $18_{3} ;$ good and ezil, 13 .

Object, of knowledge, 182, Burthogge's teaching about compared with that of Kant and Locke, $x v \mathrm{ff}$, phenomenal nature of, $12 \mathrm{ff}, 57,74,77,84 \mathrm{f}, 180$. 198, complex nature of, 179, when judged as true, 182, 188, 199; of apprehension, cogitation or understanding, $11 \mathrm{f}, 18 \mathrm{f}, 27 \mathrm{f}, 31,36,40,44$, $61,66,70,88,179$; "meaning," dependent upon congruity of, with the faculties, 15; 36, 182; regarded as external, 13, 18, 24, 57, 59, 60, 62, $75,80,97,125,127,129,144,180,181$, and cause of sensations and notions, 18, 21, 76, 80,86f, 119, 121, 145, 146; of sense or perception. $20,32,34,57,59,60,69,128,180$; basis for judgment of congruity between ideas and, according to Descartes, 196.

Objective, as opposed to formal, 13, 74, 84, 90, 91, 92, 94; Burthogge's use or the term, 189 .

Passivity, an attribute of principiates, 102f, of matter, 102, 105, 106, 184.

Perception, of the understanding, $18,68,75$; clear and distinct, 34f, 37, 68 196, cf. 199; faculties of, 56; as related to knowledge, 57, 82f, 179. 199 . cf. 6o, 106; of sense, 71, 74f, 127, 135f, 172, 179, 199, 207.

Phenomena, opposed to realities or things-in-themselves, xix ff, 12, 24, 29, 49, $68,77,88,133,180,184,198,205$; of Nature, 156, 162, 163, 169, 172, 173, 174, 175. See Appearance and Apparitions.

Philosophy, Fludd's "Mosaick Philosophy," 16; enthusiasts in, 17; cause of errors in, 26; authority for, $159 \mathrm{ff}$.

Platonists, The. See Cambridge Platonists.

Powers, Cogitative and conceptive, 13, 55, 57, 58, 59, 60, 82, 87, 123, 135, 180; mental and spiritual, 55, 57, 61; of the soul, 149; mechanick and material, 55, 57, 61, 169; perceptive, appetitive and motive, 104, 153 . See Faculties.

Principle, see Vital principle.

Principles, 159, 181; innate notions of the mind, 37ff, cf. 188; uncaused substances, 96, $101 \mathrm{ff}, 107,119,122,124,184$.

Principiates, Nature of, $96,101,184$.

Proportion, as test of truth, 4 If, 44f. See Congruity and Harmony.

Quakers, 189, 192, 194.

Ratiocination, Nature of, $3^{8}$; kinds of, 48.

Reality, opposed to phenomena, I2ff, 17, 24, 28f, 38, $76,80 \mathrm{ff}, 88 \mathrm{f}, 9 \mathrm{I}, 93,104 \mathrm{f}$. $110,182,183,198,204 f$; a notion, 90 . 


\section{PHILOSOPIICAL WRITINGS OF BURTHOGGE.}

Reason, 5, I3, 37, 42, 46, 48, 50, 86, 141, 142, 189, 199, 200, 202, 220; nature of, $9 \mathrm{f}, 30,49,55 \mathrm{ff}, 60 \mathrm{ff}, 65 \mathrm{f}, 72,109,117,179,180,188$; notions or ideas of, $18,75,80,179,181$; light of, 19 ff, 188 ; kinds of, $31 \mathrm{f}$.

Reasoning, $28,33,40,98$, 153 ; nature of, 30, 32, 44, 45, 55 ff, 81,182 ; methods of, $3 \mathrm{r}, 43 \mathrm{f}, 48 \mathrm{f}$; impertinent, a cause of error, $6,8 \mathrm{f}$.

Religion, 7, 9, 25, 115; as related to reason, 48; in England in the 17th cen. tury, xii, xv; Christian, 2off; Abraxas religion, 19r; natural, 199.

Remembrance, sensible and intellectual, 63,64 .

Representation, 12, 22, 27, 63, 76, 77, 11 , 184. See Appearance and Phenomena.

Revelation as related to sense, xvi, I43, is3ff, and reason, xvi, 10, $19 f, 48$. I 43, I $53 \mathrm{ff}$.

Rosicrucians, 69, $189 \mathrm{f}$.

Science, Unitary nature of, $43: 47$.

Sensation, of sense, $18,57,76,123,130,146,173$; nature of, 6off, 127, 181 , 204; of understanding (internal or "sublimated"), 55,63, 180; rỏle of, in knowledge, 59. See Sense.

Sense, External, 19, 42, 90, 92, 94, 101, 104, 107, 130, 134, 17 1f, 199, 203, nature of, $55,57 \mathrm{ff}$, roble of, in knowledge, $20,39,47,60,76,79,83 \mathrm{f}$, 89, III, 179ff, 199, 200, 204, 206f, object of, 13,17, 24, 58, 69, $77 \mathrm{ff}$, 146 , 179f, Burthogge's teaching about, compared with that of Kant and Locke, xvi ff; intellectual or internal, 32, 35, 78, 92, 119, 188, 199; or "meaning," 9, I Iff, 25ff, 36, 64, 66, 68, 70. See Sensation and Sentiment.

Sentiment, of sense, $12,13,17 \mathrm{ff}, 58,62,70 \mathrm{f}, 75 \mathrm{f}, 77 \mathrm{ff}, 82 \mathrm{ff}, 85,87,89,92$, $93 \mathrm{f}, 111,146,180$; of understanding, 66, 71, 78, 79, 80, 82ff, 146, 180. See Sense.

Soul, of World, 126, $128 \mathrm{ff}, 134,14 \mathrm{ff}, 132,158,159 \mathrm{ff}, 163,164,169,173,175$, 180, 205, 208, 212, 214, Burthogge's teaching about, compared with that of Cambridge Platonists, xiv f; particular souls, 152f, 156, 163, 180, human, 135, 141ff, 147, 156, 158, 169, 172, 174f, 201, 206, as related to body, 38, 125f, 128f, 152; perceptions of, 127; of animals, 142, 156 , 172; as related to life, 145, $147 \mathrm{ff}$; of plants, 156, Burthogge's teaching about, compared with that of Cambridge Platonists, xiv $f$; creation of, 17of. See Spirit.

Spirit, 38, 133, 134, 173, 189, 191, 193, 194; demoniacal, cause of enthusiasm. 16; of passion, 8; nature of $99 f, 134148,163,170,209,211$; of God, 19, $103,109 f, 115,118,123,146,156 f, 174,175$; abstract, $123,125,132$; of the universe $x i v, 118,126,128 \mathrm{ff}, 143 \mathrm{ff}, 158,16 \mathrm{I}$ : of $\operatorname{man}, 126,20 \mathrm{r}$ : of animals, 126, 131, 166; mechanical, 132. See Soul.

Spontaneous generation, of animals, $163 \mathrm{ff}, 216,217,221,222$.

Stoics, 102, 148, 197.

Subject, of accidents, Substance conceived as, $81,85,95,97 \mathrm{ff}, 106,107,183$, 205, 209.

Substance, a Notion, xvi, 75, 77, 79, 80ff, 88, 90, 91, 93, 94, 95, 180, 182f: conceived as subject of accidents, $81,85,95,97 \mathrm{ff}, 106,107,183,205$. 209: Spinoza's conception of, criticized, $92 \mathrm{f}, 95,98,101,108,113 \mathrm{f}$; kinds of, 96, 99, 101, 104, 105, 134, 136, 184; in itself unknown, 97, 106, 182f; universe conceived as corporeal substance by Hobbes, 197 .

Thing. I1, 73,80, 146, 157, 161, 162, 169, 182, 207; kinds of, 89, 91; as know'n 12, 14, I5, I8, 19, 24, 26, 27, 30, 3iff, $41 \mathrm{ff}, 75,78,80 \mathrm{ff}, 88,90 f$, $97 \mathrm{ff}, 111 \mathrm{f}, 116 \mathrm{f}, 123,180 \mathrm{f}$; spiritual, 22, 48 ; conceived as a notion, 79 . $80,90,91$; conceived as a cause of notions, $45,87,89,93,18 \mathrm{t}$. 
Things-in-themselves, 11, 13, 45, 67, 89; Burthogge's doctrine of, compared with that of Kant, xviii ff; unknown, 12, 74, 77, 83, 84, 97, 1 isf, 180, $183 \mathrm{f}, 198$; ground, or cause of knowledge, $85,87 \mathrm{f}, 93,130,179,18 \mathrm{I}$. 204; formal existence of, 189 .

Thought, or conception, 61, 65,70,74, 81, 100, 105, 106, 116, 183, 204, 206, 207, 209, 210.

Time, a notion, 92, 124; God conceived as independent of, 125 .

Truth, 5, 6, 24, 49, 50, 88; interpretation of Burthogge's doctrine of, xiv, $x v$, xxiii $f$; as related to reason or mind, $9,11,32,36,44 \mathrm{ff}$; relation of sense to, 20, 47, 199; definition of, 33, 181; criterion of, 20, 34ff, 40 ff, $182,188,207$.

Understanding, Function of, in knowlcdge, $13 \mathrm{f}, 18,43,58,60,63 \mathrm{f}, 66,75 \mathrm{ff}$, $90,93 \mathrm{ff}, 97 \mathrm{f}, 179$, Burthogge's teaching about, compared with that of Kant, xvi ff; function of, in knowledge of truth, 6, 32, 36f, 40; nature of, roff, 19, 21, 29f, 55, 61 ff, 65, 74, 78, 82, 116, 119, 146, 160, 174, 210 ; inadequacy of, for knowledge of reality, $6,70,75 \mathrm{ff}, 83,85$, 89; innate notions of, 71 ; of God, $23,110$.

Universe, God not to be identified with, 113; Vital Priaciple or Spirit of, 128ff, 143,158 , conceived as Spirit of God, 158.

Unknown substance, or thing, 12, 97, 106, 182f, 209; Burthogge's teaching about, compared with that of Kant, xviii ff.

Upstart Sect, 17, 194.

Verity, 6, 11, 13, 32, 33, 36. See Truth.

Vital principle, or soul, 125, 128, 129, $131 \mathrm{f}, 134,135,142,148,152,153,156$, $157,163 \mathrm{f}, 175$. See Soul.

Words, as carriers of "meaning," $14 \mathrm{ff}, 18,26 \mathrm{f}, 65 \mathrm{fl}, 73 \mathrm{f}, 203$.

World, 24, 38, I32; ratiocination, the power of interpreting the, 48; God not to be identified witb, 113,205 ; Soul of, $113,131,142 \mathrm{ff}, 179,184,211$. 



BMC 1201 .B/ 1921

SMC

Burthogge, Richard, 1638?-ca. 1700 .

The philosophical

writings of Richard

AEL-6903 (mcsk) 
